\title{
IV. Die jüngste deutsch-spanische Vergangenheit als Gegenstand der westdeutschen Politik
}

Durch die vehemente Kritik des Auslands an den Plänen für eine militärische Zusammenarbeit mit dem franquistischen Spanien war auch das bislang in der Bundesrepublik weitgehend verdrängte bzw. einseitig wahrgenommene Thema der Verbindung Hitler-Franco in das öffentliche Bewußtsein gerückt worden. Es mag an der "geistig-politische[n] Autarkie“ im „Dritten Reich“ und dem antikommunistischen Klima der 50er Jahre gelegen haben, daß den Deutschen in der Nachkriegszeit eine differenzierte Sicht auf den Spanischen Bürgerkrieg und die nationalsozialistische Parteinahme für die Putschisten um Franco schwerfiel. Denn das antisowjetisch ausgerichtete Spanienbild der NS-Propagan$\mathrm{da}^{2}$, die die legitime republikanische Regierung in Madrid seit dem Aufstand der Militärs im Juli 1936 immer wieder als „Rotspanien“ und „bolschewistisches Regime“ bezeichnet hatte ${ }^{3}$, sollte die publizistische Wahrnehmung noch lange prägen ${ }^{4}$. Doch welche Auswirkungen hatte dies auf den „vergangenheitspolitischen“ Umgang mit der Hinterlassenschaft der deutschen Intervention in Spanien und dem zeitweiligen Bündnis von Hitler und Franco im Zweiten Weltkrieg, deren Symbol die „Legion Condor“5 und die „Blaue Division" "' waren? Und wie verhielten sich Politik und Behörden gegenüber den Verlierern des Bürgerkriegs, die Opfer des NS-Regimes wurden?

1 So anläßlich der Debatte um die deutschen Stützpunkt-Pläne; NZZ, 6. 3. 1960.

2 Der Spanische Bürgerkrieg brachte „einen Höhepunkt in der propagandistischen antisowjetischen Strategie des Dritten Reiches". Messerschmidt, Außenpolitik und Kriegsvorbereitung, S. 609.

${ }^{3}$ Vgl. Bernecker, Das nationalsozialistische Spanienbild und Hitlers Eingreifen in den Spanischen Bürgerkrieg, S. 31.

+ Vgl. Wohlfeil, Der Spanische Bürgerkrieg 1936-1939, S. 101-119. Anhand einer Analyse von Artikeln zum 30. Jahrestag des Beginns des Bürgerkrieges stellt Wohlfeil fest, daß „Voreingenommenheit oder ideologische Bindung " noch immer für das veröffentlichte Spanienbild bestimmend seien. Vgl. ebenda, S. 119. Eine umfassende Studie zur Nachwirkung der NS-Propaganda auf das Bild Spaniens in der Bundesrepublik ist nach wie vor ein Desiderat.

${ }^{5}$ Was als Transporthilfe für die Aufständischen begonnen hatte, wuchs sich seit Oktober 1936 zu einer massiven militärischen Intervention, vor allem der Luftwaffe, an der Seite Italiens aus. Insgesamt waren 600-700 deutsche Flugzeuge und bis zu 5000 Soldaten gleichzeitig im Einsatz. Da die „Freiwilligen“ fortwährend ausgetauscht wurden, um möglichst vielen zu Kriegserfahrungen $\%$ verhelfen, kämpften bis zum Frühjahr 1939 etwa 19000 Mann gegen die Republik. Vgl. Bernecker, Krieg in Spanien, S. 55; zum militärischen Einsatz: Whealey, Hitler and Spain, S. 101-128. Von der Anwesenheit der Legion Condor in Spanien erfuhr die deutsche Öffentlichkeit offiziell erst bei ihrer Rückkehr im Frühjahr 1939. Das Deutsche Reich wollte seine Tcilnahme am Bürgerkrieg lange Zeit nicht eingestehen, verfolgte es doch - wie auch andere Staaten - nach außen hin eine Politik der Nichteinmischung. Vgl. dazu Viñas, Der internattionale Kontext, S. 187-295.

6 Franco-Spanien stellte nach dem deutschen Angriff gegen die Sowjetunion im Juni 1941 eine Freiwilligen-Formation aus Falangisten und aktiven Soldaten auf, die sich seit Oktober am sogenannten Kreu\%zug Europas gegen den Bolschewismus beteiligte. Die Division, offiziell División Español de Voluntarios, wurde bald wegen der blauen Hemden der Falangisten als Blauc Division (División Azul) bezeichnet. Der Verband mit seinen rund 18000 Mann wurde als Folge der nationalsozialistischen Rassenideologie wie die anderen „nichtgermanischen" Freiwilligen (Franzosen, Kroaten und Wallonen) - in die Wehrmacht eingeordnet, während die "germanischen" Freiwilligen (Flamen, Finnen, Norweger und Schweden) zur Waffen-SS kamen. Die Blaue Division war nicht nur eine Art Gegenleistung für die Legion Con- 


\section{Doppelte Anrechnung der Dienstzeit für die „Freiwilligen“ der Legion Condor?}

So umstritten die jüngste deutsch-spanische Vergangenheit und die Ursachen des Bürgerkriegs in Spanien zwischen Regierung und SPD-Opposition waren, im Hinblick auf den Einsatz des Sonderverbands der Wehrmacht, die „Legion Condor", hatte es bisweilen auch Einigkeit gegeben. Im Juli 1954 wurde das deutsche Eingreifen im Bundestag zwar einhellig als „völkerrechtswidrig“verurteilt, die Soldaten der Legion Condor wurden aber entlastet ${ }^{7}$.

Ausgelöst worden war die Parlamentsdebatte durch die Frage, ob und inwieweit bei den Versorgungs- und Pensionsansprüchen der ehemaligen Berufssoldaten nach Art. 131 GG $^{8}$ ihre in Spanien verbrachte Zeit als Dienstzeit angerechnet werden sollte. Die ungeklärte rechtliche Situation hatte zunächst zu ablehnenden Bescheiden geführt. Daraufhin bat der Verband deutscher Soldaten (VdS) das Bundesinnenministerium im Oktober 1952 um eine Prüfung 9 . Auch das Bundesministerium für Arbeit und Soziales, das für Ansprüche nach dem Bundesversorgungsgesetz (BVG) verantwortlich war, drängte nun auf eine einheitliche Beurteilung gegenüber den ehemaligen Angehörigen der Legion Condor ${ }^{10}$. Bisher habe er entsprechende Anträge abgewiesen, teilte der zuständige Referent mit, da seiner Auffassung nach der „Dienst der Angehörigen dieser Freiwilligenverbände nicht als Dienst nach deutschem Wehrrecht" anerkannt werden könne. Denn das Deutsche Reich sei „an diesem Kriege nicht beteiligt“ gewesen. Die endgültige rechtliche Klärung erwies sich als schwierig.

Erst neun Monate später, im Juli 1953, teilte das Innenministerium in einem Zwischenbescheid mit, es könne noch keine endgültige Stellungnahme abgeben. So seien die ent-

dor, sondern entsprang auch innenpolitischen Motiven, da hiermit die Kräfte in Spanien, die auf einen Kriegseintritt drängten, beruhigt werden konnten. Mit der sich abzeichnenden deutschen Niederlage schwand auch dic offene Unterstützung Francos. Ab Herbst 1943 begann der Rückzug des Verbandes. Bis Januar 1944 wurden - durch einen stetigen Wechsel nach einigen Monaten - insgesamt etwa 47000 Mann in der 250. Infanterie-Division eingesetzt. Vgl. Förster, Freiwillige für den „Kreuzzug Europas gegen den Bolschewismus“, S. 908-915. Vgl. zur Gründung und dem Ende der Blauen Division: Ruhl, Spanien im Zweiten Weltkrieg, S. 27-34 und S. 233-245. Ebenso Kleinfeld/Tambs, Hitler's Spanish Lcgion; zur generellen Einordnung: Bowen, Spaniards and Nazi Germany, S. 105-123 und S. 166-174. Siehe umfassend Moreno, La División Azul.

7 Der Vorsitzende des Beamtenrechts-Ausschusses Josef Kleindinst demonstricrte der SPD im Namen der CDU/CSU-Fraktion Gemeinsamkeit: „Sie werden überzeugt sein, daß wir bezüglich der völkerrechtlichen Beurteilung des Eingreifens in Spanien einer Meinung sind, aber auch einer Meinung darüber, daß die Leute der Legion Condor tatsächlich kommandiert worden sind und es bei den Fragen keinen Widerspruch geben konnte." Deutscher Bundestag, 37. Sitzung, 8. 7.1954, Stenographische Berichte, Bd. 20, S. 1752-1758, hier S. 1757.

${ }^{8}$ Vgl. zu dem im April 1951 vom Bundestag einstimmig verabschiedeten „131er“-Gesetz, durch das im Verlauf der Entnazifizierung entlassene Beamte und Berufssoldaten in ihre früheren Positionen zurückkehren bzw. Versorgungsansprüche geltend machen konnten, ausführlich Frei, Vergangenheitspolitik, S. 69-99, sowie Garner, Der öffentliche Dienst in den 50er Jahren, S. 759-790.

9 Schreiben Generalmajor a. D. Kurt Linde an das Bundesministerium des Innern, 16. 10. 1952, BA, B 106, Bd. 32535. Zu den allenthalben entstehenden Soldatenverbänden in der Frühzeit der Bundesrepublik und der im September 1951 erfolgten Gründung des VdS als Dachverband vgl. Meyer, Soldaten ohne Armee, S. 683-750.

${ }^{10}$ Schreiben Schönleiter an das Bundesministerium des Innern, 16. 10. 1952, BA, B 106, Bd. 32535. Hier auch das Folgende. 
sprechenden Erlasse und Schriftwechsel als geheim behandelt und 1945 überdies größtenteils vernichtet worden ${ }^{11}$. Inzwischen hatte sich der Regelungsbedarf erhöht; bereits seit Februar war der Dienst in der Legion Condor als „anrechnungsfähige Dienstzeit in Bayern anerkannt“. Jetzt drängte auch das Ministerium für den Marshallplan auf eine baldige bundeseinheitliche Entscheidung ${ }^{12}$. Am 11. Februar 1954 wurden schließlich die obersten Bundes- und Landesbehörden in einem Rundschreiben ${ }^{13}$ darüber informiert, daß das Bonner Innenministerium keine rechtlichen Einwände habe, die Zeit der Zugehörigkeit zur Legion Condor als „berufsmäßige Wehrdienstzeit“ und als „Kriegsjahr“ auf die ruhegehaltsfähige Dienstzeit nach Art. 131 GG anzurechnen. Die im Rahmen des „Sondereinsatzes“ verwendeten Berufssoldaten seien nach den vorliegenden Quellen nicht aus dem „berufsmäßigen Wehrdienst" ausgeschieden und hätten weiterhin der Wehrmacht angehört.

Im Bundestagsausschuß zum Schutze der Verfassung ${ }^{14}$ stieß dieser Erlaß bei Abgeordneten der SPD wie auch zwei Vertretern der CDU allerdings auf „politische Bedenken"15. Es gehe nicht an, hieß es, Personen, die sich „freiwillig an den völkerrechtswidrigen Kampfhandlungen beteiligt hätten, Rechte einzuräumen“. Damit, so die Kritiker, werde das „Eingreifen der nationalsozialistischen Machthaber in Spanien als legal anerkannt“. Demgegenüber wiesen andere Mitglieder der Koalitionsparteien darauf hin, daß der "politische Streit“ darum, ob der Einsatz der Legion Condor „unter dem Gesichtspunkt der Bekämpfung des Kommunismus“ zu rechtfertigen sei, „nicht zu Lasten der beteiligten Soldaten“ gehen dürfe. Der Berichterstatter des Innenministeriums, Ministerialdirigent Anders, betonte, das Schreiben seines Hauses habe „ohne jeden politischen Akzent" ausschließlich das Ziel verfolgt, eine Zweifelsfrage rechtlich zu klären. Anspruchsberechtigt seien allein frühere Berufssoldaten der Wehrmacht: „Um ,Freiwillige‘ habe es sich nur der äußeren Form nach gehandelt, da es nach dem Nichteinmischungsabkommen der Großmächte verboten gewesen sei, in Spanien militärisch einzugreifen." Seiner Ansicht nach bestehe juristisch „keine Möglichkeit, den Betroffenen die Anrechnung zu versagen "16. Er empfahl daher Innenminister Gerhard Schröder, trotz der Bitte des Verfassungsschutzausschusses $^{17}$, das beanstandete Rundschreiben nicht aufzuheben. Schröder folgte dem Rat

11 Antwortentwurf für den Bundesminister für Arbeit und den Verband deutscher Soldaten, Juli 1953, betr. Versorgung ehem. Angehöriger der Legion Condor, BA, B 106, Bd. 32535.

12 Bundesministerium für den Marshallplan an Innenministerium, 1. 8. 1953, BA, B 106, Bd. 32535.

${ }^{13}$ Bundesinnenministerium an die obersten Bundesbehörden und Landesbehörden, 11.2. 1954, BA, B 106, Bd. 32535. Hier auch das Folgende.

${ }^{14}$ Der Verfassungsschutzausschuß hatte seit September 1950 die alleinige Zuständigkeit für das Thema Entnazifizierung. Vgl. Frei, Vergangenheitspolitik, S. 58.

15 Vermcrk Anders für den Minister, 5. 5. 1954, BA, B 106, Bd. 32535. Hier auch das Folgende. Ministerialdirigent Georg Anders, Leiter der Abteilung für Beamtenrecht - bis 1945 Ministerialrat im Reichsjustizministerium und NSDAP-Mitglied - kam selbst aus dem Kreis der „131er“. Vgl. Garner, Der öffentliche Dienst in den 50er Jahren, S. 774.

${ }_{16}$ Anders hatte darauf hingewiesen, daß bei der Anerkennung von Kriegsjahren als Rechtsgrundlage die vom Bundestag eingefügte - Vorschrift des $§ 181$ Abs. 5 Nr. 1 Bundesbeamtengesetz. (BBG) gelte, die vorsehe, die Kriegsjahre „nach bisherigem Recht" anzurechnen. Als bisheriges Recht müsse die Verordnung vom 7. 7.1939 angesehen werden.

17 Der Ausschußvorsitzende Menzel (SPD) hatte darum gebeten, das Innenministerium möge seine Position angesichts der bestehenden Einwände noch einmal überprüfen und den Erlaß aufheben. Allerdings nahmen an der Sitzung (4.5. 1954) - die ohne Abstimmung zu Ende gegangen war - nur 6, zeitweise 7 von 16 Abgeordneten der Koalitionsparteien teil, während die SPD mit 7 Mitgliedern vollzählig vertreten war. 
und teilte dem Vorsitzenden des Ausschusses, Menzel, wenig später mit, er „sehe keinen Grund"18 in diesem Fall etwas zu ändern. Es gehe dabei allein um Rechtsansprüche, die „anerkannt werden müssen“, nicht um die Frage der „völkerrechtlichen Legalität“ des Einsatzes der Legion Condor in Spanien.

Die Sozialdemokraten wollten es bei dieser Entscheidung nicht bewenden lassen. Ende Mai brachten sie im Bundestag den Antrag ein, den Erlaß des Bundesministers des Innern aufzuheben ${ }^{19}$. Gleichzeitig geriet das Thema, sehr zum Verdruß von Minister Schröder ${ }^{20}$, in die Schlagzeilen: „Skandal um Schröder-Erlaß - Zulage für Legion Condor" lautete die Überschrift der „Neue[n] Rhein Zeitung“"21 am 25. Mai. Der Artikel griff die von der SPD vorgebrachte Kritik an der Dienstzeiten-Regelung auf und wies darauf hin, daß dadurch unter Umständen „das Ansehen der Bundesrepublik im Ausland geschädigt werden könne“. Das Innenministerium in Bonn reagierte prompt: Noch am selben Tag setzte es sich mit einer Pressemitteilung ${ }^{22}$ zur Wehr. So wurde insbesondere der von der „Neue[n] Rhein Zeitung“ unterstellte Vorwurf, mit dem Rundschreiben sei die völkerrechtliche Legalität des Einsatzes der Legion Condor „bejaht“ worden, vehement zurückgewiesen. Allein die „Tatsache“, daß die nach Spanien entsandten Soldaten auch dort „Berufssoldaten der Deutschen Wehrmacht geblieben sind“ und deshalb ein „klarer Rechtsanspruch“ bestehe, habe zu dieser Entscheidung geführt. Das Innenministerium rückte außerdem die soziale Dimension in den Vordergrund. Die Angehörigen der Legion Condor galten nun als pflichtgetreue Soldaten, die einer Diktatur dienen mußten. So wäre es „höchst unbillig“, den in Frage kommenden Berufssoldaten und „ihren Witwen und Waisen die ihnen zustehende Versorgung lediglich deswegen zu verweigern, weil sie von den Machthabern des Dritten Reiches zu einem derartigen Einsatz befohlen worden sind“. Denn die sogenannte Freiwilligkeit habe nur der „Tarnung dieses Hitlerschen Unternehmens“ gegolten. Damit wurde das bis 1945 bestehende öffentliche Bild der Legion Condor grundlegend revidiert. Waren es noch zuvor die von der NS-Propaganda bejubelten „Freiwilligen“ im Kampf gegen den Bolschewismus, bei deren Rückkehr im Frühjahr 1939 der „Aufbau einer Heldenlegende"23 begonnen hatte, ging es der Bundesregierung in der

18 Schröder an Menzel, 19.5. 1954, BA, B 106, Bd. 32535. Hier auch das Folgende.

19 Antrag der SPD-Fraktion betr. Legion Condor, 26.5. 1954, Deutscher Bundestag, Drucksache 553, Bd. 29.

20 Schröder an Brentano, 25. 6. 1954, BA, B 106, Bd. 32535. Er warf dem SPD-Abgeordneten Menzel vor, Informationen an die Presse weitergegeben zu haben. Dadurch sei es zu einer „Aufbauschung“ und „entstellenden Behandlung der Angelegenheit" gekommen.

21 Neue Rhein Zeitung, 25.5. 1954. Zudem griffen dic FR und die SZ das Thema auf. Vgl. „Dienst in ,Legion Condor" zählt doppelt“, 26.5. 1954, und: „Legion Condor - als Dienstzeit angerechnet“.

${ }_{22}$ Mitteilung an die Presse, 25.5. 1954, BA, B 106, Bd. 32535. Hier auch das Folgende.

23 Vgl. Bernecker, Das nationalsozialistische Spanienbild und Hitlers Eingreifen in den Spanischen Bürgerkrieg, S. 28. Allein 1939 wurden 17 Publikationen veröffentlicht, die sich propagandistisch mit dem Bürgerkrieg in Spanien und der Legion Condor beschäftigten. Insbesondere die in hohen Auflagen erschienenen Erlebnisberichte der Militärs prägten das zeitgenössische Bild des Krieges. Die als Angehörige der Wehrmacht abgeordneten Soldaten stilisierten sich dabei stcts als „Freiwillige“, die ihrer Überzeugung folgend, in den Kampf gegen den „Weltfeind Bolschewismus“ nach Spanien gegangen seien. Manche berichten ausführlich, „wie es ihnen nur durch gute persönliche Beziehungen gelang, aus der groBen Zahl von Bewerbern für den Einsat\% in Spanien ausgewählt zu werden“. Vgl. Schmigalle, Deutschc schreiben für Hitler und Franco, S. 203. Die Darstellungen der Militärs lassen aber auch andere Motive wie Abenteuerlust, Fernweh und Elitenbewußtsein erkennen. Überdies gab es handfeste finanzielle Anreize. Die Mitglieder der Legion Condor erhielten zusätzlich zu ihrem weiterlaufenden Verdienst eine 
Dienstzeiten-Frage um eine möglichst politikfreie, sozialrechtliche Bewertung eines Einsatzes der Wehrmacht.

Dagegen empörte sich die SPD nun auch öffentlich. Die vom Innenministerium vorgesehene Versorgungslösung bedeute, hieß es im "SPD-Pressedienst“, in der Konsequenz „nichts anderes als eine kalte Rehabilitierung des Dritten Reiches und eine politische Rechtfertigung des blutigen Abenteuers, das Hitler und sein Freund Mussolini in Spanien unternahmen, um ganz Europa der faschistischen Diktatur zu unterwerfen "24. Schwerer als solche Vorwürfe der Opposition wog für Innenminister Schröder sicherlich die interne Kritik des CDU/CSU-Fraktionsvorsitzenden Brentano ${ }^{25}$, der Ende Juni, aufgeschreckt durch einen Artikel in der „Frankfurter Rundschau“, wissen wollte, wie es zu der Anordnung gekommen sei, die „Dienstzeit in der sogenannten Legion Condor als Kriegsdienstzeit anzurechnen“. Er halte „persönlich“, schrieb Brentano dem Innenminister, diese „Auffassung auch nicht für richtig“. Außerdem werde man wohl „im Ausland eine solche Praxis nicht sehr wohlwollend" beurteilen.

Brentano hatte mögliche außenpolitische Weiterungen, Schröder mögliche Klagen der Betroffenen vor Augen. In seiner Antwort bemühte sich der Innenminister, kurz vor der Debatte im Bundestag, vor allem um rechtliche Aufklärung. Für ihn war die Rechtslage „eindeutig“26. Die in Spanien eingesetzten Berufssoldaten seien damals Angehörige der Wehrmacht geblieben und hätten deshalb einen Anspruch auf Versorgung nach Art. 131 GG. Daß zusätzlich „Kriegsjahre“ berücksichtigt werden müßten, beruhe auf einer Verordnung vom 7.Juli 1939, an deren Gültigkeit das Bundesbeamtengesetz nichts geändert habe. Dieses sehe ausdrücklich vor, daß sich die ruhegehaltfähige Dienstzeit um die „nach bisherigem Recht anrechenbaren Kriegsjahre erhöht“. Der Minister unterstrich, er wolle damit den Einsatz der Legion Condor politisch nicht legitimieren. Schließlich hänge die „Rechtsstellung“ der Berufssoldaten nicht „von der Legitimität dieses Hitler'schen Unternehmens ab“. Im übrigen stellte sich Schröder vor die Angehörigen der Legion Condor und entlastete sie, indem er ihren Einsatz im Bürgerkrieg als unpolitische Pflichterfüllung deutete ${ }^{27}$. So sei es falsch, anzunehmen, daß „diese Soldaten ,freiwillig“ nach Spanien ge-

nicht unbeträchtliche Aufwandsentschädigung. Vgl. ebenda, S. 204. Vgl. zur Legion Condor und ihrer Rolle in den nationalsozialistischen Massenmedien: Peter, Das Spanienbild in den Massenmedien des Dritten Reiches 1933-1945, S. 124-135. Zum Nachhall des Bürgerkriegs in der deutschen Literatur siehe: Pichler, Der Spanische Bürgerkrieg (1936-1939) im deutschsprachigen Roman.

24 SPD-Pressedienst: Legion Condor - eine kalte Rehabilitierung, 31. 5. 1954.

${ }^{25}$ Brentano an Schröder, 22. 6. 1954, BA, B 106, Bd. 32535. Hier auch das Folgende. Brentano bezog sich dabei auf eine am selben Tag in der FR veröffentlichte Notiz mit der Überschrift „Innenministerium gegen Innenministerium".

26 Schröder an Brentano, 25.6, 1954, BA, B 106, Bd. 32535. Dort das Folgende.

27 Überhaupt wurde in der gesamten Auseinandersetzung nicht ein klärendes Wort über den militärischen Einsatz der Truppe verloren. Dagegen wird in der Darstellung von Birgit Aschmann ein ideologisiertes Bild gezeichnet, wenn sie davon spricht, daß „neben Kampferfahrung [...] dieser Einsatz einen ungewöhnlich hohen Identifikationseffekt bewirkt und ein starkes ,Wir-Gefühl“ erzeugt" habe. An anderer Stelle sind es gar die „durch Kriegspropaganda tatendurstigen Soldaten“, die „verstärkt durch den Nimbus des Geheimnisvollen einer verdeckten Operation, einer relativen Gefahrlosigkeit und der ideellen Indoktrination“ davon ausgingen, „als elitäre Vorkämpfer an vorderster Front den Erzfeind Kommunismus bekämpfen zu können“. Vgl. Aschmann, „Treue Freunde..."?, S. 27f. Zudem hält Aschmann fälschlicherweise dem Nationalsozialismus nahestehende Publizisten wie Werner Beumelburg und Karl Georg von Stackelberg, die Propagandaliteratur über den Einsatz verfaßt hatten, für Angehörige der Legion Condor. Vgl. ebenda, S. 377. 
gangen sind“. Die Freiwilligkeit habe nur als „Tarnung“ gedient, „um den Schein aufrechtzuerhalten, daß sich Deutschland nicht am Kriege beteilige“. Die Sorge vor einem negativen Echo im Ausland hielt er überdies für unbegründet, da bisher eine nennenswerte Reaktion - abgesehen von einem „sachlichen“ Artikel in der „Times“28 - ausgeblieben sei.

Am 8. Juli 1954 war die Pensions- und Versorgungsfrage schließlich Thema im Deutschen Bundestag. Hermann Schmitt-Vockenhausen erinnerte im Namen der SPD-Fraktion die Bundesregierung daran, daß bislang die deutsche Hilfe für die Aufständischen um Franco übereinstimmend als einer jener Fälle angesehen wurde, „in denen der Nationalsozialismus in völkerrechtswidriger Weise in die inneren Verhältnisse eines anderen Landes eingegriffen hat “29. Angesichts der großen sozialen Probleme, unter denen vor allem die „Opfer des Krieges"30 in der Bundesrepublik zu leiden hätten, hielt er es auch nicht für angemessen, diesen militärischen Einsatz besonders zu honorieren. Der SPD gehe es mit ihrem Antrag allein darum, warb Schmitt-Vockenhausen, daß die Dienstzeit in der Legion Condor „normal wie jede andere behandelt "31 wird. Ob dies in erster Linie ein taktisches Argument war, um die Mehrheitsverhältnisse zu beeinflussen, bleibe dahingestellt. In jedem Fall sprach sich die SPD jetz.t nur noch gegen einen erhöhten Rentenanspruch aus. Die Sozialdemokraten empfanden die von der Bundesregierung vorgesehene Regelung als ,verspätete Solidaritätserklärung für das nationalsozialistische Regime und für sein Eingreifen im spanischen Bürgerkrieg“. Diesen Vorwurf wies Innenminister Schröder weit von sich. Er pochte darauf, daß es sich hier nicht um eine politische Frage, sondern um eine „Rechtsfrage" handele. Schließlich seien gesetzlich geregelte Versorgungsansprüche von Berufssoldaten zu erfüllen. Daß dabei zusätzlich „Kriegsjahre“ angerechnet werden müßten, beruhe auf einer Änderung am Regierungsentwurf zum Bundesbeamtengesetz, die damals von allen Fraktionen aus sozialen Gründen gewünscht worden sei ${ }^{32}$. Damit gelte für die Legion Condor nichts anderes als für andere Kriegsteilnehmer. Insofern sei ihr Antrag falsch gestellt, belehrte Josef Kleindinst, der Vorsitzende des Beamtenrechtsausschusses, die sozialdemokratische Opposition und befand, er sehe „ein Mißverhältnis von Aufwand, Ziel und Zweck“, das Gesetz „wegen dieser wenigen Leute“"33 $\mathrm{zu}$ ändern. Das sahen die meisten Abgeordneten wohl ähnlich; der Antrag der SPD wurde mit Stimmenmehrheit abgelehnt.

Der Verlauf der Debatte hatte gezeigt, wie schonend die Angehörigen der Legion Condor von allen Parteien behandelt wurden. Auch die Sozialdemokraten scheuten vor Kritik

28 Vgl. The Times, 28.5. 1954, „The German Pensions Controversy“.

29 Deutscher Bundestag, 37. Sitzung, 8.7.1954, 2. Wahlperiode, Stenographische Berichte, Bd. 20, S. 1752-1758, hier S. 1752. Schmitt-Vockenhausen verwies dabei auf die gemeinsame Haltung der vergangenen Jahre in den Beratungen über das Bundesversorgungsgesetz.

30 Ebenda.

31 Ebenda, S. 1754. Hier auch das Folgende.

32 Vor allem aus den Reihen der SPD sei bei den Beratungen im Bcamtenrechtsausschuß, wie sich dessen Vorsitzender Kleindinst (CSU) erinnerte, argumentiert worden: „Man kann doch den Kriegsteilnehmern, die bisher die doppelte Anrechnung haben, sie nun nicht wieder nehmen." Ebenda, S. 1757. Im übrigen, bedeute, so der Innenminister, die Anrechnung von Kriegsjahren nicht, daß die Pensionen verdoppelt würden. Als Folge könne es lediglich zu einer Erhöhung um ein bis zwei Prozentpunkte auf der „Pensionsskala“ kommen. Ebenda, S. 1755.

${ }^{33}$ Ebenda, S. 1757. Wie groß letztlich der Kreis der Anspruchsberechtigten war, konnte nicht geklärt werden, da die Umsetzung der Versorgungsansprüche den Bundesländern vorbehalten blieb.

34 Die SPD-Opposition sah in den Soldaten ebenso wie die Regierung Adenauer unschuldige Opfer des NS-Regimes. So wollte Helmut Schmidt - selbst Wehrmachtoffizier - später auch keinen Zweifel aufkom- 
gegenüber den ehemaligen Soldaten zurück ${ }^{34}$. Ihr argumentativer Spielraum war angesichts der großen öffentlichen Solidarität mit verurteilten und inhaftierten deutschen Militärs ${ }^{35}$ ohnehin gering, zumal sie sich im Bundestag gegen den Verdacht verteidigen mußten, „künstlich Ressentiments“36 schüren zu wollen. Der Einsatz der Legion Condor blieb in seinem tatsächlichen Verlauf und in seinen Einzelheiten - wohl auch als Folge des fehlenden historischen Wissens - im Dunkeln. Selbst der Bombenangriff auf die baskische Stadt Guernica im April 1937, der vor allem durch Pablo Picassos Gemälde zu einem Symbol des Kriegsterrors gegen die Zivilbevölkerung wurde, spielte im Bewußtsein der westdeutschen Öffentlichkeit und Politik in den 50er Jahren noch keine Rolle ${ }^{37}$.

$\mathrm{Zu}$ einer grundsätzlichen Auseinandersetzung über das Wirken der Deutschen im spanischen Bürgerkrieg war es im Parlament nicht gekommen. Zwar hatte der SPD-Abgeordnete Hauffe darauf gedrängt, künftig ebenso „nationalsozialistische Verfolgungszeiten“ “98

men lassen „an der Gutgläubigkeit jener jungen deutschen Soldaten, die damals der Legion Condor angehört haben. Die konnten das ganze Spiel selbstverständlich nicht durchschauen und nicht überschauen." Deutscher Bundestag, 108. Sitzung, 6.4. 1960, 3. Wahlperiode, Stenographische Berichte, Bd. 45, S. 5894.

${ }_{35}$ Vgl. Frei, Verwandlungspolitik, S. 266-306.

36 So Innenminister Schröder. Die SPD habe die Versorgung der Legion Condor zu einer "politischen Affäre" machen wollen. Deutscher Bundestag, 37. Sitzung, 8. 7. 1954, Stenographische Berichte, Bd. 20, S. 1755 .

37 Es herrschte Unwissenheit. Als das deutsche Konsulat in Bilbao im Sommer 1958 erstmals mit dem Fall Guernica konfrontiert wurde, stützte es sich bei seinen Recherchen allein auf Aussagen ehemaliger Condor-Legionäre. Nach Zeitungsberichten über den Angriff und seine Folgen hatte ein früheres Mitglied der Einheit aus Trier um Auskunft gebeten, ob dabei tatsächlich nahezu tausend Zivilisten ums Leben gekommen seien. Nach „schwierig[en]“ Nachforschungen berichtete die deutsche Vertretung an das Auswärtige Amt: Guernica ist „,von Flugzeugen der Legion Condor in Auftrag nationalspanischer Militärstellen, denen sie unterstand, bombardiert und durch das dabei entstandene Großfeuer fast völlig zerstört worden“. Dic Augenzeugen - darunter pikanterweise ein in Guernica lebender Ex-Legionär hätten die Zahl von 1000 Toten bestätigt und sogar eingeräumt, daß flüchtende Personen aus Flugzeugen gezielt mit Maschinengewehren beschossen worden seien. Das Konsulat fürchtete angesichts der politischen Brisanz des Themas offenbar unliebsame Enthüllungen. So schlug es vor, zunächst Erkundigungen über den Fragesteller einzuholen. Denn es könnte sich hicrbei, so wurde vermutet, möglicherweise um einen „Agent provocateur" einer „östlichen Macht“ handeln. Konsulat Bilbao an Auswärtiges Amt, 12. 9. 1958, PA/AA, Ref. 205, Bd. 7604. Im Spanien Francos war das Thema tabu. Das verordnete Schweigen sollte 40 Jahre andauern. Erst im April 1977, nach dem Tod des Diktators, konnten die Bewohner Guernicas (baskisch: Gernika) öffentlich der Toten gedenken. Ihre genaue Zahl ist auch heute noch heftig umstritten; fest stcht jedoch, daß Hunderte ums Leben kamen. Vgl. zum Stand der Forschung Bernecker, Gernika 1937 - Kontroversen und deutsche „Vergangenheitsbewältigung“, S.39; Maier, Guernica, 26. April 1937. Die deutsche Intervention und der Fall Guernica. Die Bundesrepublik fand jahrzehntelang offiziell kein Wort des Bedauerns. Wie schwer eine angemessene Geste fiel, zeigte sich, als Bundespräsident Roman Herzog im Jahr 1997 erstmals eine Botschaft „des Gedenkens, des Mitgefühls und der Trauer" an die Überlebenden des Bombardements richtete. Darin sprach er lediglich von der „schuldhaften Verstrickung deutscher Flieger“ und bot seine Hand „mit der Bitte um Versöhnung“. Vgl. SZ, 28.4. 1997.

${ }_{38}$ Deutscher Bundestag, 37. Sitzung, 8. 7. 1954, Stenographische Berichte, Bd. 20, S. 1757. Hauffe hatte sich bereits Anfang Juni empört über die „doppelte“ Anrechnung der Dienstzeit in der Legion Condor mit diesem Vorschlag an den SPD-Fraktionsvorstand gewandt. Der sozialdemokratische Politiker hielt es „für unerträglich, daß der Dienst im spanischen Bürgerkrieg ehrenhafter sein soll als die Leiden in einem nationalsozialistischen $\mathrm{KZ}$ “. Allerdings konnte er sich damit selbst in der eigenen Partei nicht durchsetzen. In der im Januar 1955 eingebrachten Novelle der SPD-Fraktion zum Bundesergänzungsgesetz war davon keine Rede mehr. Vgl. Bracher u. a. (Hrsg.), Die SPD-Fraktion im Deutschen Bundestag. Sitzungsprotokolle 1949-1957, S. 62. 
doppelt anzurechnen. Über die etwa 3000 antifaschistischen Deutschen, die freiwillig auf republikanischer Seite in den "Internationalen Brigaden"39 gekämpft hatten, war aber kein Wort verloren worden. In der frühen Bundesrepublik mochte man, anders als etwa in Italien und Frankreich, wo die Kommunistischen Parteien akzeptiert waren, die linken Spanienkämpfer nicht. Sie erhielten keine mit der Legion Condor vergleichbaren staatlichen Versorgungsleistungen.

Ihr Einsatz in Spanien, den sie auch als Widerstand gegen Hitler verstanden, wurde von der Gesellschaft ignoriert bzw. pauschal unter Kommunismusverdacht gestellt. Kaum einer der sogenannten Rotspanienkämpfer, die das KZ Dachau - Sammelpunkt der ehemaligen Interbrigadisten - überlebt hatten, erhielt daher eine Entschädigung ${ }^{40}$. Erst unter anderen politischen Vorzeichen wurden 1972 durch eine Novelle im Bundesversorgungsgesetz die Voraussetzungen für Leistungsansprüche geschaffen, um damit, wie das Bundesverfassungsgericht später befand, „dem Unwerturteil deutlich entgegenzutreten“, das „ursprünglich" gegenüber den republikanischen Spanien-Freiwilligen geherrscht habe ${ }^{41}$.

\section{Heikle Traditionspflege: Die Treffen der Veteranenverbände der Legion Condor und der Blauen Division}

In den ersten Jahren der Bundesrepublik war es still um die Legion Condor. Doch mit dem massenhaften Erscheinen militärischer Erinnerungsschriften über den Zweiten Welt-

${ }^{39} \mathrm{Zu}$ der im Oktober 1936 begonnenen Bildung der Internationalen Brigaden, ihrer Zusammensetzung und Geschichte vgl. von zur Mühlen, Spanien war ihre Hoffnung, S. 205-238; der Anteil der deutschen Freiwilligen wird hier mit 5000 angegeben; ebenda, S. 239-285; zusammenfassend: ders., Deutsche Emigranten im Spanischen Bürgerkrieg, in: Mythen des Spanischen Bürgerkriegs, S. 48-58. Neuere Forschungen lassen vermuten, daß die Zahl auf etwa 3000 korrigiert werden muß. Vgl. Uhl, Mythos Spanien, S. 55. Eine Statistik der „Kommission der ausländischen Kader beim ZK der KP Spaniens" verzeichnet insgesamt 2318 deutsche Interbrigadisten, unter ihnen 1440 Kommunisten - ein Anteil von 62,1\%. Vgl. Mallmann, „Kreuzritter des antifaschistischen Mysteriums“, S. 35. Zu den deutschen Kämpfern auf republikanischer Seite gehörten neben Kommunisten auch Sozialdemokraten und Anarchisten. Insofern zeichnet Aschmann ein einseitiges Bild, wenn sie davon spricht, daß viele der „deutschen Kommunisten“ nach der Auflösung der Brigaden in Frankreich interniert und später an die Gestapo ausgeliefert worden seien. Vgl. Aschmann, „Treue Freunde..."?, S. 37.

t0 Vgl. Mallmann, „Kreuzritter des antifaschistischen Mysteriums“, S. 36; von zur Mühlen, Spanien war ihre Hoffnung, S. 306-314. Zur restriktiven Entschädigungspraxis gegenüber Kommunisten: Jasper, Die disqualifizierten Opfer, S. 361-384. Im östlichen Teil Deutschlands sah dies ganz anders aus. In der DDR galten die Spanien-Veteranen als antifaschistische Widerstandskämpfer, deren Einsatz in vielfältiger Weise öffentlich gewürdigt wurde. Die Staatspropaganda heroisierte die Internationalen Brigaden als ein Vorbild des kommunistischen „besseren Deutschland“. Vgl. umfassend Uhl, Mythos Spanien. Ferner: von zur Mühlen, Spanien war ihre Hoffnung, S. 307-311; Mallmann, „Kreuzritter des antifaschistischen Mysterium“, S. 50 ff.; Kessler/Peter, Antifaschisten in der SBZ, S. 611-633. Damit gerieten die Freiwilligen zum Objekt der vergangenheitspolitischen Konkurrcn\% beider deutscher Staaten im Kalten Krieg. Vgl. weiterführend: Danyel, Die geteilte Vergangenheit.

${ }^{41}$ Vgl. Beschluß des Ersten Senats (1 BVI, 26/76), 30.5. 1978, in: Entscheidungen des Bundesverfassungsgerichts, 48. Band, S. 281-291, hier S. 289. Allerdings setzte sich die Ungleichbehandlung fort. Die Verfassungsrichter urteilten, es sei mit dem Grundgesetz vereinbar, dic im Ausland lebenden ehemaligen Brigadisten, im Gegensatz zu den früheren Angehörigen der Legion Condor, von Versorgungsleistungen auszuschließen. So hätten die Soldaten der Lcgion Condor ihren Wehrdienst nach deutschem Recht leisten müssen, während es sich beim Einsatz der Deutschen auf republikanischer Seite um ein „Sonderopfer für ein anderes Staatswesen“ gehandelt habe. Vgl. auch SZ, 16. 6. 1978. 
krieg, etwa den populären „Tatsachenberichten“ der Soldaten in Zeitschriften wie „Quick“ und „Stern“, sogenannten Landserheften und der weitverbreiteten Memoiren von deutschen Generälen ${ }^{42}$, schritt die gesellschaftliche Rehabilitation der Wehrmacht voran ${ }^{43}$.

Im Gefolge dieses Booms geriet auch die Teilnahme der Legion Condor am Bürgerkrieg in Spanien in den Blickpunkt der westdeutschen Öffentlichkeit. So wurden die 1953 unter dem Titel „Die Ersten und die Letzten“ erstmals erschienenen Erinnerungen von Adolf Galland, einem der militärisch erfolgreichsten deutschen Jagdflieger und SpanienKämpfer, zu einem Bestseller mit einer Auflage von etwa zwei Millionen ${ }^{44}$.

Mitte der 50er Jahre - parallel zum Aufbau der Bundeswehr - entdeckte dann das Kino den Krieg in Spanien als Unterhaltungsstoff ${ }^{45}$. Unter dem neuen Titel „Der Kampf um Alkazar" kam 1955 eine italienische Produktion von 1939/40 in die westdeutschen Filmtheater, die sich bereits im „Dritten Reich“ als „Kassenschlager"46 erwiesen hatte. Die „heroische" Darstellung der franquistischen Verteidigung des Alcázar von Toledo war für das westdeutsche Publikum umgearbeitet worden. Die jetzige „entnazifizierte“ Version enthielt eine 1941 fehlende „zentrale“ achtminütige Szene einer Meßfeier, die den Katholizismus der Belagerten aus der Sicht des NS-Regimes allzusehr betont hätte.

Der Ende 1955 in den Kinos anlaufende deutsche Spielfilm „Solange du lebst“47 nutzte den Bürgerkrieg als Kulisse für eine Liebesgeschichte. Eine junge Lehrerin, Braut eines nationalspanischen Offiziers, entdeckt auf der Flucht vor den „Roten“ ein abgeschossenes deutsches Flugzeug und rettet unter Lebensgefahr den einzigen Überlebenden, einen deutschen Flieger. Auf die Legion Condor wird nicht weiter eingegangen; ja ihr Name

42 Vgl. Danyel, Die Erinnerung an die Wehrmacht in beiden deutschen Staaaten, S. 1140-1142. "Quick“ und „Stern“ hatten zusammen genommen regelmäßig 20 Mio. Leser. Vgl. Berghoff, Zwischen Verdrängung und Aufarbcitung, S. 107; Schornstheimer, Die leuchtenden Augen der Frontsoldaten. Vgl. ferner Gerstenberger, Strategische Erinnerungen, S. 620-629; Naumann, Nachkrieg, S. 11-25.

${ }^{43}$ So äußerten im August 1953 in einer repräsentativen Umfrage mehr als die Hälfte der Befragten (55\%) die Ansicht, den deutschen Soldaten könne kein Vorwurf wegen ihres Verhaltens im Zweiten Weltkrieg gemacht werden. Vgl. Brochhagen, Nach Nürnberg, S. 198. Die allenthalben aufblühende Vcteranenkultur tat ein übriges. Vgl. dazu Kühne, Zwischen Vernichtungskrieg und Freizeitgesellschaft, S. 90-113; allerdings konnten dic Veteranenorganisationen mit ihren etwa 500000 Mitgliedern nur eine Minderheit der über 10 Mio. ehemaligen Wehrmachtsoldaten erreichen. Echternkamp, Arbeit am Mythos, S. 431. Zur öffentlichen Rehabilitierung der einstigen Berufssoldaten in der frühen Bundesrepublik siehe Manig, Die Politik der Ehre.

${ }^{44}$ Vgl. Schmigalle, Deutsche schreiben für Hitler und Franco. S. 216 f. Galland beriet seit seiner Rückkehr aus Argentinien 1955 Firmen der Luftfahrtindustrie.

4.5 Kriegs- und Militärfilme waren insgesamt beim westdeutschen Publikum gefragt. Zwischen 1949 und 1960 fanden 470 Kriegsfilme den Weg in die Kinos. Vgl. Schmidt, „Wehrzersetzung“ oder „Förderung der Wehrbereitschaft"?, S. 387 f. Zur Erinnerung, Wahrnehmung und Deutung von Krieg im Film siehe: Chiari/Rogg/Schmidt (Hrsg.), Krieg und Militär im Film des 20. Jahrhunderts.

${ }^{46}$ Regel, Han pasado - Sie sind durchgekommen, S. 546. Nach dem Überfall auf die Sowjetunion im Juni 1941 benötigte das NS-Regime wicder antibolschewistische Filmpropaganda, die zu Zeiten des Hitler-Stalin-Pakts weniger erwünscht gewesen war. Deshalb gelangte der schon 1939/40 gedrehte Film erst im September 1941 unter dem Titel „Alkazar“ in die deutschen Kinos. Hier auch das Folgende.

4 Vgl. FAZ, 17. 11. 1955. Der Film, besetzt mit populären Darstellern wie Adrian Hoven und Marianne Koch, mußte nach einer Rüge der Frciwilligen Selbstkontrolle - einer Institution der Filmwirtschaft, der Vertreter des Bundes, der Länder und Kirchen angehörten - wegen „militaristischer Tendenzen“ vor seiner Uraufführung gekürzt werden. Die Filmbewertungsstelle der Länder wiederum gab dem Melodram das Prädikat „Wertvoll“. Siche weitere Kritiken in: Frankfurter Neue Presse, 17. 11. 1955, SZ, 24. 11. 1955, Der Tagesspiegel, 21.6.1956. 
wird nicht einmal erwähnt. Ansonsten fehlt es nicht an ehedem bekannten Schwarz-WeißMustern: Hier die Disziplin und Sauberkeit der Franco-Truppen, dort die Zügellosigkeit und Brutalität der „Roten“. Der Zuschauer, so merkte der „FAZ“-Kritiker sarkastisch an, bekomme den Trost, „wenigstens waren wir einmal auf der richtigen Seite“, hier „unausgesprochen" mitgeliefert.

In dieser filmischen Darstellung fanden sich wohl auch ehemalige Soldaten der Legion Condor wieder. Während sie zur Diskussion um die Anrechnung ihrer Dienstzeiten noch geschwiegen hatten, meldeten sie sich im Sommer 1956 - 20 Jahre nach dem Beginn ihres Einsatzes - aber zu Wort und beklagten die fehlende öffentliche Aufmerksamkeit der Nachkriegsgesellschaft. So wisse die deutsche Jugend „kaum noch etwas von ihren Taten“48, hieß es bei der Gründung der „Kameradschaft Legion Condor" am 9. August ${ }^{49}$ in Bingen. Schließlich sei es doch ihnen zu verdanken, meinten die rund 50 Anwesenden geschichtsklitternd, „daß heute weder in Frankreich noch in Spanien der Kommunismus herrsche“50. Deshalb müsse an den erfolgreichen Kampf der Legion Condor und die deutsch-spanische Waffenbrüderschaft erinnert werden. Die Kameradschaft, die alsbald Verbindungen zu Angehörigen der ehemaligen Blauen Division und zur deutschen Kolonie in Spanien herstellen wollte, war vor allem eine Vereinigung der sogenannten kleinen Leute mit einem früheren Unteroffizier als Vorsitzenden ${ }^{51}$. Prominente Vertreter der Legion wie Galland, Trautloft ${ }^{52}$ oder Trettner ${ }^{53}$ hielten sich fern; offenbar wollten sie sich in der Nachkriegsgesellschaft nicht mit den rückwärts orientierten Kameraden öffentlich identifizieren lassen und Trautloft und Trettner ihre Karriere in der Bundeswehr nicht gefährden.

18 Vgl. Kraushaar, Die Protest-Chronik 1953-1956, S. 1423.

49 Ebenda. Die Deutsche Soldaten-Zeitung nennt im November 1956 allerdings den 30.Juni bis 1.Juli als Zeitpunkt des Gründungstreffens, an dem etwa 160 Personen teilgenommen hätten.

${ }^{50}$ Vgl. Kraushaar, Die Protest-Chronik, S. 1423. Hier auch das Folgende.

51 Bundesverteidigungsministerium an Auswärtiges Amt, 7.1.1958, PA/AA, Ref. 206, Bd. 76. Der Führungsstab der Bundeswehr berichtete hier erstmals über den Traditionsverband, dessen Gründung hier irrtümlich auf Anfang Juni 1957 datiert wurde. Der Vorsitzende der Kameradschaft, Storz, war außerdem Vorsitzender des Verbands der SBZ-Flüchtlinge in Rheinland-Pfalz.

${ }^{52}$ Hannes Trautloft gehörte zu den ersten Fliegern, die in Spanien eingesetzt wurden. 1939 veröffentlichte er seine Kriegserinnerungen „Als Jagdflieger in Spanien“. Vgl. weiterführend Schmigalle, Deutsche schreiben für Hitler und Franco, S. $238 \mathrm{f}$. Im Oktober 1957 wurde Trautloft als Brigade-General und Kommandeur der Schulen der Luftwaffe in die Bundeswehr übernommen und später zum Stellvertreter des Inspekteurs der Luftwaffe befördert.

${ }_{53}$ Heinz Trettner war zwischen November 1936 bis Januar 1938 als Adjutant und Staffelkapitän bei der Legion Condor. Im November 1956 trat Trettner in die Bundeswehr ein. Bei SHAPE, dem Hauptquartier der NATO, war er für die Abteilung Logistik verantwortlich. Anfang 1964 wurde er zum Generalinspekteur der Bundeswehr berufen. Vgl. Munzinger-Archiv. Im Februar 1964 legte die DDR eine Dokumentation vor, die dem neuernannten Gencralinspekteur unterstellte, seine „Blitzkarriere“ in der Wehrmacht habe er einer prononciert „nazistische[n] Einstellung“ z.u verdanken. Der Führungsstab im Bundesverteidigungsministerium stellte nach einer ersten Analyse der Kampagne erleichtert fest, daß diese „wesentlich schlechter geplant und belegt" sei als die früheren Aktionen gegen die Generale Speidel, Heusinger und Foertsch. „Mangels Material“ scien die „Kommunisten gezwungen“ gewesen, die Vorwürfe gegen Trettner in eine allgemeine Kampagne gegen die „Bonner Generale“ einzubauen. Die von OstBerlin insinuierte Teilnahme Trettners an der Bombardierung Guernicas sei haltlos, so das Bundesverteidigungsministerium. Der damalige Hauptmann Trettner sei im April 1937 Kommandant des Stabsquartiers der Kampfgruppe 88 gewesen. Erst seit Oktober 1937 habe er in Spanien als Staffelkapitän an „fliegerischen Einsätzen“ teilgenommen. Dokumentation Trettner, 5.3. 1964, BA-MA, Pers 1 (12627). Den Hinweis verdankt der Verfasser Dr. Stefanie Schüler-Springorum (Hamburg). 
Bundesverteidigungsministerium und Auswärtiges Amt hatten von dem neu gegründeten Traditionsverband zunächst anscheinend keine Notiz genommen. Als das Generalkonsulat in Barcelona aber ankündigte, daß Ende September 1956 ein Deutschland-Besuch von Mitgliedern der sogenannten Bruderschaft der Blauen Division bevorstehe ${ }^{54}$, schreckte dies die Verantwortlichen in den Ministerien auf. Eine offizielle Unterstützung der ,privaten" Reise zu den früheren Garnisonen in Süddeutschland, wie sie vom Generalkonsulat vorgeschlagen wurde, kam für das Auswärtige Amt aus politischen Gründen nicht in Betracht. Zwar gebe es keinen Anlaß, einer solchen Erinnerungsfahrt „Hindernisse in den Weg zu legen" ${ }^{\text {"55 }}$, befördern wollte man das Ganze aber nicht.

Der Zeitpunkt war für Bonn denkbar ungeeignet, hatte doch im Sommer 1956 die Einstellung ehemaliger SS-Soldaten in die Bundeswehr für erhebliches Aufsehen im In- und Ausland gesorgt ${ }^{56}$. Zugleich sei die Bundesregierung, so hieß es in einer Aufzeichnung für Staatssekretär Hallstein, „einer Propaganda-Welle des Ostblocks“ wegen des gerade erfolgten Verbots der KPD ${ }^{57}$ „ausgesetzt“. Deshalb verfolge die „Weltöffentlichkeit mit großem Mißtrauen “ alle Vorgänge, die den Anschein erweckten, daß die Bundesrepublik ,auf dem Wege sei, angeblichen neo-nazistischen Strömungen nachzugeben“. Wenn eine amtliche Hilfe für die Blaue Division bekannt würde, bräche erneut ein „Entrüstungssturm“ im Osten, aber auch in den „meisten Ländern des freien Westens“ los, „die das Franco-Regime auch heute noch ablehnen“. Im übrigen wolle sich die spanische Regierung augenscheinlich auch nicht für den Deutschland-Besuch einsetzen. Unter diesen Umständen erschien dem Auswärtigen Amt eine mögliche Verstimmung im Kreis der Blauen Division als das „kleinere Übel“. Obwohl der Ausflug in die Vergangenheit am Ende nicht zustande kam ${ }^{58}$, hätte er Anlaß für eine Klärung über die offizielle Haltung gegenüber den deutsch-spanischen Veteranenverbänden und dem Problem der militärischen Traditionspflege sein können.

Ein tiefergehendes Nachdenken setzte jedoch erst Ende 1957 mit einer Anfrage von Botschafter Knappstein zum bevorstehenden Volkstrauertag ein. Das bisherige „Beiseitestehen der Vertreter der Bundesrepublik "59 bei der Ehrung gefallener deutscher Soldaten

54 Generalkonsulat Barcelona an Auswärtiges Amt, 4.9. 1956, PA/AA, Ref. 206, Bd. 41. Wie ernst man im Auswärtigen Amt das Vorhaben nahm, zeigte die Reaktion von Außenminister Brentano auf einen ersten Hinweis der Botschaft Madrid Ende August. Er ließ nachforschen, ob andere Stellen in der Bundesrepublik über weitergehende Informationen verfügten. Das Bundesverteidigungsministerium, die beiden Soldatenverbände VdS und Kyffhäuser-Bund sowie der vom Innenministerium eingeschaltete Verfassungsschutz hatten jedoch keinerlei Mitteilung erhalten. Aufzeichnung Carstens an Brentano, 31. 8. 1956, PA/AA, Ref. 206, Bd. 41. Veteranen der División Azul hatten im Mai 1952 in Madrid die Bruderschaft gegründet. Vgl. Aschmann, „Treue Freunde...?“, S. 376.

55 Aufzeichnung Ministerialdirigent von Marchtaler an Staatssekretär, 13.9. 1956, PA/AA, Ref. 206, Bd. 41. Hier auch das Folgende.

56 Vgl. weiterführend Brochhagen, Nach Nürnberg, S. 202-210.

57 Die KPD war am 17.8. 1956 als verfassungswidrig verboten worden.

58 Jedenfalls ist in den einschlägigen Archivalien und Pressebeständen kein Nachweis über eincn Deutschland-Aufenthalt von Mitgliedern des Traditionsverbands der Blauen Division im Jahr 1956 enthalten. Vermutlich kam der Besuch aufgrund fehlender finanzieller Mittel nicht zustande. So hatte das Generalkonsulat in Barcelona schon auf entsprechende Probleme aufmerksam gemacht und für Einladungen deutscher Städte geworben. Generalkonsulat Barcelona an Auswärtiges Amt, 4. 9. 1956, PA/AA, Ref. 206, Bd. 41. ${ }^{59}$ Aufzeichnung von Trützschler, 4. 11. 1957, betr. Volkstrauertag, hier: Kranzniederlegung am Denkmal der Gefallenen der Legion Condor in Madrid, PA/AA, Ref. 206, Bd. 76. Hier auch das Folgende. Knappstein hatte diese Frage schon kurz nach seinem Amtsantritt - im Jahr zuvor - offenbar ohne Resonanz aus Bonn aufgeworfen. 
am Denkmal der Legion Condor in Madrid erschien ihm nicht mehr zeitgemäß und sollte überprüft werden. Ohnehin habe dies ,weder in der spanischen Öffentlichkeit noch in der hiesigen [deutschen] Kolonie Verständnis gefunden“. Das Auswärtige Amt wies jedoch den Gedanken an eine Kranzniederlegung in diesem Jahr entschieden zurück, insbesondere weil das Denkmal nach wie vor mit nationalsozialistischen Symbolen versehen war. Damit in Zukunft „alle "60 in Spanien gefallenen Deutschen am Volkstrauertag geehrt werden könnten, empfahl der Leiter der Länderabteilung, von Welck, die Hakenkreuze zu entfernen und eine Kranzaufschrift zu finden, welche die „Gefühle aller in Spanien lebenden Deutschen und Spanier berücksichtigt“ und „durch die eine Identifizierung mit dem gegenwärtigen Regime vermieden wird" ${ }^{\text {"61. }}$.

Nun fand auch die Kameradschaft der Legion Condor in Bonn Aufmerksamkeit. Die Frage nach ihrer politischen Haltung gegenüber der Bundesrepublik und dem FrancoRegime wurde gestellt ${ }^{62}$. Das Bundesverteidigungsministerium erklärte im Januar 1958 beruhigend $^{63}$, es handele sich um eine "lose Verbindung“, deren Einstellung zu den innenpolitischen Verhältnissen als "positiv“ bezeichnet werden könne und deren Haltung gegenüber der Bundeswehr „sehr aufgeschlossen“ sei. Über eine Teilnahme von Soldaten der Bundeswehr sei nichts bekannt. Der Traditionsverband wolle in erster Linie die Kameradschaft pflegen sowie für die Versorgungsansprüche der Mitglieder eintreten. Zum Verlauf des 2. Bundestreffens im Juni 1957 wurde mitgeteilt, daß die „anfangs starke[n] Einwände“ des Verfassungsschutzes ${ }^{64}$, der hier die „Gefahr der Förderung neonazistischer Bestrebungen“ gesehen hatte, durch das Treffen selbst „zerstreut“ worden seien. Ob dieser Eindruck allerdings ganz zutreffend war, muß bezweifelt werden.

So lehnte der Vorstand eine Aufnahme in den wahrlich nicht linksorientierten Verband deutscher Soldaten (VdS) mit der Begründung ab, daß dort „eine kommunistische Unterwanderung "65 festzustellen sei. Möglicherweise war die Wahrnehmung der Verfassungsschützer aber auch bestimmt durch die sehr geringe Zahl der Teilnehmer: Anstatt der erwarteten 500 Personen hatten nur knapp 50 den Weg in die Stadthalle von Bingen gefun-

60) Aufzeichnung von Welck an Staatssekretär, 9. 11. 1957, PA/AA, Ref. 206, Bd. 76.

61 Die Botschaft ließ daraufhin im Frühjahr 1958 zumindest das Fries von Hakenkreuzemblemen entfernen. Das Denkmal mache jetzt, wie Militärattaché Oster befand, einen „gepflegten, würdigen Eindruck“, das sich auch als „Gedenkstätte“ für die Legion Condor insgesamt cigne. Bericht Oster an Auswärtiges Amt, 6. 8. 1958, BA-MA, BW 4, Bd. 744. Am Volkstrauertag 1958 kam cs am deutschen Kriegerdenkmal in San Sebastián zu einer offiziellen Kranzniederlegung durch Militärattaché Oster; am 20. November, dem Gedenktag für die Gefallenen Spaniens, wurde die Ehrung am instandgesetzten Denkmal auf dem Madrider Ostfriedhof im Beisein von ehemaligen Angehörigen der Legion Condor und der Blauen Division wiederholt. Der Text der Kranzschleife galt, wie von Welck vorgeschlagen hatte, allen in Spanien gefallenen Deutschen. Botschaft Madrid an Auswärtiges Amt, 25. 11. 1958, PA/AA, Ref. 602, Bd. 65.

62 Aufzeichnung von Welck an Staatssekretär, 9. 11. 1957, PA/AA, Ref. 206, Bd. 76. Auch das Bundeskanzleramt wollte jetzt vom Innenministerium wissen, ob Erkentnisse vorlägen. Das Innenministerium konnte aber nur mitteilen, daß beim Bundesamt für Verfassungsschut\% kein Material vorhanden sei, das für die „politische Beurteilung“verwendet werden könnte. BA, B 106, Bd. 15455.

${ }^{63}$ Bundesverteidigungsministerium (Führungsstab der Bundeswehr) an Auswärtiges Amt, 7.1.1958, PA/AA, Ref. 206, Bd. 76. Hier auch das Folgende.

64 Das Bundesamt für Verfassungsschutz war wohl erst durch einen offenen Brief der „Interessengemeinschaft der republikanischen Spanienkämpfer" an die Presse auf die Veranstaltung aufmerksam geworden. Darin hatte man gefordert, die Versammlung der Condor-Legionäre zu verbieten. Vgl. Schreiben Karl Sauer (Esslingen), 24. 5. 1957, Spiegel-Archiv.

6.5 Vgl. FR, 4. 6. 1957. Hier auch das Folgende. 
den. Es war ein „Reinfall“, berichtete die „Frankfurter Rundschau“. Mangels Interesse wurde die vorgesehene Reise zu den „Kampfstätten der Legion“ in Spanien abgesagt. Statt dessen wollte man nun 1959 mit einer größeren Gruppe an den Feiern zum 20. „Sieges$\operatorname{tag}^{“ 66}$, wie das Bürgerkriegsende vom Bundesministerium der Verteidigung bezeichnet wurde, teilnehmen.

Eigentlich Anlaß genug für das Auswärtige Amt, eine Position gegenüber den Veteranenverbänden und ihrer Traditionspflege zu entwickeln, zumal seit Frühjahr 1958 die deutsche Botschaft in Madrid auf eine Weisung zur Blauen Division drängte ${ }^{67}$. Die in Spanien bestehenden Traditionsvereine bildeten ein „Reservoir an Sympathie für Deutschland - und zwar nicht nur für das Deutschland Hitlers“, befand Botschafter Knappstein, das politisch genutzt werden sollte.

Denn die einstigen Soldaten des Freiwilligen-Verbands, zu denen auch Außenminister Castiella und Generalstabschef Muñoz Grandes gehörten, nähmen inzwischen vielfach führende Positionen in Politik, Wirtschaft, Verwaltung und Militär ein. Außerdem, so rechtfertigte Knappstein die Teilnahme der Blauen Division am Krieg gegen die Sowjetunion, habe sie sich für die "Idee der Eindämmung des Kommunismus" eingesetzt, ähnlich wie dies die westliche Politik heute tue. Das Auswärtige Amt war jedoch mit dem Thema zunächst überfordert, da es ihm vor allem an grundlegenden Informationen fehlte. Eine Sprachregelung, in die auch die SPD-Opposition eingebunden werden sollte ${ }^{68}$, erforderte Zeit. Bei einer ersten Besprechung wurde überlegt, das „Institut für Zeitgeschichte“ in München mit einer Untersuchung über die Blaue Division zu beauftragen. Vorläufig zog man das gerade ins Deutsche übersetzte Buch des letzten Kommandeurs der Blauen Division, General Esteban Infantes, zu Rate ${ }^{69}$. So recht helfen konnte auch die Stellungnahme des Bundesverteidigungsministeriums ${ }^{70}$ nicht: Die ehemalige Blaue Division bestand aus Freiwilligen, hieß es, „die sich zum Kampf mit der Waffe gegen den Bolschewismus verpflichtet fühlten“. Im Hinblick auf die damalige „Waffenbrüderschaft" solle sich „die deutsche Bevölkerung“ dieser „Traditionsgemeinschaft“ gegenüber „kameradschaftlich verhalten“. Das Verteidigungsressort empfahl, „amtlicherseits“ der Blauen Division „eine wohlwollende Haltung“ entgegenzubringen. In ihrer Hilflosigkeit kamen die mit dem Traditionsproblem befaßten Referate im Auswärtigen Amt überein, diese Frage dilatorisch zu behandeln ${ }^{71}$.

Gegen ein weiteres Zuwarten wandte sich allerdings im August 1958 der Nachfolger Knappsteins in Madrid, Botschafter von Welck, der zuvor die Länderabteilung im Bonner Außenamt geleitet hatte ${ }^{72}$. Er machte deutlich, daß das Thema der sogenannten Waffen-

66 Bundesverteidigungsministerium an Auswärtiges Amt, 7. 1. 1958, PA/AA, Ref. 206, Bd. 76.

67 Botschaft Madrid an Auswärtiges Amt, 29. 3. 1958, PA/AA, Ref. 206, Bd. 76. Hier auch das Folgende. Die Frage nach dem „offiziellen deutschen Standpunkt“ gegenüber der ehemaligen Blauen Division war durch ein Schreiben eines in Valencia lebenden Deutschen an das Generalkonsulat Barcelona ausgelöst worden.

${ }^{68}$ Aufzeichnung betr. Besprechungen über die Legion Condor und die Blaue Division, 23.5. 1958, PA/AA, Ref. 206, Bd. 76.

69) Ebenda. Vgl. Esteban Infantes, Blauc Division. Über die Legion Condor wurde in der Sitzung nur am Rande gesprochen.

70 Bundesverteidigungsministerium an Auswärtiges Amt, 31. 7. 1958, PA/AA, Ref. 206, Bd. 76. Hier auch das Folgende.

${ }^{71}$ Schmidt-Schlegel an Botschafter von Welck, 4. 8. 1958, PA/AA, Bestand Botschaft Madrid, Bd. 7656.

${ }^{72}$ Welck an Auswärtiges Amt, Fragen betreffend die Legion Condor und die Blaue Division, 22. 8. 1958, PA/AA, Bestand Botschaft Madrid, Bd. 7656. Hier auch das Folgende. 
brüderschaft an den Nerv der deutsch-spanischen Beziehungen rührte. Die Legion Condor wie auch die Blaue Division genössen in Spanien große Wertschätzung, zumindest „bei allen Spaniern, die das gegenwärtige Regime bejahen“, erläuterte Welck. Dies sei auch eine Generationsfrage, schließlich stünden die meisten führenden Politiker und Militärs ,jetzt in den besten Jahren“ und hätten den Bürgerkrieg „aktiv mitgemacht“. Im Zweiten Weltkrieg habe Deutschland in Spanien, so der Botschafter, durch „seine militärischen Leistungen die Bewunderung weiter Kreise erworben“. Das Ausmaß des deutschen Zusammenbruchs 1945 und seine Folgen seien hier nicht ,in vollem Umfang“ ins „Bewußtsein gelangt“.

Deshalb neigten die Spanier dazu, die Bundesrepublik, „viel mehr mit dem alten Deutschen Reich zu identifizieren“, als dies andere Länder in Europa täten. Aus der Perspektive Welcks erschien die Bundesrepublik quasi als politische Geisel des Franco-Regimes: Die Spanier hätten „einfach kein Verständnis dafür, wenn wir es ablehnen, uns mit der Beteiligung des Dritten Reiches am spanischen Bürgerkrieg und mit der Legion Condor ohne weiteres zu identifizieren ${ }^{73}$. Noch weniger würden sie es verstehen, wenn wir uns der im Krieg gegen die Sowjetunion geleisteten Waffenhilfe nicht mit Dankbarkeit erinnerten. Es würde sie nur verletzen, wenn wir versuchen, ihnen zu erklären, warum wir die damaligen Ereignisse heute mit anderen Augen betrachten als sie“. Andererseits sorgte sich der Botschafter um die möglichen Konsequenzen eines Spanien-Besuchs der Kameradschaft der Legion Condor, der „mit großer Wahrscheinlichkeit“ im kommenden Jahr erfolgen wer$\mathrm{de}^{74}$. Da die Kameradschaft hieran kaum zu hindern sei, forderte er die zuständigen Stellen in Bonn, in erster Linie das Bundesverteidigungsministerium dazu auf, Einfluß zu nehmen. Es müsse erreicht werden, daß die Delegation „richtig zusammengestellt" sei, „richtig“ auftrete und vor allem keine „unvernünftigen Reden“ halte. Dabei sprach Welck von „nichtberufenen Persönlichkeiten“, die nicht nur in Spanien sondern auch bei unseren Verbündeten „Schaden anrichten“ könnten.

Insgesamt war seine Stellungnahme ein beredtes Beispiel für die Schwierigkeiten mancher Diplomaten und Beamter sich von NS-geprägten Vorstellungen zu lösen und ein Beleg für das deutsch-spanische Sonderverhältnis in den 50er Jahren. Während ansonsten der Verweis auf den Bruch mit dem Nationalsozialismus zum Grundkanon westdeutscher Außenpolitik gehörte, war dies im Falle Spaniens anders.

Ähnlich argumentierte Militärattaché Oster, der sich der Traditionspflege naturgemäß mit besonderer Aufmerksamkeit annahm. Schon vor seiner Entsendung nach Madrid unterstrich er, sicherlich nicht ganz uneigennützig: „Bei den wachsenden politischen und demnächst auch militärischen Beziehungen "75 zwischen Bonn und Madrid werde „an der

${ }^{73}$ Die nationalsozialistische Intervention in den Spanischen Bürgerkrieg beurteilte Welck kritisch. Sie sei ein „Teil der Hitlerschen Politik“ gewesen, „die letzten Endes auf die Unterwerfung Europas abzielte". Die Freiwilligen der Legion wurden von ihm aber in Schutz genommen. Diese Soldaten seien - und damit folgte er einem weitverbreiteten Entlastungsmuster - genau wie die Millionen von Soldaten im Zweiten Weltkrieg vom NS-Regime „mißbraucht worden“. Ebenda.

${ }^{74}$ Bereits an der diesjährigen "Siegesparade“ im Mai habe eine Gruppe teilnehmen wollen. Die Absage sei, so Welck, mit dem damals noch mit Hakenkreuzen versehenen Ehrenmal der Legion Condor begründet worden, dessen Zustand eine Kranzniederlegung unmöglich mache. Ebenda. Was unter Umständen an politischen Problemen auf die Bundesregierung zugekommen wäre, zeigt die ursprüngliche Absicht der Kameraden, ,in Uniform in der Siegesparade milzumarschieren“. Davon seien sie erst nach spanischen Bedenken abgerückt. Botschaft Madrid an Auswärtiges Amt, 18. 4. 1958, PA/AA, Ref. 206, Bd. 76.

${ }^{75}$ Aufzeichnung Oster 1a/58, Aufstellungsstab Bonn, 5. 5. 1958, PA/AA, Ref. 206, Bd. 76. Hier auch das Folgende. 
Erinnerung an gemeinsame Feldzugserlebnisse nicht vorbeizusehen sein“. Aus seiner dezidiert antikommunistischen Einstellung machte Oster keinen Hehl. Den NS-Eroberungsund Vernichtungskrieg gegen die Sowjetunion funktionierte er ganz im Zeichen des Kalten Krieges in einen antibolschewistischen Verteidigungskampf um. So habe die Blaue Division „teilgehabt an dem Abwehrkampf der deutschen Wehrmacht gegen Sowjet-Rußland“. Daher hätten die spanischen Freiwilligen, wie der Militärattaché betonte, „ein Anrecht auf kameradschaftliche Achtung"von amtlicher deutscher Seite. Nach seiner Ansicht sollten die Verbindungen zur Bruderschaft der Blauen Division „ausschließlich Sache“ offizieller Stellen sein, um zu verhindern, daß der „Ausbau der Traditionspflege einen eigenständigen und nicht zu steuernden Charakter annimmt“. Der Einsatz der Legion Condor im Bürgerkrieg hatte für ihn nichts Anstößiges. Es war eine Erinnerung an „gemeinsame Kämpfe gegen den Bolschewismus"76. Denn die "Sowjets" hätten „damals auf spanischem Boden“, so Oster, „den offenen Versuch gemacht, bereits im Jahre 1936 ein Sowjetregime im westlichen Europa zu etablieren“. Dies sei „mit" durch die italienischen Freiwilligen und die Legion Condor „verhindert" worden.

Eine derartige Deutung erlaubte eine positive Bezugnahme auf die Spanienpolitik des „Dritten Reiches“, die gleichsam von ihrem nationalsozialistischen Gehalt befreit wurde. Das Feindbild Sowjetunion bildete so im Hinblick auf Spanien die ideologische und politische Klammer zwischen NS- und Nachkriegszeit. Oster hielt die ,junge deutsche Demokratie“ für so "gefestigt“, daß sie „zur ,moderaten“ Traditionspflege der Legion Condor und der Blauen Division Ja [...] sagen " könne ${ }^{77}$. Soweit mochte das Auswärtige Amt indes nicht gehen. Die Diplomaten in Bonn scheuten eine inhaltliche Auseinandersetzung und verhielten sich weiterhin abwartend. Unterstützt wurden sie dabei auch von der sozialdemokratischen Opposition, die das unliebsame Thema gleichfalls zu vermeiden suchte. Bundestags-Vizepräsident Carlo Schmid (SPD) empfahl, „nach Möglichkeit nicht an diesem Fragenkomplex zu rühren" "78. Allzu nahe wollte die offizielle Politik den Veteranenverbänden nicht kommen.

Andererseits war man an Informationen über Geist und Stimmung in diesen Vereinigungen durchaus interessiert. Auswärtiges Amt und Verteidigungsministerium vertrauten hier auf den umtriebigen Kapuziner-Pater Konrad Simonsen, der in Bonn als „treibende

${ }^{76}$ Bericht Oster 2/58, 17. 7. 1958, BA-MA, BW 4, Bd. 752. Dort auch das Folgende.

7 Der Militärattaché plädierte beispielsweise dafür, Kontakte zwischen ehemaligen Angehörigen der Legion Condor, die heute in der Bundeswehr aktiv seien, und ihren spanischen Kameraden herıustellen. Ihm „schwebte“ ein Austausch von Luftwaffenangehörigen vor, die „entweder im Bürgerkrieg oder im Rußlandfeldzug [...] mit unseren Fliegern zusammen geflogen sind“. So genieße eine Persönlichkeit wie General Trautloft, der Kommandeur der Schulen der Luftwaffe, hier „einen hevorragenden Ruf" und sei ,jederzeit aufrichtig willkommen“. Bericht Oster 29/59. 27. 7. 1959, BA-MA, BW 4, Bd. 745. Derart rückwärts gewandte Verbindungen stießen aber in der Bundeswehr auch auf Widerstand. Oberst Roedel, selbst einst Mitglied der Legion Condor und inzwischen im NATO-Hauptquartier (SHAPE) tätig, sprach sich gegenüber Oster für eine klare Grenzziehung zur NS-Zeit aus: „Er habe kein Verständnis dafür, wenn aktive BW-Offiziere an Veranstaltungen teilnähmen, wo auch nur in irgendeiner Weise der nationalsozialistischen Vergangenheit in Wort und Gruß gedacht werde. " Solche Treffen schadeten „alle[n] europäischen Zukunftsabsichten“, schließlich, so Roedel, sähe er es auch nicht gerne, .wenn seine amerikanischen und englischen Kameraden bei SHAPE plötzlich eine Dresden-Zcrstörungs-Erinnerungsfeier" machten. Bericht Oster 5/59, 27. 7. 1959, BA-MA, BW 4, Bd. 752. Vgl. zu den britischen und amerikanischen Luftangriffen auf Dresden im Fcbruar 1945: Ueberschaer, Dresden 1945 - Symbol für Luftkriegsverbrechen, S. 382-396.

${ }^{78}$ Aufzeichnung betr. ehemalige Legion Condor und Blaue Division, 11. 2. 1959, PA/AA, Ref. 206, Bd. 76. 
Kraft "79 bei der Gründung der Kameradschaft der Legion Condor ${ }^{80}$ galt. Der einstige Feldgeistliche der Blauen Division ${ }^{81}$, in Hamburg geboren, hatte rund 30 Jahre in Lateinamerika und Spanien gelebt, bevor er 1955 zu seinem Leidwesen nach Deutschland zurückberufen wurde ${ }^{82}$. "Conrado de Hamburgo", so sein Ordensname, schien in Madrid eine beträchtliche Aktionsfreiheit besessen zu haben. Denn der Mönch mit Drang zur Politik ${ }^{83}$ blieb auch nach der Rückkehr der Blauen Division 1943 als Mitarbeiter des deutschen Militärattachés, bis zu dem für ihn „traurigen Kriegsende " ${ }^{\text {" }}$, Angehöriger der Wehrmacht. Zu Beginn der 50er Jahre suchte er den Kontakt zur Dienststelle Blank, um Erfahrungen über das „gleiche Schicksal“ der deutschen und spanischen Kriegsgefangenen in der Sowjetunion auszutauschen. Mehr als eine kurze „Fühlungnahme“ ${ }^{\text {"85 }}$ entstand daraus aber nicht. Simonsen, dem es „weder an Selbstbewußtsein noch an Eitelkeit mangelte" ${ }^{\text {" }}$, berief sich in Gesprächen mit der bundesrepublikanischen Botschaft gern auf seine guten Beziehungen zu hochrangigen spanischen Militärs, die auf seine Zeit im Hauptquartier der Blauen Division zurückgingen. In der deutschen Kolonie spielte Pater Konrad in der Nachkriegszeit, abgesehen von „einigen NS-Restbeständen“, keine „besondere Rolle“. Er

${ }^{79}$ Fernschreiben Auswärtiges Amt an Botschaft Madrid, 23.4. 1958, PA/AA, Ref. 206, Bd. 76.

s0 Der Traditionsverband stieß im Auswärtigen Amt auf Wohlwollen. Nach Ansicht des Parlamentsreferenten handele es sich „hierbei keineswegs um eine in überholten weltanschaulichen Begriffen denkende Gruppe“. Zudem gebe es „weitere Beweise“ für ihre „demokratische antinationalsozialistische Grundhaltung“. Vermerk Junges, 14. 1. 1959, PA/AA, Ref. 206, Bd. 76.

81 Vgl. zu seiner Biographie die Aufzeichnung von Asmus Christian Simonsen, wie Pater Konrad mit bürgerlichem Namen hieß, über „Dic Geschichtc cincs Fricdensfühlers“, Nl. Simonsen, Provinz der Rheinisch-Westfälischen Kapuziner, Koblenz. Das Auswärtige Amt unterstellte ihm irrtümlich, gleichfalls für die Legion Condor im geistlichen Einsatz gewesen zu sein. Fernschreiben Federer an Botschaft Madrid, 23. 4. 1958, PA/AA, Ref. 206, Bd. 76. Von antibolschewistischem Eifer erfüllt, bedauerte Pater Simonsen in der Nachkriegszeit, daß es ihm als katholischen Priester nicht vergönnt gewesen sei, während des spanischen Bürgerkrieges „als Märtyrer zur Ehre der Altäre“ berufen worden zu sein. Vgl. schriftliche Mitteilung Botschafter a. D. Rupprecht von Keller an den Verfasser, 25. 3. 1992.

82 Simonsen empfand diese Weisung der Kapuziner offfenbar sogar als „unfreundlichen Akt“. Vgl. schriftliche Mitteilung Botschafter a. D. Rupprecht von Keller an den Verfasser, 25. 3. 1992.

${ }^{83}$ Simonsen beschreibt in sciner Geschichte eines „Friedensfühlers“ seine Mitwirkung an einer Friedensinitiative des spanischen Außenministeriums im Jahre 1943. Ziel war es demnach, durch einen „Putsch“ oder „Regimewechsel“ in Deutschland nicht nur zu einem Waffenstillstand mit den Westalliierten, sondern zu einem sofortigen Bündnis mit den Amerikanern zu gelangen, um „den Sowjets die Stirn zu bieten und das Vordringen der Russen nach Mitteleuropa zu verhindern, und am besten gleich gemeinsam den Kommunismus zu zerschlagen“. Dazu sollte Generalfeldmarschall Wilhelm Ritter von Leeb, der ehemalige Oberkommandierende der Heeresgruppe Nord, dem auch die Blaue Division mit ihren insgesamt 21 Feldgeistlichen unterstanden hatte, von Simonsen gewonnen werden. Allerdings verliefen die Gespräche mit Leeb und dem amerikanischen Botschafter in Madrid im Sande. Vgl. Nl. Simonsen. Zumindest der Kontakt mit Botschafter Hayes wird von diesem bestätigt. Vgl. Foreign Relations of the United States. Diplomatic Papers, 1944, Bd. I, S. 546 f. Vgl. zu den spanischen Versuchen zur Friedensvermittlung weiterführend: Ruhl, Spanien im Zweiten Weltkrieg, S. 211-217. Zur Vita Leeb siehe Weiß (Hrsg.), Biographisches Lexikon zum Dritten Reich, S. 293.

84 Vgl. Die Geschichte eines Friedensfühlers, Nl. Simonsen, S.9. In einem Beitrag für die Deutsche Soldaten-Zeitung schrieb er im April 1955 gar bedauernd, daß vor fast zehn Jahren "die tapfere, ruhmbcdeckte deutsche Armee die Waffen“ niedergelegt habe, „von Ihrer politischen Führung verlassen“. Vgl. ebenda, Heft 4.

${ }^{85}$ Aufzeichnung Oster 1a/58, Aufstellungsstab Bonn, 5.5. 1958, PA/AA, Ref. 206, Bd. 76. Oster erinnerte sich an eine erste Verbindung, die „ungefähr 1951“ aufgenommen worden sei.

${ }^{86}$ Schriftliche Mitteilung Botschafter a. D. Rupprecht von Keller an den Verfasser, 25. 3. 1992. Hicr auch das Folgende. 
gehörte zu ,jenen Leuten“, so der damalige Botschaftsrat von Keller, „deren ,große“ Vergangenheit in der Zeit des Dritten Reiches lag“. Als katholischem Ordensgeistlichen, politisch unverdächtig, fiel es ihm jedoch nicht schwer, in Bonn als Ansprechpartner akzeptiert zu werden. Simonsen war im Sommer 1957 an das Auswärtige Amt herangetreten ${ }^{87}$. Dabei präsentierte er sich gegenüber dem Spanienreferenten als Verbindungsmann zu den Traditionsverbänden der Legion Condor und der Blauen Division. Pater Konrad gab an, über „langjährige Beziehungen“ zu Staatschef Franco zu verfügen. Eine deutsche Regierung, die die „Verdienste und das Ansehen“ der Legion Condor in Spanien „ignorieren oder mißachten würde“, stieße nach seiner Meinung in Madrid auf „Befremden und Unwillen“. Gleiches gelte für die Blaue Division.

In den folgenden Jahren kam es wiederholt zu einem Informationsaustausch mit dem Spanienreferat. Simonsen, der sich ebenso wie die Kameradschaft der Condor-Legionäre dazu bekannte, ein „fanatischer Gegner des Weltbolschewismus" ${ }^{\text {"88 }}$ zu sein, unterrichtete das Auswärtige Amt offenbar schon im Februar $1959^{89}$ über die bevorstehende Spanienfahrt der deutschen Veteranen. Davon wurde die Botschaft allerdings nicht informiert. Ob es sich dabei um ein bloßes Versehen handelte oder das Spanienreferat die Nachricht auf die leichte Schulter nahm, bleibt ungeklärt. Diese Nachlässigkeit sollte jedoch unangenehme Folgen haben. Konsterniert berichtete Militärattaché Oster später, daß er erst durch die Bruderschaft der Blauen Division zehn Tage vor Ankunft der etwa 100 Kameraden überhaupt von der Reise erfahren habe ${ }^{90}$. Daher konnte die deutsche Vertretung in Madrid sich nur noch in Schadensbegrenzung üben. Bruderschaft und spanische Regierung waren ebenso von dem „Massenanmarsch“91 überrascht. Auch sie stellte der Programmvorschlag der Legion Condor vor Probleme. Denn neben Kranzniederlegungen und der Teilnahme an der Siegesparade am 3. Mai wurde auch eine Audienz bei Staatschef Franco erwartet ${ }^{92}$. Entgegen früherer Vermutungen der westdeutschen Diplomatie erschienen derartige Demonstrationen einstiger Waffenbrüderschaft dem Regime, das hoffte, in die NATO aufgenommen zu werden, inzwischen als nicht mehr zeitgemäß ${ }^{93}$. Dies machte Falangeminister Solís Ruíz, der von der Blauen Division um finanzielle Hilfe gebeten worden war, Botschaftsrat Werz deutlich: Es sei ärgerlich, daß die deutsche Seite ohne Absprache „eine Unternehmung starte, die unter Umständen doch erhebliche poli-

${ }^{87}$ Simonsen an Legationsrat Schmidt-Schlegel, 26.8.1957, PA/AA, Ministerbüro, Bd. 60. In seinem Schreiben bedankte sich Simonsen für die ,lange Unterhaltung“ über die deutsch-spanischen Beziehungen. Hier auch das Folgende.

88 Kameradschaft Legion Condor (Simonsen, Storz) an Bundeskanzler Adenauer, 31. 8. 1957, PA/AA, Ministerbüro, Bd. 60. Dcr Traditionsverband versicherte Adenauer, ihn bei den anstehenden Bundestagsivahlen unterstützen zu wollen.

89 Vgl. Aschmann, „Treue Freunde..."?, S. 380.

90 Bericht Oster 12/59, 11.5. 1959, BA-MA, BW 4, Bd. 745.

91 Aufzeichnung Welck betr. Spanienreise der Kameradschaft Legion Condor, 13. 5. 1959, PA/AA, Bestand Botschaft Madrid, Bd. 7656.

92 Bericht Oster 12/59, 11.5. 1959, BA-MA, BW 4, Bd. 745.

93 So registrierten die deutschen Diplomaten in Madrid, daß der Caudillo bei offiziellen Anlässen ,jede Reminiszenz an deutsche oder italienische Waffenhilfe im Bürgerkrieg zu vermeiden pflegt“. Aufzeichnung Welck betr. Spanienreise der Kameradschaft Legion Condor, 13.5. 1959, Bestand Botschaft Madrid, Bd. 7656. Womöglich war diese Zurückhaltung auch innenpolitisch begründet. Schließlich dürftc das Regime kein allzu großes Interesse daran gehabt haben, bei seiner Selbstinszenicrung an die Hilfe von außen erinnert zu werden. 
tische Auswirkungen, insbesondere außenpolitischer Art"94 haben könne. Da Spanien sich aber „auf keinen Fall Undankbarkeit“ gegenüber der deutschen Hilfe im Bürgerkrieg „nachsagen lassen“ wolle, werde es eine „freundschaftliche Aufnahme“ der Gäste geben, jedoch müßte dies alles „im privaten Rahmen“ bleiben. In jedem Fall wolle seine Regierung dafür sorgen, daß „keinerlei Pressepublizität“ entstehe. Der Verlauf des Besuchs bestätigte bestehende Befürchtungen. Sowohl in Barcelona wie in Madrid kam es während der Totenehrungen zu nationalsozialistischen Sympathiebekundungen ${ }^{95}$ : In der katalanischen Metropole wurde bei dem Lied „Ich hatt einen Kameraden“ von deutschen Teilnehmern die Hand zum Hitler-Gruß erhoben. Gegen Ende ließen überdies einige spanische Veteranen es sich nicht nehmen, „Hochrufe auf das nationalsozialistische Deutschland“ und „Heil-Hitler-Rufe“ anzubringen. Der Vorsitzende der Kameradschaft, Storz, konnte es nicht unterlassen, auch während der Erinnerungsfeier auf dem Madrider Friedhof, „die Hand zum deutschen Gruß zu erheben“.

Angesichts solcher Demonstrationen „alter“ Gesinnung galt das besondere Augenmerk der Botschaft der Audienz bei Franco ${ }^{96}$. Hier versuchte sie Einfluß zu nehmen ${ }^{97}$. Es entspann sich nun eine Posse um die Teilnahme von Bundeswehr-Offizieren. Oberst Bothe ${ }^{98}$, der im Gegensatz zu den übrigen Mitgliedern der Condor-Gruppe sich nicht scheute, die deutsche Vertretung aufzusuchen, wurde bei dieser Gelegenheit auf die politische Dimension dieser Erinnerungsreise aufmerksam gemacht. „Mit großem Nachdruck“ sei, so Oster, von ihm und Botschaftsrat Werz darauf hingewiesen worden, daß ein etwaiger Empfang durch Staatschef Franco „für aktive Angehörige der Bundeswehr Folgerungen“ haben könnten. Als kurz darauf die Blaue Division auf der Suche nach präsentablen Persönlichkeiten für die Audienz um Vorschläge bat, fiel die Wahl unter anderem auf die drei anwesenden Offiziere der Bundeswehr. Nun herrschte Konfusion. Militärattaché Oster riet ihnen telefonisch nochmals eindringlich ab. Werz, dagegen, der erst nach diesem Anruf von der namentlichen Einladung erfahren hatte, wollte „einen Affront des Staatschefs“99 ver-

91 Aufzeichnung Werz betr. spanischer Besuch der Legion Condor, 29.4. 1959, PA/AA, Bestand Botschaft Madrid, Bd. 7656. Gegenüber dem spanischen Außenministerium versuchte der Diplomat dem Eindruck entgegenzuwirken, daß die Gruppe „sich selbst und ohne vorherige Rückfrage eingeladen habe“. Unter Umständen sei die Blaue Division auf die Reiseankündigung mit der in Spanien „üblichen höflichen Form" eingegangen. Dies habe die Legion Condor wohl als Einladung gedeutet. Ebenda. Dort auch das Folgende.

${ }_{95}$ Aufzeichnung Oster 5/59, 6.5. 1959, PA/AA, Bestand Botschaft Madrid, Bd. 7656. Hier auch das Folgende.

${ }_{96}$ Das Thema war anscheinend selbst in der spanischen Regierung kontrovers diskutiert worden. Nach Informationen von Oster hatten sich das Heeres- und Außenministerium wie auch Franco selbst gegen einen Empfang ausgesprochen. Erst nach einem Einspruch von Solís Ruíz, der aus einer Unkenntnis der innenpolitischen Verhältnisse in der Bundesrepublik fürchtete, „eine Verstimmung der alten SpanienKämpfer" könne sich negativ auf seinen bevorstehenden Deutschlandbesuch auswirken, wurde dem Wunsch der Kameradschaft nachgegeben. Bericht Oster 19/59, 3. 7. 1959, BA-MA, BW 4, Bd. 745.

97 Die Vertretung hatte sich beispielsweise beim Außenministerium gegen einen Empfang ausgesprochen. Aufzeichnung Welck betr. Legion-Condor-Treffen in Madrid, 6. 8. 1959, PA/AA, Bestand Botschaft Madrid, Bd. 7656.

${ }_{98}$ Aufzeichnung Oster 5/59, 6.5. 1959, PA/AA, Bestand Botschaft Madrid, Bd. 7656. Hier auch das Folgende.

99 Aufzcichnung Welck betr: Legion-Condor-Treffen in Madrid, 6. 8.1959, PA/AA, Bestand Botschaft Madrid, Bd. 7656. Der Botschafter spricht in seiner detaillierten Schilderung von drei Offizieren, die im übrigen ihre Vorgesetzten nicht über die Exkursion unterrichtet hätten. Bei Oster wird hingegen neben Bothe nur Oberstleutnant Reuter erwähnt. Aufzeichnung Oster 5/59, ebenda. 
meiden und empfahl deshalb die Teilnahme. Am Ende stand der vergebliche Versuch, die Gäste Francos über den Meinungswandel der deutschen Vertretung zu informieren. Oster bilanzierte lakonisch: „Es mußte bei der Absicht bleiben. "100 Die Herren waren bereits abgereist. So vertrat die deutschen Veteranen bei Franco als „Wortführer"101 ein in Madrid lebender Angehöriger der Legion Condor, der allerdings nicht der Kameradschaft angehörte. Augenzeugen betonten die herzliche Atmosphäre; der Generalissimus habe unterstrichen, daß ungeachtet der sich verändernden politischen Verhältnisse die „Waffenbrüderschaft aus den Jahren 1936-39 in Spanien immer unvergessen bleiben werde“. Auch der Abschied gestaltete sich emotional: Franco habe dabei seine „Rührung“ nicht „verbergen können".

Der Öffentlichkeit sollte diese freundschaftliche Inszenierung aber vorenthalten bleiben. Die franquistische Zensur funktionierte. Zeitungen und Zeitschriften in Spanien nahmen wie gewünscht keine Notiz, von der Einladung ${ }^{102}$. Dies lag jedoch nicht allein im Interesse des Franco-Regimes, auch der westdeutschen Regierung war sehr daran gelegen, jede Nachricht tunlichst zu vermeiden. Hier zogen Bonn und Madrid an einem Strang. Denn das peinliche Auftreten der Kameraden hätte wohl international für großes Aufsehen gesorgt. Schlagzeilen wie: „Condor-Legionäre bei Franco“ wären insbesondere für die Bundesrepublik höchst unangenehm gewesen. So konnte die Regierung Adenauer nicht nur erleichtert ${ }^{103}$ über das von Franco verordnete Schweigen sein; auch die Vertretung in Madrid hatte bei den deutschen Korrespondenten das Ihre zur Ruhe beigetragen: „Nur mit Mühe"104, berichtete Botschafter Welck, sei es "gelungen, die deutschen Journalisten von einer Berichterstattung über die ganze Angelegenheit abzuhalten“. Durch Gespräche mit „dpa- und einzelnen anderen Pressevertretern“ habe man „darauf hingewirkt, daß jede Publizität in Deutschland vermieden werde“. Der befürchtete Skandal blieb aus.

Vorwürfe kamen lediglich aus dem Umfeld der Legion Condor. Die offenbar beleidigten Bundeswehr-Offiziere beschwerten sich gar über Militärattaché Oster, der sie gemeinsam mit Werz daran gehindert habe, an der Franco-Audienz teilzunehmen ${ }^{105}$. In mehreren Artikeln der „Deutsche[n] Soldatenzeitung“ wurde unter anderem von Pater Simonsen das Verhalten der Botschaft heftig kritisiert. Verärgert wies Welck derlei Angriffe zurück und machte zugleich seinen Unmut über die bisherige Tatenlosigkeit der mit der

100 Aufzeichnung Oster 5/59, 6.5. 1959, PA/AA, Bestand Botschaft Madrid, Bd. 7656.

101 Aufzeichnung Oster 12/59, 11.5. 1959, BA-MA, BW 4, Bd. 745. Hier auch das Folgende. Wer ansonsten noch am 6.5. den spanischen Staatschef aufsuchen durfte, ließ sich nicht klären.

102 So fehlten in der veröffentlichten Liste der Audienzteilnehmer die Namen der deutschen Veteranen. Aufzeichnung Welck betr. Spanienreise der Kameradschaft Legion Condor, 13. 5. 1959, PA/AA, Bestand Botschaft Madrid, Bd. 7656.

103 Vgl. Aschmann, „Treue Freunde..."?, S. 384. Die Autorin übersieht dabei ganz und gar den Eingriff der deutschen Diplomaten in die Pressefieiheit und das Wohlverhalten der Journalisten, die anderenfalls wohl Sanktionen durch das franquistische Regime hätten befürchten müssen. Auch Korrespondenten aus anderen Ländern hielten sich an das Schweigegebot. Dazu mag auch die Überzeugungsarbeit der Botschaft beigetragen haben.

10.4 Aufzeichnung Welck betr. Legion-Condor-Treffen in Madrid, 6. 8. 1959, PA/AA, Bestand Botschaft Madrid, Bd. 7656; Welck betr. Spanienreise der Kameradschaft Legion Condor, 13. 5. 1959, PA/AA, Bestand Botschaft Madrid, Bd. 7656.

${ }_{105}$ Aufzeichnung Welck betr. Legion-Condor-Treffen in Madrid, 6. 8. 1959, PA/AA, Bestand Botschaft Madrid, Bd. 7656. Hier auch das Folgende. Zu den Attacken gegen Oster ebenso Bericht Oster 18/59, 30.6. 1959, BA-MA, BW 4, Bd. 745. 
Traditionspflege befaßten Stellen im Bundesverteidigungsministerium und Auswärtigen Amt deutlich. Trotz der Warnungen der Botschaft sei es versäumt worden, „über den Verband deutscher Soldaten“ auf die Kameradschaft einzuwirken, „um ihr die politische Bedeutung dieser Fahrt klarzumachen“. Außerdem hätte das Auswärtige Amt vermutlich die Arbeit der Vertretung „durch eine rechtzeitige Unterrichtung“, bemängelte Welck, um einiges „erleichtern können“.

In Bonn wurden nach dem Besuchsdebakel Konsequenzen gezogen. Die Veteranen hatten mit ihrer offen zur Schau getragenen Nähe zum Nationalsozialismus eine Grenze überschritten, die die Verantwortlichen zum Handeln nötigte. Das Vertrauen in Pater Simonsen, der die Reise nicht mitgemacht hatte, war nachhaltig erschüttert. Seine wiederholten Beteuerungen, daß die Kameradschaft „auf dem Boden der Demokratie stehe“106 und der Veteranenverband „Rücksicht auf die innen- und außenpolitischen Belange der Bundesrepublik und Spaniens“ nehmen wolle, hatten sich als unglaubwürdig erwiesen. Allerdings stellten Auswärtiges Amt und Verteidigungsministerium sich auch selbst mit der zwei Jahre andauernden Zusammenarbeit kein gutes Zeugnis aus. Wes Geistes Kind Simonsen war, hätten die Beteiligten wissen können. Erst jetzt nahmen die mit der Traditionspflege befaßten Ressorts Abschied von ihrer bisherigen passiven Haltung. Pater Simonsen sollte als „Verbindungsmann " 107 in Zukunft „soweit wie möglich“ ausgeschaltet werden. Stattdessen hoffte man über den Verband deutscher Soldaten und die Bundeswehr-Angehörigen in der Kameradschaft mäßigend einwirken zu können.

Darüber hinaus rang sich das Auswärtige Amt nunmehr zu einer Richtlinie durch ${ }^{108}$. Darin wurden deutliche Unterschiede zwischen der Blauen Division und der Legion Condor gemacht ${ }^{109}$. In der Beurteilung der beiden Verbände gab es einen grundlegenden Wandel zum Bild der NS-Zeit. Während die Kriegsbeteiligung der Blauen Division im nationalsozialistischen Deutschland nur geringe Aufmerksamkeit fand ${ }^{110}$ und Vorurteile gegenüber der militärischen Leistungsfähigkeit der spanischen Verbündeten an der Tagesordnung waren ${ }^{111}$, ließ sich ihr Einsatz gegen die Sowjetunion in der Nachkriegszeit hingegen als positives Moment der bilateralen Beziehungen beschreiben. Die „ausgesprochene Sympathie“ der früheren Angehörigen der Blauen Division "gegenüber Deutsch-

106 Aufzeichnung Garstens betr. Legion Condor und Blaue Division, 27. 7. 1959, PA/AA, Ref. 206, Bd. 76. Hier auch das Folgende.

107 Aufzeichnung betr. Fragenkomplex Legion Condor/Blaue Division, 31. 8. 1959, PA/AA, Ref. 206, Bd. 76. Dort auch das Folgende.

108 Aufzeichnung Carstens betr. Legion Condor und Blaue Division, 27. 7. 1959, PA/AA, Ref. 206, Bd. 76. Hier auch das Folgende.

109 Diesem Aspekt wie auch der Differenzierung zwischen beiden militärischen Formationen durch das Auswärtige Amt schenkt Aschmann keine Beachtung. Die Schlußfolgerungen der westdeutschen Politik nach der Reise der Kameradschaft werden von ihr nur zum Teil wahrgenommen. So zeichnet sie ein unvollständiges Bild, wenn sie über das Verhalten des Auswärtigen Amts abschließend urteilt: „Die Einsätze von Legion Condor und Blauer Division wurden [...] als Engagement eines antikommunistischen Abwehrkampfes gutgeheißen." Vgl. Aschmann, „Treue Freunde..."?, S. 452.

110 Vgl. Peter, Das Spanienbild in den Massenmedien des Dritten Reiches 1933-1945, S. 181-186. Dort auch Beispicle, die das damalige Klischee von den „schlampigen und tapferen Spaniern“ belegen. Vgl. hier, S. 183.

111 Vgl. Förster, Freiwillige für den „Kreuzaug Europas gegen den Bolschewismus“, S. 908-915. So lehnte es Generalfeldmarschall von Kluge ab, „die Spanier in seinem Bereich einzusetzen“, da er offensichtlich der Auffassung war, „es handle sich mehr um Zigeuner als um Soldaten“. Die 250. Infanteriedivision wurde auch anderenorts zunächst als nicht „angriffsfähig“ eingestuft. Vgl. hier, S. 914. 
land" stelle "grundsätzlich ein Aktivum dar", urteilte Ministerialdirektor Carstens, zumal viele „heute in Spanien einflußreiche Stellungen, u. a. im Außenministerium und im Generalstab innehaben“. Daher bestünden gegen eine „unauffällige und zurückhaltende“ Traditionspflege „keine Bedenken“.

Das Gegenteil galt jedoch für die Legion Condor, deren Beteiligung am Bürgerkrieg von den NS-Medien in besonderer Weise gefeiert worden war. Ungeachtet der Tatsache, daß einige ihrer früheren Angehörigen in der Bundeswehr hohe Ränge bekleideten, ging die Bundesregierung auf Distanz: „Zurückhaltung“ sei „bei offiziellen Kontakten“ geboten. Neben innenpolitischen Problemen, die ansonsten auf die Bundesrepublik zukämen, könnte es für beide Länder, so Carstens, „außenpolitisch ungünstige Auswirkungen im Verhältnis zu unseren westlichen Alliierten " geben. Wie unsicher das Auswärtige Amt aber nach wie vor über den politischen Wert der Vergangenheit im Verhältnis zu Spanien trotz der anderslautenden Berichterstattung der Botschaft war, zeigte die Reaktion auf den Franco-Empfang: Die Audienz beweise, „daß die deutsch-spanische Waffenbrüderschaft aus der Zeit des Bürgerkriegs dort heute noch in hohem Ansehen steht“.

Nach den Entgleisungen der deutschen und spanischen Veteranen ging es Bonn und Madrid bei dem für Herbst angekündigten Gegenbesuch der Blauen Division vor allem darum, keinen politischen Schaden entstehen zu lassen. Die beiden Regierungen sorgten deshalb vor. Sie stimmten darin überein, die Reise „möglichst unauffällig" ${ }^{112} \mathrm{zu}$ gestalten. Der in Bonn zunächst aufgekommene Gedanke an einen Empfang durch Bundeskanzler Adenauer wurde verworfen. Der deutsche Botschafter hatte dringend abgeraten: Die Blaue Division werde durch die "teilweise ziemlich rechtsradikale Kameradschaft"113 betreut und daher unter Umständen ,in falschem Fahrwasser segeln“. Eine Massenreise der spanischen Veteranen in die Bundesrepublik wurde, wohl unter sanftem Druck des FrancoRegimes, verhindert. So fiel der für Ende September geplante Besuch aus „Mangel an Beteiligung "1/4 ins Wasser. Lediglich eine kleine Gruppe von vier Personen sollte nach Rücksprache mit dem Außenministerium in Madrid am Bundestreffen der Kameradschaft in Bingen teilnehmen. Der Aufenthalt verlief harmonisch und in aller Stille ${ }^{115}$.

Dazu beigetragen hatte sicherlich auch, daß es zuvor erstmals zu direkten Gesprächen zwischen der Kameradschaft der Legion Condor und amtlichen Stellen gekommen war. Der Vorstand mit seinem Vorsitzenden Storz, dessen Ausfälle in Spanien noch für Unruhe gesorgt hatten, machte auf die Beamten von Verteidigungsministerium und Auswärtigem Amt einen „durchaus für vernünftige Argumente zugänglichen Eindruck“. Die Veteranen seien, so die Reaktion nach dem ersten Treffen, „nicht als Vertreter eines neuen Rechtsradikalismus" anzusehen, hieß es milde aus dem Auswärtigen Amt. Da das Besuchsprogramm keine politischen Termine vorsah, blieb es bei Begegnungen unter Soldaten, die „Schulter an Schulter gegen einen gemeinsamen Feind gekämpft hätten“, wie General a. D.

112 Aufzeichnung Knappstein betr. Gespräch mit dcm spanischen Botschafter Marqués de Bolarque, 24. 8. 1959, PA/AA, Ref. 206, Bd. 76.

113 Telegramm Welck an Auswärtiges Amt, 29. 8. 1959, PA/AA, Bestand Botschaft Madrid, Bd. 7656.

11. Bericht Oster 41/59, 17.9. 1959, BA-MA, BW 4, Bd. 745.

115 Aufzeichnung Schmidt-Schlegel betr. Besuch einer Delegation der Blauen Division in der Bundesrepublik, 14. 10. 1959, PA/AA, Ref. 206, Bd. 76. „Selbst der SPD“, vermerkte der Spanien-Referent erleichtert, „bot der Besuch keine Angriffsmöglichkeiten“. Hier auch das Folgende. Allerdings hatte es offenbar Proteste der rheinhessischen SPD gegen das 4. Bundestreffen der Kameradschaft in Bingen gegeben. Vgl. Kraushaar, Die Protest-Chronik, Bd. 3 (1957-1959), S. 2279. 
Linde vom Verband deutscher Soldaten pathetisch betonte. Ansonsten kam es - nachdem ein zunächst vom Auswärtigen Amt vorgesehener Besuch in Berlin als zu brisant gestrichen worden war - zu einer Exkursion an die niedersächsische Zonengrenze. Dort sollte den spanischen Gästen ein Einblick ,in die Infiltrationsarbeit des Bolschewismus"116 gegeben und ihnen der „Abwehrwille der westdeutschen Bevölkerung“ vermittelt werden.

Nach der Affäre um die geplanten Bundeswehr-Depots war die Sorge vor einer erneuten Spanienfahrt der Legion Condor im Frühjahr 1960 besonders groß. Militärattaché Oster zweifelte vor allem daran, daß es in diesem Jahr wiederum gelingen werde, die Korrespondenten in Madrid „dahin zu bringen "117 über einen solchen Besuch „Schweigen zu bewahren “. Daher schlug er vor, die Kameradschaft, unter Umständen durch die Vermittlung von General a. D. Galland, zu einem „Verzicht“ zu bewegen. Um so erleichterter registrierte das Auswärtige Amt, daß fehlende finanzielle Mittel und ein interner Streit um die zukünftige politische Linie des Traditionsverbandes eine Reise verhinderten ${ }^{118}$. Der Ausflug im Jahr 1959 sollte eine Ausnahme bleiben. Die ohnehin kleine Kameradschaft der Legion Condor versank in den folgenden Jahren in der Bedeutungslosigkeit und geriet aus dem Blickfeld der Politik ${ }^{119}$.

Daß aber bei der Traditionspflege der Bundeswehr im Hinblick auf die Legion Condor noch heute manches im argen liegt, zeigte Anfang der neunziger Jahre eine Anzeigenkampagne, in der die Bundeswehr ausgerechnet mit Picassos „Guernica“ für sich warb" Unter der Abbildung war der pazifistische Slogan „Feindbilder sind die Väter des Krieges“ zu lesen. Im Text erfuhr man, daß die Bundeswehr kein Feindbild habe. Was man nicht erfuhr, war der Anlaß für „Guernica“. Schließlich gab das Gemälde dem Entsetzen angesichts der spanischen Opfer der Legion Condor Ausdruck. Auch im Militärhistorischen Museum der Bundeswehr in Dresden wird die Bombardierung von Guernica nicht erwähnt ${ }^{121}$. Die Beteiligung von deutschen Soldaten am Bürgerkrieg in Spanien findet unter der Überschrift „Schnelle Siege“ statt. Der Krieg habe die Möglichkeit geboten, heißt es dort, „Waffen und Truppe im scharfen Schuß zu erproben“.

\section{Bundesdeutsche Kriegsopferversorgung für die Blaue Division}

Eines der Themen bei den Begegnungen der Veteranen waren die zwischen beiden Ländern umstrittenen Versorgungsansprüche der spanischen Kriegsgeschädigten. Die Kameradschaft der Legion Condor bemühte sich um Hilfe. Durch die im Januar 1960 von ihr erreichte korporative Mitgliedschaft der Bruderschaft der Blauen Division im Verband

\footnotetext{
116 Auswärtiges Amt an Botschaft Madrid betr. Deutschland-Besuch einer Delegation von Vertretern der Kameradschaft der ehemaligen Blauen Division und der Legion Condor, 23. 10. 1959, Bestand Botschaft Madrid, Bd. 7656.

117 Bericht Oster 31/60, 29. 3. 1960, BA-MA, BW 4, Bd. 746. Hier auch das Folgende.

118 Vermerk Schmidt-Schlegel, 4. 5. 1960, PA/AA, Ref. 301, Bd. 117.

119 Pater Simonsen erfuhr im Januar 1960 noch einmal öffentliche Aufmerksamkeit. In einer Sendereihe des SFB „Die schönsten Jahre meines Lebens“ kam auch der Kapuziner-Pater zu Wort. Simonsen verteidigte in dem Interview die Legion Condor gegen kritische Anwürfe und erwähnte dabei ganz freimütig den Empfang bei Franco. Eine Bemerkung, die aber offenbar unbeachtet blieb. Vgl. Interviewauszug, 15. 1. 1960, PA/AA, Ref. 206, Bd. 85.

120 Vgl.: art, Heft 11 (1990), S. 3. Ebenso: Die Zeit, 22. 3. 1991.

121 Vgl.: Die Zeit, 10.2. 2000.
} 
deutscher Soldaten ${ }^{122}$ sollte diesem Anliegen größerer Nachdruck verliehen werden. Bonn und Madrid hatten sich schon seit längerem in einen stillen Streit um die Kriegsopferversorgung verwickelt. Beide Regierungen waren an einer öffentlichen Auseinandersetzung nicht interessiert. Sie stimmten darin überein, daß dieses Thema ihnen und nicht den Soldatenverbänden vorbehalten sein sollte ${ }^{123}$. Anlaß war die Forderung nach Wiederaufnahme der Versorgung von 2420 ehemaligen Angehörigen der Blauen Division bzw. ihrer Hinterbliebenen ${ }^{124}$, die nach einem Erlaß des Oberkommandos der Wehrmacht (OKW) vom September 1941 von Deutschland übernommen und noch bis zum Kriegsende 1945 geleistet wurde. Die spanischen Freiwilligen seien damals, hieß es 1953 aus dem zuständigen Bonner Arbeits- und Sozialministerium, in den OKW-Erlaß einbezogen worden, weil der „Eindruck“125 vorhanden gewesen sei, die von der Franco-Regierung zugesagte Versorgung habe nur „mehr oder weniger auf dem Papier“ gestanden.

Ausgelöst hatte die erneute Beschäftigung mit dieser Frage der sozialdemokratische Bundestagsabgeordnete Pfarrer Hans Merten ${ }^{126}$. Der Experte für Kriegsgefangenenfragen machte das Ministerium im Sommer 1952 auf die Situation dieser Geschädigten aufmerksam, die nach seinen Erkenntnissen mitunter in „bitterste Not geraten “127 seien, und bat um eine Klärung. Nach neun Monaten erhielt Merten eine Antwort ${ }^{128}$. Das Arbeitsministerium wies darauf hin, daß der spanische Staat für die Kriegsopfer und ihre Hinterbliebenen selbst aufkomme und das Bundesversorgungsgesetz (BVG) bei Ausländern im Ausland auch „keine Anwendung“ finde. Daher bestehe „keine Veranlassung“, entsprechende Anträge „entgegenzunehmen“ und sie zur Prüfung weiterzuleiten. Den fraglichen OKW-Erlaß sahen die Fachleute im Ministerium durch das BVG ohnehin als „überholt" ${ }^{229}$ an. Zwar kam man bei einer ressortübergreifenden Zusammenkunft im November 1953 überein, prüfen zu lassen, „welche Leistungen“130 die Betroffenen von der Regierung in Madrid „tatsächlich“ erhielten.

Eine gewisse Klarheit brachte aber erst ein Bericht der deutschen Botschaft im Oktober 1955. Dieser stützte sich vor allem auf eine mündliche Auskunft eines Madrider Mini-

122 Mitteilung VdS an den Verfasser, 4. 3. 1991. Militärattaché Oster ging irrtümlich im Mai 1959 davon aus, daß die Aufnahme in den VdS bereits „vor einigen Wochen“ erfolgt sei. Bericht Oster 12/59, 11.5. 1959, BA-MA, BW 4, Bd. 745.

${ }^{123}$ Aufzeichnung Botschaftsrat Werz über Gespräch mit dem Leiter der politischen Abteilung im spanischen Außenministerium, 29. 4. 1959, PA/AA, Bestand Botschaft Madrid, Bd. 7656.

124 Nach Angaben der Botschaft in Madrid wurden bis zum 8.5. 1945 in 2200 Fällen eine Beschädigtenrente und in 220 Fällen eine Witwenrente von deutscher Seitc gezahlt. Zu diesem Zeitpunkt waren überdies noch 500 bzw. 20 Anträge nicht abschließend entschieden worden. Botschaft Madrid betr. Kriegsopferversorgung an Auswärtiges Amt, 5. 10. 1954, BA, B 149, Bd. 11878.

125 Aufzeichnung über Fragen der Kriegsopferversorgung im Ausland, 4. 11. 1953, BA, B 149, Bd. 11878.

126 Zu Merten vgl. Frei, Vergangenheitspolitik, S. 279.

127 Merten an Bundesministerium für Arbeit, 14. 7. 1952, BA, B 149, Bd. 11878. Bei dem Abgeordneten waren Anfragen von in Spanien lebenden Deutschen eingegangen, die von den Veteranen der Blauen Division um Hilfe gebeten worden waren.

128 Bundesministerium für Arbeit an Merten, 29. 4. 1953, BA, B 149, Bd. 11878.

129 Bundesministerium für Arbeit an Auswärtiges Amt, 13. 4. 1953, BA, B 149, Bd. 11878. Außerdem ließe sich heute kein Rechtsanspruch mehr aus dem Erlaß des OKW vom 30. 9. 1941 ableiten, urteilte das Arbeitsministerium Anfang 1957. Schließlich sei dieser bereits durch das Kontrollratsgesetz Nr. 34 (Auflösung der Wehrmacht) vom 20. August 1946 außer Kraft gesetzt worden. Aufzeichnung Ioffmann betr. Versorgung der Blauen Division, 11. 1. 1957, PA/AA, Ref.506, Bd. 717.

${ }^{130}$ Aufzeichnung über Fragen der Kriegsopferversorgung im Ausland, 4. 11. 1953, BA, B 149, Bd. 11878. 
sterialbeamten, der versichert habe, daß die Freiwilligen der Blauen Division ,in jeder Hinsicht allen übrigen versorgungsberechtigten Soldaten der spanischen Armee und deren Hinterbliebenen gleichgestellt"131 seien. Bonn sah also keinen Anlaß, von seiner Rechtsposition abzurücken. Gelegentliche Vorstöße der Franco-Regierung wie bei den Handelsvertragsgesprächen im November $1953^{132}$ oder den Vorverhandlungen über das enteignete deutsche Vermögen Ende $1956^{133}$ sorgten zumindest dafür, daß das Thema auf der Tagesordnung blieb. All diese eher beiläufigen Versuche ${ }^{134}$ sollten jedoch ohne Erfolg bleiben. Noch im Frühjahr 1958 betonte die Rechtsabteilung im Auswärtigen Amt: „Angesichts der Rechtslage“ 135 gebe es auch „keine Möglichkeit, diesen Standpunkt zu revidieren“. Außerdem warnte sie davor, einen „Präzedenzfall zu schaffen“, der im Hinblick auf andere Länder „untragbare finanzielle Verpflichtungen“ nach sich ziehen würde.

Die ganze Situation änderte sich dann mit dem Amtsantritt von Militärattaché Oster im Sommer 1958. In Oster fanden die spanischen Veteranen einen überaus engagierten Fürsprecher, der sich seit seinem Wechsel nach Madrid bemühte, einen Sinneswandel in der westdeutschen Politik herbeizuführen. Schon bei seinem Antrittsbesuch bei Generalstabschef Muñoz Grandes ${ }^{136}$ hatte Oster keinen Hehl aus seiner Verbundenheit mit der Blauen Division gemacht. Das von der Erinnerung an den gemeinsamen Kampf im Osten bestimmte Gespräch zeigte, daß Spanien für deutsche Militärs in der Nachkriegszeit in gewisser Hinsicht ein Refugium darstellte. Wohl in keinem anderen Land gab es von offizieller Seite so viel Verständnis und Respekt für die sogenannten soldatischen Leistungen der

131 Botschaft Madrid betr. Versorgung von Angehörigen der ehemaligen Blauen Division, 4. 10. 1955, BA, B 149, Bd. 11878.

132 Aufzeichnung über Fragen der Kriegsopferversorgung im Ausland, 4. 11. 1953, BA, B 149, Bd. 11878. 133 Am 31. Oktober 1956 hatte Spanien in einer Note zahlreiche Gegenforderungen präsentiert. Dabei wurden auch die Versorgungsansprüche der Blauen Division geltend gemacht. Das Auswärtige Amt lehnte dies damals jedoch unter Verweis auf die rechtliche Situation ab. Vgl. Schreiben Ministerialdirektor Berger (Rechtsabteilung) an Bundesminister Lübke, 29. 11. 1956, PA/AA, Ref. 206, Bd. 76. Im Februar 1956 war das Außenministerium in Madrid bereits an die deutsche Botschaft mit der Anfrage herangetreten, welche "Maßnahmen“ die Bundesrepublik im Hinblick auf die spanischen Invaliden "ergreifen" wolle. Die Botschaft hatte zuvor in spanischen Zeitungen eine Bekanntmachung über gesetzliche Änderungen in der Kriegsopferversorgung für deutsche Staatsangehörige veröffentlicht. Botschaft Madrid betr. spanische Forderung auf Übernahme der Versorgung, 26. 3. 1956, PA/AA, Ref. 506, Bd.57; hier auch Verbalnote des spanischen Außenministeriums, 16. 2. 1956.

134 Dazu gehörte auch ein Leitartikel der Abendzeitung La Prensa vom 7. März 1957. Der Kampf der Blauen Division, diese „direkte Hilfeleistung an Deutschland“, wie das Generalkonsulat Barcelona urteiltc, sei bisher in der spanischen Presse „verschwiegen“ oder in Berichten zumindest "stark abgedämpft" worden. Nummehr, schrieb das Blatt aus Barcelona, sei aber die „schwierige Nachkriegslage des deutschen Volkes“ überwunden. Die deutsche Wirtschaft sei „die blühendste in Europa“. Deutschland werde es deshalb „verstehen, einer heiligen Verpflichtung würdig nachzukommen“. Vgl. auszugsweise Übersetzung in: Generalkonsulat Barcelona an Auswärtiges Amt, 12.3. 1957, BA, B 149, Bd. 11878.

13. Aufzeichnung Kothy, 14.3. 1958, PA/AA, Ref. 206, Bd. 163. Hier auch das Folgende. Die in diesem Zusammenhang von Militärattaché Oster aufgestellte Behauptung, die Blaue Division sei doch der einzige ausländische Hecresverband in der Wehrmacht gewesen, trifft nicht zu. Aschmann dagegen übernimmt Osters Behauptung offenbar ungeprüft. Tatsächlich waren außer den Spaniern nämlich ebenso andere „nichtgermanischc" Freiwillige wie Franzosen und Kroaten mit eigenen Verbänden in die Wehrmacht eingegliedert worden. Vgl. Förster, Freiwillige für den „Kreuzzug Europas gegen den Bolschewismus“, S. 908-915; vgl. Aschmann, „Treue Freunde..."?, S. 387.

136 Bericht Oster 17/58, 16. 7. 1958, BA-MA, BW 4, Bd. 744. Hier auch das Folgende. 
Wehrmacht. Oster verwies darauf, daß er Muñoz Grandes als Kommandeur der Blauen Division im Gefechtsstand am Wolchow persönlich kennengelernt und ihn sein damaliger Korpschef, der jetzige Bundeswehr-General Siewert, beauftragt habe, ,in Erinnerung an gemeinsame Rußlandkämpfe Grüße zu überbringen“. Als Zeichen seiner Wertschätzung hatte der Militärattaché, wie er stolz betonte, ,entgegen den jetzt in der deutschen Armee geltenden Bestimmungen heute das Eiserne Kreuz I. Klasse angelegt"137. Damit wolle er „den Kommandeur der Blauen Division und all die tapferen spanischen Soldaten" würdigen, die ,in Rußland geblieben seien“.

Die Hilfe für die kriegsgeschädigten spanischen Veteranen, um die er nun bei der Bundesregierung unentwegt warb, war für Oster (Jahrgang 1914) offenbar ein Gebot einer tief empfundenen soldatischen Kameradschaft. Dabei argumentierte er immer wieder mit dem Hinweis, die Blaue Division sei schließlich ein deutscher Heeresverband zur „Bekämpfung des Bolschewismus"138 an der Ostfront und nicht Teil der verbrecherischen Waffen-SS gewesen. Den Gedanken an mögliche kriminelle Handlungen der Blauen Division wollte Oster erst gar nicht aufkommen lassen: Nach seiner Ansicht war der Einsatz der Spanier „nicht belastet“ mit ,irgendwelchen Kriegsverbrechen oder sonstigen Greueltaten“139. Daher gebe es auch keinen Grund, „sich als Deutscher“ nicht dankbar dieser „Waffenhilfe“ zu erinnern. Dies gelte insbesondere für die Hinterbliebenen und Kriegsgeschädigten, deren Versorgungsanträge teilweise ein „erschütterndes Bild“ ihrer Lebensumstände vermittelten. Die nach dem Zweiten Weltkrieg entstandene rechtliche Situation, die er als eine Folge der „allgemeinen Ächtung des spanischen Regimes“ in den ersten Nachkriegsjahren wahrnahm, könne doch angesichts einer veränderten Haltung der meisten westlichen Alliierten gegenüber Spanien nun von der Bundesregierung berichtigt werden.

$\mathrm{Zu}$ Hilfe kam Oster bei seinem Anliegen ausgerechnet der im Bundesentschädigungsgesetz (BEG) 1956 geregelte finanzielle Anspruch für die spanischen Opfer des National-

137 Die Frage der militärischen Ehrenzeichen hatte im Sommer 1957 den Bundestag beschäftigt. Im Vorfeld war es zu einer Auseinandersetzung über das öffentliche Tragen der in manchen Orden enthaltenen Hakenkreuze gekommen. Dabei wurde das Plädoyer einiger Soldatenverbände für die Auszeichnungen in alter Form erst nach einem Protest aus Washington fallen gelassen. Im Parlament ging es dann nur noch um das schwarz-weiß-rote Ordensband. Vgl. Dubiel, Niemand ist frei von der Geschichte, S. 56-59. Das Gesetz über Titel, Orden und Ehrenzeichen vom 26. 7. 1957 schuf eine neue Rechtsgrundlage für die seit 1945 verbotenen Kriegsauszeichnungen. Demnach durften Auszeichnungen ohne Hakenkreuz-Emblem getragen werden. Vgl. Deutsche Orden und Ehrenzeichen, S. 10. Der in diesem Zusammenhang der Blauen Division von der Bundesregierung angcbotene Ordensumtausch kam indes nicht zustande. Die Bruderschaft der Blauen Division lehnte dies unter Hinweis auf ein nach wie vor gültiges Gesetz Karls III. aus dem Jahr 1792 ab. Änderungen bei ausländischen Orden könnten danach nur vom stiftenden Souverän selbst angeordnet werden. Dies habe nichts mit „Freundschaft für den Nationalsozialismus“ zu tun, versicherten die Veteranen. Bericht Oster 41/59, 17.9. 1959, BA-MA, BW 4, Bd. 745.

138 Bericht Oster 2/58, 17. 7. 1958, BA-MA, BW 4, Bd. 752. Hier auch das Folgende.

139 Ein Hinweis der FR, die Blaue Division habe sich 1943 in Weißrußland an Aktionen zur sogenannten Partisanenbekämpfung beteiligt, konnte nicht bestätigt werden. Der Artikel hatte diese Behauptung unter Bezug auf die Untersuchung von Ghristian Gerlach über die deutsche Vernichtungspolitik in Weißrußland aufgestellt. Vgl. FR, 28. 11. 2001; Gerlach, Kalkulierte Morde. Dort fehlen jedoch entsprechende Aussagen. Auch der Katalog zur überarbeiteten „Wehrmachtsausstellung“ enthält keine Angaben zu etwaigen Kriegsverbrechen der Blauen Division. Vgl. Verbrechen der Wehrmacht. Allerdings liegen bislang erst vereinzelte Forschungsergebnisse über das Verhalten der über 100 Divisionen an der Ostfront vor. Vgl.: Der Spiegel Nr. 48, 2001, S. 89. 
sozialismus $^{140}$. Hier sah er einen Ansatzpunkt, um Bewegung in die starre Bonner Position zu bringen. Bei Gesprächen im Auswärtigen Amt wies der Militärattaché im Januar 1959 darauf hin, daß bereits in mehreren Fällen „deutsche Wiedergutmachungsleistungen "141 an „solche Spanier“ gelangt seien, „deren Angehörige im Bürgerkrieg auf der Seite der Roten gekämpft hätten“. Politisch sei dies um so gravierender, weil „einflußreiche Kreise“ in Spanien darüber klagten, daß die Divisionäre dagegen aus Deutschland keinerlei Versorgungszahlungen erhielten. Ein Entgegenkommen Bonns könne deshalb, so Oster, „propagandistisch“142 gegenüber Madrid „besonders bedeutungsvoll“ sein. Sein Einsatz zeigte Wirkung:

Das Auswärtige Amt rückte daraufhin von seinem bisherigen Nein in der Versorgungsfrage $a b$, machte aber den Vorbehalt, daß eine Regelung erst nach dem Abschluß der laufenden Entschädigungsverhandlungen mit elf westlichen Staaten ${ }^{143}$ in etwa ein bis zwei Jahren in Angriff genommen werden könnte.

Der Militärattaché ließ es dabei aber nicht bewenden. In seinen Berichten rechnete er immer wieder Leid gegeneinander auf: Dabei benutzte er häufig das Bild eines kleinen spanischen Dorfes in Kastilien oder der Extremadura, in dem eine alte Frau, die Witwe eines „Rotspaniers“, 26000 DM Wiedergutmachung ${ }^{144}$ und eine Rente von 250 DM bis an ihr Lebensende bekomme, der „einarmige Angehörige der Blauen Division“ hin-

\footnotetext{
1.40 Bundesgesetz zur Entschädigung für Opfer der nationalsozialistischen Verfolgung vom 29. Juni 1956, in: BGBl. 1956 I, S. 559. Zur Problematik der Entschädigung spanischer NS-Opfer siehe S. 205 ff. Das Gesetz löste das bis dahin gültige Bundesergänzungsgesetz für Opfer nationalsozialistischer Verfolgung ab. ${ }^{141}$ Vermerk Carstens betr. Gespräch mit Oster, 10.2. 1959, PA/AA, Ref. 206, Bd. 76. Hier auch das Folgende.

142 Vermerk Junges, 14. 1. 1959, PA/AA, Ref. 206, Bd. 76.

143 Aufzeichnung betr. ehemalige „Legion Condor" und „Blaue Division“, 11.2. 1959, PA/AA, Ref. 206, Bd. 76. Im Bundesentschädigungsgesetz waren die Ansprüche der ausländischen NS-Verfolgten - abgesehen von den Staatenlosen und den Flüchtlingen, die keinen Staat hatten, an den sie sich wenden konnten - nicht berücksichtigt worden. Daher hatten acht westeuropäische Staaten (Frankreich, die BeneluxStaaten, Griechenland, Großbritannien, Dänemark und Norwegen) die Bundesregierung 1956 zu Entschädigungsleistungen von Staat zu Staat aufgefordert, über die seit Ende 1958 multilateral, später bilateral verhandelt wurde. Zwischen 1959 und 1964 vereinbarte die Bundesrepublik mit elf Staaten (hinzu kamen noch Italien, die Schweiz und Schweden) sogenannte Globalabkommen, mit denen insgesamt 876 Mio. DM für die „Westverfolgten“ bereitgestellt wurden. Vgl. Hockerts, Wiedergutmachung in Deutschland, S. $192 \mathrm{f}$. Die Geschichte dieser Abkommen ist Gegenstand eines laufenden Forschungsprojekts: „Integration-Exklusion. Die deutsche Entschädigung für NS-Opfer in West- und Osteuropa“ an der LudwigMaximilians-Universität München. Ferner: Herbert, Nicht entschädigungsfähig?, S. 286; Goschler, Wiedergutmachung. Westdeutschland und die Verfolgten des Nationalsozialismus 1945-1954, S. 304 f.

${ }_{144}$ Undatierter Bericht Oster zur Versorgung der ehemaligen Blauen Division, BA-MA, BW 4, Bd. 745. Ebenso Bericht 21/59, 4. 7. 1959, BA-MA, BW 4, Bd. 745. Die genannten Zahlen stimmten nicht ganz mit den Angaben des nordrhein-westfälischen Innenministeriums überein. Demnach beliefen sich die Bezüge der Witwen auf 27000 bzw. 220 DM, während Eltern eine einmalige Zahlung von $12000 \mathrm{DM}$ und eine laufende Rente von 110 DM erhielten. Im November 1959 lagen 421 Anträge auf Witwen- und Waisenrente vor, von denen bis dahin 189 positiv beschieden waren. Von den 165 Anträgen auf Elternrente hatte das Innenministerium bis dahin 80 bewilligt. Außerdem lagen Anträge von 899 spanischen Flüchtlingen vor, die gesundheitliche Dauerschäden geltend machten, von denen erst 49 bereits Entschädigung erhielten. Schreiben Loos, Innenministerium Nordrhein-Westfalen an Bundesministerium für Arbeit, 20. 11. 1959, BA, B 149, Bd. 11878. Die Durchführung des BEG oblag den Bundesländern. Nach § 185 Abs. 5 BEG war Nordrhein-Westfalen für die ausländischen NS-Verfolgten zuständig, deren Wohnsitz am 1. 10.1953 in Europa lag. Vgl.: Die Wiedergutmachung nationalsozialistischen Unrechts durch die Bundesrepublik Deutschland, Bd. V, hrsg. vom Bundesminister der Finanzen, S. 406.
} 
gegen nichts erhalte. Dessen Versorgung durch den spanischen Staat erwähnte er allerdings nicht. Oster warnte die Bundesregierung zudem vor möglichen politischen Folgen der Entschädigung. Sollte die „Zahlung an die Rotspanischen Hinterbliebenen "145 in Spanien bekannt werden, könnte dies die bilateralen Beziehungen absehbar belasten.

Im Juli 1959 mobilisierte der Militärattaché Arbeits- und Sozialminister Theodor Blank: In einem persönlichen Schreiben warb er bei seinem langjährigen Vorgesetzten aus der früheren Dienststelle Blank und dem Verteidigungsministerium für eine Versorgung der Beschädigten und Hinterbliebenen der ehemaligen Blauen Division, die „auf dem Wege der Gesetzesparagraphen allein "146 nicht gelöst werden könne. Dies sei eine Frage, deren „Bedeutung“, so Oster, „in erster Linie im Politischen“ liege. Erneut führte er aus, daß die Angehörigen der „Rotspanier“, die in „deutschen Lagern“ umgekommen seien, als Folge des Bundesentschädigungsgesetzes „für spanische Verhältnisse sehr hohe Abfindungssummen“ erhielten. Das deutsch-spanische Verhältnis, so fürchtete er, könnte Schaden nehmen, wenn sich die „durch die Wiedergutmachung an Rotspaniern aufgebrachten Mitglieder der ehem. Blauen Division" in dieser Angelegenheit vor allem auf die Kameradschaft der Legion Condor und weniger auf die offizielle westdeutsche Politik stützen müßten. Hinzu komme noch, daß viele der ehemaligen Divisionäre inzwischen einflußreiche Positionen in der spanischen Regierung innehätten. Dieser Hinweis löste im Arbeitsministerium allerdings die naheliegende Frage aus, warum die von Oster ins Feld geführten Persönlichkeiten wie Außenminister Castiella oder Generalstabschef Muñoz Grandes sich nicht selbst für "eine bessere Versorgung"147 einsetzten bzw. nicht bereit waren, die Lage ihrer früheren Soldaten zu verbessern.

Dennoch verlief die Kampagne Osters für seine früheren Frontkameraden überaus erfolgreich. Nachdem bereits das Auswärtige Amt „aus moralischen Gründen “148 eine Übernahme der Versorgung durch eine Vereinbarung mit Spanien grundsätzlich befürwortet hatte, signalisierte im September auch das in dieser Frage federführende Arbeits- und Sozialministerium Entgegenkommen. Ausschlaggebend für den Sinneswandel war der Verweis Osters auf die Entschädigungsansprüche der sogenannten Rotspanier. In Bonn hatte er es leicht, mit diesem Argument durchzudringen. So wurde der abwertende Begriff „Rotspanier“, der aus dem Fundus der nationalsozialistischen Propaganda stammte, von der offiziellen Politik in der Nachkriegszeit weiter verwendet. Im Gegensatz zur Anteilnahme, mit der die Versehrten und Hinterbliebenen der Blauen Division bedacht wurden, standen Politik und Behörden in der Bundesrepublik dem Schicksal der spanischen NS-Verfolgten - abgesehen von ihrer Rolle als finanzielle Nutznießer der Entschädigung weitgehend unbeteiligt gegenüber.

145 Bericht Oster 21/59, 4. 7. 1959, BA-MA, BW 4, Bd. 745.

146 Oster an Bundesminister Blank, 20.7. 1959, BA, B 149, Bd. 11878. Er hob hervor, daß die Angehörigen der Blauen Division überwiegend „Berufssoldaten waren, die zum Kampf gegen den Bolschewismus eingesetzt wurden und als überzeugte Katholiken z. T. eine recht kritische Einstellung zum Nationalsozialismus einnahmen“. Hier auch das Folgende. Daß sich viele Falangisten mit einer großen ideologischen Nähe zum Nationalsozialismus gerade in der Blauen Division gesammelt hatten, sagte der Militärattaché indes nicht.

147 Ebenda, handschriftiche Anmerkung.

148 Schreiben Rechtsabteilung (Ref. 505) an Länderabteilung, 3. 3. 1959, PA/AA, Ref. 206, Bd. 76. 
Wie ungebrochen die im Nationalsozialismus geprägten Vorurteilsstrukturen in der Zeit des Kalten Krieges fortwirkten, zeigte die Argumentation des Arbeitsministeriums: Regierung und Öffentlichkeit in Spanien würden es „kaum verstehen, daß die Bundesrepublik Deutschland den kommunistischen Gegnern Spaniens hohe Entschädigungen zahlt und denjenigen Spaniern, die auf deutscher Seite gegen den Bolschewismus gekämpft haben, nicht einmal eine Teilversorgung gewährt" ${ }^{49}$. Dies sollte sich ändern. Bonn erwartete allerdings, daß Madrid den ersten Schritt zu Verhandlungen tat. Außerdem brachte das Auswärtige Amt jetzt Gegenleistungen ins Spiel: Eine mögliche „Beteiligung "150 an der Versorgung der Blauen Division sollte von der Rückgabe enteigneter kultureller Einrichtungen sowie einer spanischen Versorgung der wenigen „dort ansässigen"151, ehemaligen Angehörigen der Legion Condor abhängig gemacht werden.

Eine Gesprächsinitiative Spaniens blieb jedoch zunächst aus. Selbst Außenminister Castiella war nicht bereit, dieses Thema auf die Agenda seines Deutschlandbesuchs im November 1959 zu setzen. Das Franco-Regime betrieb damals verstärkt eine außenpolitische Annäherung an den Westen und wollte sich deshalb wohl in einer Frage, die den Zweiten Weltkrieg und den Einsatz spanischer Soldaten an der Seite des „Dritten Reiches“ betraf, nicht öffentlich engagieren. Offenbar fürchtete es, daß das westliche Ausland an die faschistische Vergangenheit erinnert werden könnte. So wurde die Kriegsopferversorgung von spanischer Seite in Bonn nur eher beiläufig angesprochen. Lediglich dem Leiter der politischen Abteilung im Madrider Außenministerium, Sedó, auch er einst Angehöriger der Blauen Division, blieb es vorbehalten, politischen Druck zu entfalten: Bis jetzt habe sich die Bruderschaft der Blauen Division „verhältnismäßig ruhig verhalten “152, hieß es gegenüber dem Auswärtigen Amt, doch könne bei einer „weiteren Verzögerung“ damit gerechnet werden, daß der Traditionsverband durch die Presse oder „auf anderen Wegen energisch eine Kriegsopferversorgung aus deutschen Mitteln fordern werde“. Sedó hatte cine Drohkulisse aufgebaut, die zu diesem Zeitpunkt bereits überflüssig geworden war. Denn die Bundesregierung wartete eigentlich nur noch auf ein Zeichen aus Madrid. So ergab sich die paradoxe Situation, daß die beteiligten Ministerien in Bonn enttäuscht feststellten, auch nach dem Besuch des spanischen Außenministers habe sich ,in der Angelegenheit bisher nichts Entscheidendes getan "153. Zu guter Letzt mußte das Franco-Regime

149 Schreiben Oberregierungsrat Ruh, Bundesarbeitsministerium, an Auswärtiges Amt, 28. 9. 1959, BA, B 149, Bd. 11878. Die Entscheidung für eine Versorgung der Blauen Division war eine politische Entscheidung, die auch anders hätte ausfallen können. Es kann keine Rede davon sein, daß die Bundesregierung sich den Argumenten Osters nicht verschließen „konnte“, wie dies Aschmann unterstellt. Vgl. Aschmann, „Treue Freunde..."?, S. 450.

${ }_{150}$ Auswärtiges Amt an Bundesarbeitsminister, 31. 10. 1959, PA/AA, Ref. 206, Bd. 76.

151 Vermerk über Fragen der Kriegsopferversorgung. 2. 11.1959, PA/AA, Ref. 206, Bd. 76. Aschmann irrt, wenn sie davon spricht, daß das Bundesfinanzministerium im Gegenzug „eine spanische Versorgung der Legion Condor-Angehörigen " gefordert habe. Bei diesen Überlegungen ging es allenfalls um die wenigen Personen, die in Spanien lebten. Das Auswärtige Amt selbst ging nur von etwa 10 früheren Angehörigen der Legion Condor aus. Schreiben Rechtsabteilung (Ref.505) an Länderabteilung, 3.4. 1959, PA/AA, Ref. 206, Bd. 76. Vgl. Aschmann, „Treue Freunde..."?, S. 389.

152 Aufzeichnung Schmidt-Schlegel betr. Kriegsopferversorgung der ehemaligen Angehörigen der Blauen Division, 24. 11. 1959, PA/AA, Ref. 206, Bd. 76. Hier auch das Folgende.

153 Aufzeichnung betr. Versorgung der Angehörigen der ehemaligen Blauen Division, 10. 12. 1959, BA, B 149, Bd. 11878 . 
sogar gedrängt werden, selbst aktiv zu werden. Botschafter von Welck sollte auf die spanische Regierung einwirken, um sie „dann doch noch“154 zu dem in Bonn „als Vorbedingung“ angesehenen „offiziellen Schritt“ zu bewegen.

Im Juli 1960 war es soweit: Die spanische Regierung bekundete in einer Verbalnote ${ }^{155}$, daß sie zu Verhandlungen bereit sei. Das Auswärtige Amt betonte zwar, die Bundesrepublik habe „eine moralische Verpflichtung ${ }^{\prime 156}$, die kriegsgeschädigten ehemaligen spanischen Angehörigen der Wehrmacht zu versorgen. Für das federführende Bundesarbeitsministerium und das Finanzministerium kam aber nur eine „deutsche Beteiligung “157 und nicht eine „völlige Übernahme“ in Betracht. Außerdem setzten die noch laufenden Wiedergutmachungsverhandlungen mit elf westlichen Ländern dem geplanten deutschspanischen Abkommen nach wie vor zeitliche Grenzen: Dieses könne, wurde die Botschaft. in Madrid instruiert, erst nach dem Ende der Entschädigungsgespräche abgeschlossen werden.

Von etwaigen Pauschalleistungen an Spanien riet Botschafter von Welck dringend ab. Ansonsten bestehe nämlich die Gefahr, daß „eine an die spanische Regierung gezahlte Globalsumme nicht vollständig an die Anspruchsberechtigten ausgezahlt" 158 werde und die Versorgungsleistung für den einzelnen „nicht über“ die im Land „sehr niedrigen Versorgungssätze hinausgehen“ könnte. Zudem hätten, so Welck, direkte Unterhaltsbeiträge aus deutschen Kassen ohnehin einen größeren politischen Effekt. Mit einer gewissen Chuzpe meldete Madrid nun auch Wiedergutmachungsansprüche für griechische Sepharden spanischer Staatsangehörigkeit an ${ }^{159}$, denen es groteskerweise aber erst auf Drängen des NS-Regimes seit 1943 die Durchreise in Drittländer gestattet hatte ${ }^{160}$.

154 Nostitz an Welck, 30. 12. 1959, PA/AA, Ref, 206, Bd. 76.

$15 \check{5}$ Auswärtiges Amt an Bundesarbeitsministerium, 5. 11. 1960, PA/AA, Ref. 501, Bd. 929 (Anlage: Verbalnote, 9.7. 1960).

1 156 Aufzeichnung betr. Versorgung der chemaligen Angehörigen der sogenannten Blauen Division, 5. 11. 1960, PA/AA, Ref. 501, Bd. 929.

157 Auswärtiges Amt an Botschaft Madrid, 26. 1. 1960, BA, B 149, Bd. 11878. Hier auch das Folgende.

J58 Botschaft Madrid an Auswärtiges Amt betr. Versorgung der Blauen Division, 30. 7. 1960, BA, B 149, Bd. 11878. Hier auch das Folgende.

159 Memorandum über schwebende Fragen, an deren Lösung die spanische Regierung interessiert isı, 17. 10. 1960, PA/AA, Ref. 501, Bd. 929. Schon bereits bei den Gesprächen über das enteignete deutsche Auslandsvermögen war das Thema Ende 1956 von Spanien angesprochen worden.

160 Von den etwa 700 spanischen Juden in Griechenland wurden im August 1943367 Juden aus Saloniki nach Bergen-Belsen deportiert. Das Franco-Regime hatte wiederholt Fristen der deutschen Regicrung verstreichen lassen. Erst im Frühjahr 1944 - auf Druck der Alliierten - erklärte sich Spanien zur Aufnahme bereit. In einer sogenannten Heimschaffungsaktion hatte das „Dritte Reich“ zehn verbündeten oder neutralen Staaten seit Ende 1942 die Möglichkeit eingeräumt, ihre jüdischen Bürger zu rcpatriieren. 1939 lebten im später nationalsozialistisch besetzten Europa rund 17000 Sepharden, Nachkommen der 1492 aus Spanien vertriebenen Juden. Abgesehen von einer kleinen Gruppe spanischer Staatsbürger (rund 4500), denen sich das Regime verpflichtet fühlte, ermöglichte Franco-Spanien etwa 20000 bis 35000 Juden den Transit nach Portugal. Im Gegensatz zur überzogenen franquistischen Selbstdarstellung nach 1945, mit der Franco scin Regime in der Nachkriegsordnung hoffähig machen wollte, hätte die spanische Diplomatic noch schr viel mehr Verfolgte vor Deportation und Vernichtung retten können. Vgl. entsprechend Rother, Spanien und der Holocaust, S. 339 ff. Ders., Franco als Retter der Juden?, S. 122-146. Vgl. zur Deportation nach Bergen-Belsen: cbenda, S. 230 ff. und S. 280 ff. Ebenso von zur Mühlen, Fluchtweg Spanien-Portugal, S. 108 f. Zu antisemitischen Ressentiments im katholischen Spanien der dreißiger Jahre siehc Böcker, Antisemitismus ohne Juden. 
Nach einem längeren Geplänkel über Forderungen und Gegenforderungen kamen beide Seiten überein, allein die Frage der Kriegsopferversorgung zu verhandeln ${ }^{161}$. Am 29. Mai 1962 lag schließlich eine Einigung vor: Der in Madrid unterzeichnete Vertrag sicherte $2315^{162}$ kriegsgeschädigten Angehörigen der Blauen Division, deren Erwerbsfähigkeit um mindestens 25 Prozent gemindert war, und ihren Hinterbliebenen eine bundesdeutsche Teilversorgung zu (Art. 1). Spanien verpflichtete sich hingegen, seine Pensionsregelungen auch weiterhin anzuwenden (Art. 2) ${ }^{163}$.

Doch auf eine rasche finanzielle Unterstützung aus Bonn mußten die Veteranen noch warten. Dort bestimmten außenpolitische Überlegungen den Beginn des parlamentarischen Ratifikationsverfahrens. Der Bundesregierung erschien es offensichtlich nicht opportun, Versorgungsleistungen für die Blaue Division vor dem Abschluß aller Entschädigungsabkommen mit elf westeuropäischen Staaten öffentlich werden zu lassen. Der deutsch-spanische Vertrag wurde deshalb erst im März 1964164 - nachdem die Globalabkommen unter Dach und Fach waren - in den Bundestag eingebracht ${ }^{165}$. Karl Carstens, Staatssekretär im Auswärtigen Amt, tat sich bei der abschließenden Beratung am 2. Dezember $^{166}$ schwer, die deutsche Hilfe inhaltlich zu begründen. Die Bundesregierung habe "geglaubt“, sich der spanischen Bitte „nicht entziehen zu sollen“, hieß es seltsam verquält bei Carstens. Er rechtfertigte diese „freundliche Geste “167 ausschließlich mit der von Madrid „stets rückhaltlos“ gewährten deutschlandpolitischen Unterstützung für den Bonner Alleinvertretungsanspruch: „Spanien ist eines derjenigen Länder, das in den für uns lebenswichtigen Fragen auf unserer Seite steht." Die dürre deutschlandpolitische Begründung wirkte vorgeschoben. Ausschlaggebend war die gemeinsame antikommunistische Frontstellung, in der Franco-Spanien als wichtiger und zuverlässiger Bündnispartner gesehen wurde. Die von Oster ins Feld geführte Aufrechnung des Leids von spani-

161 In der Frage einer Entschädigung für die sephardischen Juden zeigte sich das Auswärtige Amt zunächst durchaus gesprächsbereit. Die Rechtsabteilung trieb die Sorge um, daß ein Nein der Bundesregierung zur Wiedergutmachung Kritik in der spanischen Öffentlichkeit nach sich zichen werde. Vermerk betr. deutsch-spanische Verhandlungen über eine Versorgung der sogenannten Blauen Division durch die Bundesrepublik, 26. 1. 1961, PA/AA, Ref. 501, Bd.929. Noch im Juli 1961 waren für das Auswärtige Amt gleichzeitige Verhandlungen vorstellbar. Vermerk Ref. 505, 24. 7. 1961, PA/AA, Ref. 501, Bd. 929. Auf die Forderung nach ciner spanischen Versorgung für die in Spanien verbliebenen ehemaligen Angehörigen der Legion Condor ver\%ichtete die Bundesrepublik erst kurz vor Vertragsabschluß. Vgl. Aschmann, „Treue Freunde..."?, S. 390.

162 Diese Zahl nannte der Berichterstatter der SPD-Fraktion, Höhmann, bei der abschließenden Beratung im Bundestag, für die jährlich 1,7 Mio. DM veranschlagt wurden. Deutscher Bundestag, 4. Wahlperiode, 148. Sitzung, 2. 12. 1964, Stenographische Berichte, Bd. 56, S. 7323; Deutscher Bundestag, 4. Wahlperiode, Drucksache 1433, S. 2.

163 Der Umfang der deutschen Hilfe orientierte sich an den Vorschriften des Bundesversorgungsgesetzes. Beschädigte, Witwen und Waisen erhielten eine Grundrente in der gesetzlichen Höhe (Art. 7); Eltern eine Beihilfe in Höhe von $50 \%$ der gesetzlichen Elternrente (Art. 8). Vgl. Vertrag zwischen der Bundesrepublik Deutschland und dem Spanischen Staat über Kriegsopferversorgung, in: BGBl. 1965, Teil II, 8. 4. 1965, S. 273-280, hier S. $274 \mathrm{f}$.

164 Deutscher Bundestag, 4. Wahlperiode, Drucksache 2719.

165 Bei Aschmann bleibt dieser außenpolitische Zusammenhang völlig unberücksichtigt. Die von ihr als Motiv genannte innenpolitische „Stimmungslage“ gegenüber der franquistischen Diktatur war in diesem Fall zweitrangig. Vgl. Aschmann, „Treue Freunde..."?, S. 390.

166 Deutscher Bundestag, 4. Wahlperiode, 148. Sitzung, 2.12.1964, Stenographische Berichte, Bd.56, S. 7323-7327, hier S. 7324. Dort auch das Folgende.

167 So der CDU-Abgeordnete Majonica, ebenda, S. 7324. 
schen NS-Opfern mit dem spanischer Kriegsfreiwilliger blieb dem Parlament ebenfalls vorenthalten.

Die sozialdemokratische Opposition lehnte es dagegen ab, „dem spanischen Staat Versorgungsaufgaben abzunehmen“. Nach ihrer Ansicht trage das Franco-Regime allein die Verantwortung für die sozialen Nöte der Kriegsbeschädigten und ihrer Hinterbliebenen. Denn der Einsatz der Freiwilligen war für Fraktionsgeschäftsführer Mommer die Folge der Politik Francos, nämlich „seine[r] eigene[n] Verfilzung mit dem nationalsozialistisch-faschistischen Regime in diesem Lande"168. Die Regierungsparteien CDU/CSU und FDP stimmten dem Vertragswerk aus „sozialen und menschlichen Gesichtspunkten “169 $\mathrm{zu}$. Sie bekundeten, Verantwortung tragen zu wollen, „für die Erbmasse des Dritten Reiches“, so der christdemokratische Abgeordnete Majonica, „im Guten und im Bösen“ und auch in diesem Fall könne man diese „nicht einfach vom Tisch wischen“. Der Freidemokrat Krümmer sah darin ein Gebot der Menschlichkeit, auch wenn die Verpflichtung „aus einer Zeit stammt, die rückwärts betrachtet sehr unerfreulich gewesen ist"170.

\section{Die ausgegrenzten Opfer - Humanitäre Hilfe und Wiedergutmachung für „Rotspanier"?}

Im Gegensatz zu den Veteranen der Blauen Division hatten die Verlierer des Spanischen Bürgerkriegs, von denen Zehntausende nicht nur zu Emigranten sondern auch zu Verfolgten des NS-Regimes ${ }^{171}$ wurden, keine politisch einflußreiche Lobby, kaum einen

168 Ebenda, S. 7326.

169 Ebenda, S. 7324. Hier auch das Folgende.

170 Ebenda, S. 7325. Das Gesetz zu dem „Vertrag zwischen der Bundesrepublik Deutschland und dem Spanischen Staat über Kriegsopferversorgung und zu dem Notenwechsel vom 16. Mai 1963“ wurde mit 168 gegen 120 Stimmen angenommen, S. 7327. Die Bundesregierung hatte sich durch den Notenwechsel bestätigen lassen, daß es sich bei den vertraglichen Leistungen um Höchstsätze handele, die in bestimmten Fällen gemindert werden könnten. Vgl. Deutscher Bundestag, 4. Wahlperiode, Drucksache 2719. Rechtskräftig wurde das Abkommen erst am 1.6. 1965. Vgl. BGBl. 1965, II. Teil, S. 852. Nachdem der Bundesrat im Dezember 1964 zunächst seine Zustimmung verweigert hatte, sanktionierte der Vermittlungsausschuß im Februar 1965 schließlich das Vertragswerk. Vgl. Schreiben von Georg August Zinn, Präsident des Bundesrates, an den Bundeskanzler, 18. 12. 1964, in: Deutscher Bundestag, 4. Wahlperiode, Drucksache 2859. Ebenso Vermittlungsausschuß an den Präsidenten des Bundestages, 11. 2. 1965, Drucksache 3061 .

171 Die Gesamtzahl der dauerhaft im Exil lebenden Spanier wird auf 162000 bis 300000 geschätzt. Vgl. Bernecker, Krieg in Spanien, S. 212. Mindestens 7200 republikanische Spanier waren von 1940 bis 1945 im Konzentrationslager Mauthausen bei Linz inhaftiert. Nur etwa 2000 überlebten das Lager. Daß die große Mehrheit der in die KZs verschleppten „Rotspanier“ nach Mauthausen kam, mag damit zusammenhängen, daß das KZ zu Beginn der Deportationen im August 1940 im Aufbau begriffen war und deshalb entsprechende Kapazitäten bereitstanden. Hier sollten politische Gegner durch „Arbeit vernichtet" werden. Auch spanische Jugendliche im Alter ab 14 Jahren mußten im dortigen Steinbruch arbeiten. Weitere Spanier waren u. a. in Dachau und Buchenwald, in Sachsenhausen, Neuengamme, Auschwitz und im Frauenkonzentrationslager Ravensbrück interniert. Insgesamt kamen nach Schätzungen etwa 10000 Spanier in den KZs ums Leben. Vgl. Tuñón de Lara u. a., Der Spanische Bürgerkrieg, S.643. Zu Mauthausen vgl. Schröck, Dic republikanischen Spanier im Konzentrationslager Mauthausen, S. 181-215; Pike, Spaniards in the Holocaust. Vgl. auch den von Dorothee von Keitz und Andreas Ruppert verantworteten Themenschwerpunkt: Spanier in den Konzentrationslagern der Nationalsozialisten, in: Tranvia. Revue der Iberischen Halbinsel, 28. März 1993. Im besetzten Frankreich waren um die Jah- 
Staat, der sich für sie und ihre Interessen einsetzte ${ }^{172}$. Schon allein der Versuch, Bundespräsident Heuss im Februar 1959 für einen Spendenaufruf zur Unterstützung von notleidenden spanischen Republikanern im französischen Exil zu gewinnen ${ }^{173}$, stieß in Bonn auf Vorbehalte. Das Bundespräsidialamt sah sich außerstande, allein über die ungewöhnliche Bitte der „Interessengemeinschaft ehemaliger deutscher republikanischer Spanienkämpfer" zu entscheiden, und bat deshalb das Auswärtige Amt um eine Stellungnahme ${ }^{174}$.

Die auf den ersten Blick politisch unverfänglich erscheinenden Bemühungen um eine humanitäre Hilfsaktion lösten dort aber Abwehr aus. So wies das Spanien-Referat vorsorglich darauf hin, daß „außenpolitische Gesichtspunkte“175 hierbei „erheblich“ hineinspielten. „Nach außen hin“, insbesondere gegenüber der Interessengemeinschaft, sollte dies jedoch möglichst nicht ,in den Vordergrund“ gerückt werden. Bonn wollte Madrid offenbar nicht brüskieren. Denn ein Aufruf des Bundespräsidenten zu Spenden für spanische Emigranten wäre in den Augen des Franco-Regimes wohl einer Parteinahme für seine Gegner gleichgekommen.

Die Beamten der Rechtsabteilung trieb bei der Anfrage des Bundespräsidialamts die Sorge vor möglichen Wiedergutmachungsforderungen um. Eiligst bestritt das für Entschädigungsfragen zuständige Referat jegliche Ansprüche der Spanienflüchtlinge: Sie „gehören nicht zu dem Kreis“ der durch das Bundesentschädigungsgesetz (BEG) „erfassten Berechtigten "176, hieß es lapidar. Wider besseres Wissen oder in Unkenntnis der rechtlichen Lage wurde spanischen NS-Opfern hier pauschal abgesprochen, die Voraussetzungen im Sinne des $§ 1$ BEG zu erfüllen. Nach Ansicht der Rechtsabteilung zählten die Rotspanier nicht zu den Opfergruppen, die wegen ihrer politischen Überzeugung, aus Gründen der Rasse, des Glaubens oder der Weltanschauung verfolgt worden waren. Ein Recht auf Wiedergutmachung sei „daher nicht gegeben“. Besonders gründlich konnten die Nachforschungen nicht verlaufen sein. Zu diesem Zeitpunkt hatten nämlich bereits Mili-

reswende 1943/44 überdies knapp 27000 „Rotspanier“ von der Organisation Todt zur Zwangsarbeit herange\%ogen worden. Vgl. Alff, Dic republikanischen spanischen Flüchtlinge („Rotspanier“), S. 285. Darüber hinaus wird die Zahl der spanischen Zwangsarbeiter in Deutschland auf rund 40000 geschätzt. Vgl. Tosstorf, Spanische Flüchtlinge nach dem Ende des Bürgerkrieges, S. 199. Zum spanischen Exil nach 1939 vgl. u. a. Rafaneau-Boj, Odyssée pour la liberté; Pike, In the Service of Stalin. Zu der Verfolgung der spanischen Flüchtlinge durch das NS-Regime in Frankreich siehe als grundlegende, allerdings nur kursorische deutsche Darstellung: Alff, Die republikanischen spanischen Flüchtlinge („Rotspanier").

172 Allerdings gewährte Frankreich durch ein Dekret am 15. 3. 1945 den rund 105000 im Land lebenden spanischen Flüchtlingen politisches Asyl. Vgl. ebenda, S. 204.

173 Interessengemeinschaft ehemaliger deutscher republikanischer Spanienkämpfer an Bundespräsident Theodor Heuss, 11. 2. 1959, PA/AA, Ref. 206, Bd. 85. Auch nach 20 Jahren, so bilanzierte Karl Sauer, der Vorsitzende der Interessengemeinschaft, lebten noch 115000 Spanier, darunter 3000 chronisch Erkrankte, 5000 Schwerbeschädigte des Zweiten Weltkriegs und 3500 Überlebende deutscher Konzentrationslager in südfranzösischen „Massenlagern“. Die früheren republikanischen Spanienkämpfer erinnerten Bundespräsident Heuss daher an seine Spendenappelle für holländische und italienische Opfer von Naturkatastrophen. Ein ähnlicher Aufruf für die „durch deutsche Schuld in Not geratenen Spanier" könnte nach ihren Vorstellungen „neben der materiellen auch eine moralische Wiedcrgutmachung einleiten". Ebenda.

174 Bundespräsidialamt an Auswärtiges Amt, 20. 2. 1959, PA/AA, Ref. 206, Bd. 85.

175 Schmidt-Schlegel (handschriftliche Anmerkung) an Ref. 501, 28. 2. 1959, PA/AA, Ref. 206, Bd. 85. Hier auch das Folgende.

${ }^{176}$ Born (Ref. 501) an Ref. 206, 13. 3. 1959, PA/AA, Ref. 206, Bd. 85. Hier auch das Folgende. 
tärattaché Oster und die Botschaft in Madrid über Entschädigungszahlungen der Bundesrepublik an „Rotspanier“ und ihre Hinterbliebenen berichtet ${ }^{177}$.

Entscheidend für die Meinungsbildung im Auswärtigen Amt war außerdem die Stellungnahme des Bundesinnenministeriums zum Hintergrund der Interessengemeinschaft der ehemaligen republikanischen Spanienkämpfer ${ }^{178}$. Dieser komme mit ihren höchstens 200 Mitgliedern, ,im wesentlichen Kommunisten“, wie das Bonner Innenministerium urteilte, ,praktisch keinerlei Bedeutung zu“. Angesichts einer solch politisch einflußlosen Organisation fiel es leicht, dem Bundespräsidenten zu empfehlen, von einer Antwort ganz abzusehen ${ }^{179}$. Das Auswärtige Amt ging sogar noch einen Schritt weiter: Es sprach sich mit Rücksicht auf das Franco-Regime gegen eine in Hamburg geplante Spendensammlung zu Gunsten spanischer Flüchtlinge aus. Ministerialdirektor Carstens verwies vorauseilend darauf, daß die Genehmigung durch die Behörden der Hansestadt bei der spanischen Regierung „Verstimmung hervorrufen " 180 würde. Seine Sorge galt einem Antrag des „Deutschen Komitees zur Hilfe für demokratische spanische Flüchtlinge“, das der sozialdemokratische Bundestagsabgeordnete Peter Blachstein ${ }^{181} 1958$ in Hamburg gegründet hatte.

Die Hilfsorganisation, für die nicht nur ihr Ehrenvorsitzender, der im Exil lebende spanische Cellist Pablo Casals, sondern neben Gewerkschaftern und SPD-Politikern auch die Philosophin Hannah Arendt warben, orientierte sich am Vorbild der 1953 in den USA gegründeten „Spanish Refugee Aid“182. Das deutsche Komitee, das „mittellose und demokratisch gesinnte Spanier"183 unterstützte, bemühte sich auf sozialdemokratischen Parteitagen und bei den Gewerkschaften um Patenschaften bzw. direkte finanzielle Hilfen. Es war ein Unternehmen, das, wie der SPD-Politiker Heinz Ruhnau 1975 - dem Todesjahr Francos - bilanzierte, „unter Ausschluß der Öffentlichkeit“184 stattfand. Dennoch seien ,in jedem Jahr fast $50000 \mathrm{DM}$ “ an Spenden gesammelt worden.

Doch wie war es nun um die Wiedergutmachung der spanischen NS-Verfolgten bestellt? Mit dem Bundesentschädigungsgesetz war 1956 eine allgemeine Rechtsgrundlage für die Behandlung von Wiedergutmachungsansprüchen für Verfolgte des Nationalsozialismus

177 Vermerk Junges betr. Unterhaltung mit Oberstleutnant Oster, 14. 1. 1959, PA/AA, Ref. 206, Bd. 76. Das für Entschädigungsfragen verantwortliche Referat 501 war ebenfalls im Januar durch die Botschaft über entsprechende materielle Leistungen nach dem BEG informiert worden; Botschaft Madrid an Auswärtiges Amt, 21. 1. 1959, PA/AA, Ref. 501, Bd. 929.

178 Bundesministerium des Innern (Mosheim) an Auswärtiges Amt, 4.5. 1959, PA/AA, Ref. 206, Bd. 85. Hier auch das Folgende.

179 Auswärtiges Amt an Bundespräsidialamt, 19.5. 1959, PA/AA, Ref. 206, Bd. 85.

180 Auswärtiges Amt an Bundesministerium des Innern, 22. 7. 1959, PA/AA, Ref. 206, Bd. 85. Allerdings riet Carstens, bei der Begründung eines etwaigen ablehnenden Bescheides, außenpolitische Gründe nicht in den Vordergrund zu rücken. Er schlug stattdessen vor, darauf zu verweisen, daß die Unterstützung hilfsbedürftiger Personen Aufgabe der allgemeinen Wohlfahrt sei.

181 Der Journalist Blachstein war im November 1936 nach Barcelona gekommen und hatte sich - ähnlich wie Willy Brandt und andere - politisch und publizistisch für die Belange der spanischen Republik eingesctzt. Vgl. von zur Mühlen, Spanien war ihre Hoffnung, S. 311.

182 Vgl. zu deren Aktivitäten: McDonald, Homage to the Spanish Exiles.

183 Vgl. Werbeschrift des Deutschen Komitecs zur Hilfe für demokratische spanische Flüchtlinge 1964; zu danken ist Prof. Wilhelm Alff (Bremen) für den Einblick in Materialien der Hamburger Hilfsorganisation.

184 So Ruhnau, langjähriger Schriftührer des Komitees auf dem Bundesparteitag der SPD in Mannheim 1975, Parteitagsprotokoll S. 119. Hier auch das Folgende. 
geschaffen worden ${ }^{185}$. Dies galt auch für die republikanischen Flüchtlinge, die gegen Ende des spanischen Bürgerkrieges 1939 ins Exil nach Frankreich gegangen waren und dort nach der deutschen Besetzung im Sommer 1940 zu Opfern der nationalsozialistischen Verfolgungs- und Vernichtungspolitik wurden. Die Frage, wie und inwieweit die Bestimmungen des Gesetzes auch auf Spanier, die in irgendeiner Weise in die Mühlen des „Dritten Reiches“ geraten waren, bzw. auf ihre Hinterbliebenen Anwendung finden mußten, war in den folgenden Jahren Gegenstand langwieriger Auseinandersetzungen.

Dabei handelte es sich vor allem um drei Gruppen: 1) Angehörige von verstorbenen spanischen KZ-Opfern; 2) Überlebende der Konzentrationslager; 3) Im „Dritten Reich“ als Zwangsarbeiter eingesetzte Spanier. Die deutsche Botschaft in Madrid und das Generalkonsulat in Barcelona wurden nun erstmals direkt mit diesem Thema konfrontiert. Mancher Diplomat reagierte auf die Anfragen früherer KZ-Häftlinge oder ihrer Hinterbliebenen äußerst unwillig: Offenbar verärgert über die „ständig “186 wachsende Zahl von Wiedergutmachungsanträgen schlug Generalkonsul Schaffarczyk im Oktober 1957 sogar vor, „spanischen Staatsangehörigen Entschädigungen zu versagen [...], solange deutsche Staatsangehörige von spanischer Seite keine Entschädigung erhalten“. Schließlich, so argumentierte er, seien gegen Ende des Zweiten Weltkrieges auch zahlreiche Deutsche in spanischen Lagern interniert gewesen ${ }^{187}$, ohne je eine Entschädigung ,auf Grund dieses Freiheitsentzugs" erhalten zu haben.

185 Bundesgeset\% zur Entschädigung für Opfer der nationalsozialistischen Verfolgung vom 29. Juni 1956, in: BGB1. 1956 I, S. 559. Es trat rückwirkend zum 1. Oktober 1953 in Kraft. „Auf Druck der Westmächte“ waren auch Staatenlose und Flüchtlinge im Sinne der Genfer Konvention - und damit auch die sogenannten Rotspanier - in den Kreis der Anspruchsberechtigten aufgenommen worden. Vgl. Hockerts, Wiedergutmachung in Deutschland, S. 190.

${ }^{186}$ Generalkonsulat Barcelona an Auswärtiges Amt, 11. 10. 1957, PA/AA, Ref. 501, Bd. 929. Das Konsulat führte das gestiegene Interesse an der Wiedergutmachung vor allem auf die Aktivitäten einer Interessengemeinschaft früherer Deportierter in Paris zurück. Die „Federación Española de Deportados é Internados Políticos" fordere die früheren Insassen von Konzentrationslagern bzw. deren Angehörige dazu auf, ihre Ansprüche gegenüber der Bundesrepublik geltend zu machen. Generalkonsulat Barcelona an Auswärtiges Amt, 15. 7. 1957, PA/AA, Ref. 501, Bd. 929.

${ }^{187}$ In der Tat saßen sogar noch Ende 1949 etliche Deutsche in spanischen Gefängnissen und dem Internierungslager Nanclares de la Oca ein. Während einer Urlaubsreise hatte der Bremer Senator Wolters zufällig von dem Lager in Nordspanien sowie den dort inhaftierten Deutschen erfahren und daraufhin das Lager aufgesucht. Nach seiner Rückkehr machte Wolters durch spektakuläre Erlebnisberichte wie „Deutsche in spanischem KZ“ auf das Schicksal der deutschen Staatsangehörigen aufmerksam. Vgl. Weser Kurier, 29. 11. 1949, Die Welt, 7. 12. 1949. Nahezu zeitgleich war das Bundeskanzleramt durch den im Sommer 1948 nach Spanien zurückgekehrten früheren deutschen Militärattaché, Hans Doerr, eingehend über die Lage der Internierten informiert worden. Doerr handelte aus eigenem Antrieb, da es, wie er an Bundeskanzler Adenauer schrieb, „Berufene“ für diese Frage noch nicht gebe. Doerr an Adenauer, 28. 11. 1949, PA/AA, Abt. 2, Bd. 1970. Die Bundesregierung reagierte rasch. Allerdings waren ihr - nur wenige Monate nach Gründung der Bundesrepublik - noch weitgehend die Hände gebunden. Sie war auf das Entgegenkommen der Alliierten Hohen Kommission (AHK) und der spanischen Regierung angewiesen. Mitte Dezember bat Bundeskanzler Adenauer die AHK, im Fall der „400 noch in Spanien befindlichen deutschen Kriegsgefangenen“ auf die zeitraubenden Einzeleinreisegenehmigungen zu verzichten und einem Sammeltransport für die Rückkehrwilligen zuzustimmen. Vgl. Kabinettssitzung am 13. 12. 1949, in: Die Kabinettsprotokolle der Bundesregierung, Bd. 1, S. 266. Zu diesem Zeitpunkt handelte es sich jedoch in den allermeisten Fällen nicht mehr um ehemalige Soldaten, sondern um illegale Grenzgänger, die aus „Auswanderungsdrang“ oder „Abenteuerlust“ den Weg über Spanien genommen hatten: also Deutsche, die nach dem Eindruck des Deutschen Hilfsvereins in Madrid nicht zu Märtyrern gemacht werden sollten. Bericht aus Madrid vom Januar 1950 (vermutlich Doerr), PA/AA 205-00/70, 
Botschafter Knappstein wandte sich ganz entschieden gegen ein derartiges Junktim. Er verwies darauf, daß bei Kriegsende in vielen Staaten - auch in anderen neutral gebliebenen Ländern - Deutsche inhaftiert worden waren. Dies habe zu den „allgemeinen Folgen des vom Dritten Reich verlorenen Krieges“188 gehört, stellte Knappstein lapidar fest. Spanien sei also kein Einzelfall. Im übrigen richteten sich die Wiedergutmachungsansprüche ausschließlich nach den „einschlägigen deutschen Wiedergutmachungs- und Entschädigungsgesetzen“. Bislang hätte die Bundesregierung seines Wissens außerdem noch mit keinem anderen Staat eine solche Diskussion geführt. Für ihn kam daher eine „spezielle Diskriminierung spanischer Staatsangehöriger“ nicht in Betracht. Dies schien ihm „mit dem Sinn und dem Geist der deutschen Wiedergutmachungsgesetzgebung“ auch „nicht vereinbar zu sein".

Die Aufklärungsarbeit der in Paris beheimateten Interessenvertretung spanischer Emigranten, der „Federación Española de Deportados e Internados Políticos“189, die schon Generalkonsul Schaffarczyk zu seinem Vorstoß veranlaßt hatte, trug offenbar Früchte: Im März 1958 berichtete die Botschaft, daß die Zahl der Spanier, die sich nach den bestehenden Wiedergutmachungsmöglichkeiten erkundigt hätten, ,in letzter Zeit beträchtlich zugenommen" habe. Dadurch, so Botschafter Knappstein, scheine nun auch das Außenministerium in Madrid aufmerksam geworden zu sein. „Anscheinend“ hätten die spanischen Vertretungen in der Bundesrepublik es ,jahrelang versäumt“ hierüber zu berichten. Denn ansonsten sei die „auffällige Eile“ nicht recht zu erklären, mit der das Außenministerium sich jetzt veranlaßt gesehen habe, in der spanischen Presse „erstmalig“ eine allerdings nur „sehr allgemein“ gehaltene Bekanntmachung über die Wiedergutmachungsmöglichkeiten zu veröffentlichen. Darin wurden alle Interessierten - ohne den Kreis der Anspruchsberechtigten jedoch näher zu definieren - auf die am 31. März 1958 ablaufende Antragsfrist ${ }^{190}$ hingewiesen und dazu aufgefordert, ihre Ansprüche rechtzeitig bei der zuständigen Entschädigungsbehörde beim Regierungspräsidenten in Köln anzumelden. Die deutsche Botschaft war auch angesichts der steigenden Zahl von Anfragen und Anträgen darauf bedacht, bei diesem sensiblen Thema weiterhin sehr vorsichtig zu agieren. Sie sehe es nicht als ihre Aufgabe an, teilte Knappstein dem Auswärtigen Amt mit, „dem spani-

Bd. 1; Bericht über das Lager Nanclares de la Oca, 7. 12. 1949, PA/AA, Abt. 2, Bd. 1970. Trotz der grundsätzlichen Zustimmung zu einem Sammeltransport bestand die AHK aber nach wie vor auf einer individuellen Zuzugsgenehmigung. Nicht nur bürokratische Hemmnisse verzögerten die Repatriierung. Es mangelte auch an Transportmöglichkeiten. Mitunter mußten die Heimkehrer in Bilbao monatelang auf einen Schiffsplatz warten. Im wesentlichen war die komplizierte Heimschaffungsaktion Mitte 1951 abgeschlossen. Botschaft Madrid an Auswärtiges Amt, 22. 6. 1953, PA/AA, Ref. 206, Bd.31. Vgl. auch Weber, Spanische Deutschlandpolitik 1945-1958, S. 106-111, sowie Aschmann, „Treue Freunde..."?, S. 129-137. Zur Situation von Flüchtlingen und Transit-Emigranten im Zwciten Weltkrieg und der Entstehung der sogenannten Konzentrationslager („campos de concentración“) vgl. von zur Mühlen, Fluchtweg Spanien-Portugal, S. 95-105.

${ }^{188}$ Knappstein betr. Wiedergutmachung an Auswärtiges Amt, 29.10.1957, PA/AA, Ref.501, Bd. 929. Hier auch das Folgende.

189 Knappstein betr. Wiedergutmachung an Auswärtiges Amt, 12. 3. 1958, PA/AA, Ref. 501, Bd.929. Hier auch das Folgende.

190 Zugleich hatte der spanische Botschafter in Bonn bereits am 3. März Außenminister Brentano gebeten, sich für eine Fristverlängerung einzusetzen. Ob die Bundesregierung diesem Wunsch tatsächlich nachkam, konnte nicht geklärt werden. Schreiben Loos (Rechtsabteilung) an Botschaft Madrid, 19.3. 1958, PA/AA, Ref. 501, Bd. 929. 
schen Publikum nähere Auskünfte darüber zu geben, ob im Einzelfall ein Wiedergutmachungsanspruch besteht oder nicht“. Schließlich entschieden hierüber „ausschließlich“ Entschädigungsbehörden und Gerichte. Diese Zurückhaltung hatte aber vor allem politische Gründe: Denn die spanischen NS-Opfer und ihre Angehörigen galten zugleich auch als Gegner des Franco-Regimes, zu dem die Bundesregierung gute Beziehungen unterhielt. Eine allzu große Nähe gegenüber den sogenannten Rotspaniern wollten die deutschen Diplomaten daher tunlichst vermeiden. Die spanische Regierung beobachte, so Knappstein, „diesen Personenkreis auch heute noch mit Argwohn“. Deshalb müsse es die Botschaft vermeiden, die „Rolle einer Beratungsstelle“ zu übernehmen.

Andererseits wollte Knappstein aber für eventuelle Anfragen amtlicher Stellen in Madrid gewappnet sein. Er bat deshalb darum, grundsätzlich klären zu lassen, unter welchen Voraussetzungen in Spanien lebende Hinterbliebene von Spaniern, die bis zum 8. Mai 1945 in einem Konzentrationslager verstorben waren, Wiedergutmachungsanträge „mit Aussicht auf Erfolg“ stellen können. Die Rechtslage war zu diesem Zeitpunkt in der Tat nicht ganz eindeutig: Nach dem maßgeblichen Kommentar zu den Bundesentschädigungsgesetzen $^{191}$, auf den sich auch der Botschafter bezog, besaßen die Angehörigen in einem solchen Fall kaum einen Rechtsanspruch auf Entschädigung. Entscheidend für die Kommentatoren war nämlich allein der Stichtag 1. Oktober 1953, der Tag, an dem das BEG in Kraft trat. Demnach, so ihre absurde Logik, müsse der "getötete Verfolgte [...] entweder am 1.10. 1953 staatenlos oder Flüchtling gewesen sein [...] also noch gelebt haben;"192 oder der verfolgte Staatenlose oder Flüchtling müsse nach dem Ende der Verfolgung „eine neue Staatsangehörigkeit erworben, also ebenfalls noch gelebt haben“. Denkbar sei der Wiedergutmachungsanspruch also nur dann, wenn die Hinterbliebenen selbst am 1. Oktober 1953 Staatenlose oder Flüchtlinge im Sinne der Genfer Konvention gewesen wären. Nach Ansicht von Knappstein hätte dies bedeutet, daß die "große Mehrzahl“193 der besonders „wiedergutmachungswürdigen“ Anträge "gegenstandslos“ sein würde. Das Auswärtige Amt bestätigte nur lakonisch, daß sich die zuständigen Entschädigungsbehörden derzeit an dieser „engeren " 194 Rechtsauffassung orientierten und die meisten Anträge daher unbegründet sein dürften. Es sei jedoch demnächst mit einer höchstrichterlichen Entscheidung zu rechnen, in der „möglicherweise eine für die Verfolgten günstigere Auffassung "195 vertreten werdc.

Bis dahin konnte aber noch viel Zeit vergehen. Eine Anfrage der Botschaft beim Regierungspräsidenten in Köln hatte im Oktober 1958 ergeben, daß in der „bisherigen Praxis keine Änderung eingetreten sei“"196, die Hinterbliebenen der sogenannten Rotspanier also „bislang keine Entschädigungsansprüche nach dem BEG haben“. Gleichzeitig sprächen bei der deutschen Vertretung in Madrid „immer häufiger Spanier vor“, berichtete Botschafts-

191 Vgl. Blessin/Wilden, Bundesentschädigungsgesetze, § 160, Abs. 13, S. 742 ff.

192 Vgl. ebenda, S. 742 f. Vor diesem Hintergrund entfaltet das Vorwort zur ersten Auflage aus heutiger Sicht tragikomische Wirkung: „Der Geis،“, heißt es dort, mit dem „Behörden und Gerichte an die Wiedergutmachung herangehen", werde für den „Erfolg oder Mißerfolg in der Bewältigung dieser einmaligen staatlichen Aufgabe von ausschlaggebender Bedeutung sein“. Die Verfasser "haben sich bemüht, diesen Geist in der Auslegung der gesetzlichen Vorschriften lebendig zu machen“.

193 Knappstein betr. Wiedergutmachung an Auswärtiges Amt, 12. 3. 1958, PA/AA, Ref. 501, Bd. 929.

194 Schreiben Loos (Rechtsabteilung) an Botschaft Madrid, 19. 3. 1959, PA/AA, Ref. 501, Bd. 929.

195 Ebenda.

19 Botschaft Madrid an Auswärtiges Amt, 12. 12. 1958, PA/AA, Ref. 501, Bd. 929. Hier auch das Folgende. 
rat Werz, die sich zum Teil darüber beklagten, daß sie von den zuständigen Behörden in der Bundesrepublik ,angeblich bis heute noch nicht einmal eine Bestätigung“ über den Eingang ihres Antrages erhalten hätten. Diese wiederholten Beschwerden lösten bei Werz Unmut aus, da er die Angehörigen der KZ-Opfer offenbar vor allem als lästige Bittsteller empfand, die ohnehin nur über „vermeintliche Ansprüche“ verfügten. Neben voreiligen Informationen in der spanischen Presse - gemeint war die in seinen Augen wohl unzureichende offizielle Bekanntmachung im Jahr zuvor - machte er in erster Linie die Opfer-Anwälte Rodes und Herzfelder in Paris für die entstandene Situation verantwortlich. So forderten die Rechtsanwälte die spanischen Antragsteller unter anderem dazu auf, „Bedürftigkeitsbescheinigungen beizubringen“, die sie bei der zuständigen deutschen Auslandsvertretung erhalten könnten. Der Botschaft, so Werz, erscheine das Vorgehen der Herren Rodes und Herzfelder als „unstatthaft“, da „sie wissen müssten“, daß ihre Auftraggeber „gar keine Ansprüche nach dem BEG“ haben. Er ließ es nicht bei seiner Empörung bewenden und regte an, die Botschaft in Paris anzuweisen, die Anwälte ,in geeigneter Form zu bitten, von ihrer bisherigen Praxis“, die wegen der augenblicklichen Gesetzeslage „zu keinem Erfolg führen kann“ und die ihre Klienten „nur zu Geldaufwendungen“veranlasse, „Abstand zu nehmen“. Darüber hinaus bat Werz darum, prüfen zu lassen, ob den Antragstellern nicht ein Zwischen- oder sogar ein endgültiger Bescheid erteilt werden könne.

Die deutsche Vertretung in Paris zeigte sich indes äußerst verwundert: Sie teilte im April 1959 mit, zwar sei ihr Rechtsanwalt Rodes nicht bekannt, man wisse nur, daß sich seine Kanzlei im gleichen Haus wie die von Dr. Herzfelder befinde. Herzfelder war den Diplomaten aber wohlbekannt. Er gelte als „befähigter Anwalt“197 und arbeite seit Jahren eng mit der Botschaft zusammen und habe sich dabei „stets korrekt“verhalten. Die Zweifel an der Seriosität der Opferanwälte wurden in Paris folglich nicht geteilt. Die Botschaft nehme an, daß sich beide Herren „doch wohl nur mit solchen Wiedergutmachungsfällen “von sogenannten Rotspaniern befaßten, die „tatsächlich berechtigte Ansprüche“ hätten.

Inzwischen schien sich die Rechtspraxis zu ändern: Erstaunt registrierten die deutschen Vertreter in Madrid Anfang 1959, daß in letzter Zeit nunmehr auch die Hinterbliebenen der sogenannten Rotspanier, die in deutschen Konzentrationslagern verstorben waren, Entschädigungsleistungen nach dem BEG erhielten ${ }^{198}$. Zugleich mußte die Botschaft sich angesichts dieser neuen Entwicklung nun eingehender mit einem heiklen Thema beschäftigen, das Rechtsanwalt Herzfelder aufgeworfen hatte. Der Anwalt, der nach eigenen Angaben die Entschädigungsangelegenheiten „einer beträchtlichen Zahl“199 von in Spanien lebenden Angehörigen vertrat, wollte grundsätzlich geklärt wissen, ob und in welchem Ausmaß die Eltern, Witwen oder Waisen „wegen des Todes der Verfolgten “ vom spanischen Staat eine „Betreuung“ erhalten bzw. erhalten hätten. Da die fehlende Betreuung durch einen Staat nach $\S 160$ BEG $^{200}$ eine der rechtlichen Voraussetzungen für Leistungen war, könnte eine offizielle Bestätigung, so Herzfelder, „allen Beteiligten einen erheblichen Aufwand an Zeit, Mühe und Kosten ersparen“.

197 Botschaft Paris an Auswärtiges Amt, 3. 4. 1959, PA/AA, Ref. 501, Bd. 929.

198 Die Landesrentenbehörde in Düsseldorf hatte der Botschaft einige Durchschriften von Wiedergutmachungsbescheiden zur Kenntnisnahme übermittelt. Botschaft Madrid an Auswärtiges Amt, 21. 1. 1959, PA/AA, Ref. 501, Bd. 929.

199 Ebenda. Auszüge aus einem Schreiben Herzfelders an die Botschaft vom 2. 1. 1959.

200 Vgl. Blessin/Wilden, Bundesentschädigungsgesetze, S. 743. 
Dazu war die Botschaft aber ohne weiteres nicht bereit. Den Betroffenen wurde aus politischem Kalkül zunächst die Hilfe verweigert. Die Diplomaten räumten zwar ein, daß nach ihrer Kenntnis die „Hinterbliebenen von sog. Rotspaniern vom spanischen Staat keine Betreuung“201 erhielten; sie hatten aber gleichzeitig „Bedenken“, dies öffentlich zu machen. Nun entspann sich ein groteskes Hin und Her, da auch im Auswärtigen Amt niemand die Verantwortung für dieses delikate Problem übernehmen wollte. Das für Entschädigungsfragen zuständige Referat erklärte lediglich ${ }^{202}$, es teile die - allerdings nicht näher erläuterten - Bedenken der Botschaft und empfahl deshalb, Rechtsanwalt Herzfelder an die zuständigen spanischen Behörden zu verweisen. Dies wiederum lehnte die Botschaft ab: Sie spielte auf Zeit. Solange nicht grundsätzlich geklärt sei, ob bzw. weshalb die Hinterbliebenen überhaupt Entschädigungsleistungen bekämen, wollte man dem Rat aus Bonn nicht ohne weiteres nachkommen ${ }^{203}$. Außerdem, so die paradoxe Argumentation, „dürfte den von den spanischen Behörden ausgestellten Bescheinigungen mit einem solchen Inhalt [...] kein großer Wahrheitswert beizumessen sein“. Die deutschen Diplomaten wollten offenbar unbedingt vermeiden, das Franco-Regime direkt mit diesem Tabu-Thema zu konfrontieren oder selbst eine offizielle Erklärung abzugeben, die von der spanischen Regierung als Affront hätte verstanden werden können. So wurde Herzfelder erst einmal mit einem unverbindlichen Zwischenbescheid vertröstet ${ }^{204}$.

Im Juni 1959 beendete das für die Spanier zuständige nordrhein-westfälische Innenministerium schließlich die rechtliche Ungewißheit ${ }^{205}$. Allerdings war dort die veränderte Rechtslage offenbar lange Zeit gar nicht zur Kenntnis genommen worden. Es hatte erst mehrerer Anfragen aus Bonn bedurft, bis das Innenministerium das Auswärtige Amt über eine entschädigungsfreundliche Grundsatzentscheidung informierte, die vom Bundesgerichtshof bereits im Juli 1958 - also elf Monate zuvor - getroffen worden war. Demnach konnten Hinterbliebene nun unabhängig von ihrer Staatsangehörigkeit Wiedergutmachungsansprüche nach $\S 160$, Abs. 3 BEG geltend machen. Voraussetzung dafür war, daß ein durch „Verfolgungsmaßnahmen getöteter Verfolgter [...] im Zeitpunkt seines Todes staatenlos oder Flüchtling gewesen ist".

Während die Gruppe der Angehörigen damit - unabhängig vom Stichtag 1. Oktober 1953 - ihren Rechtsanspruch auf eine materielle Wiedergutmachung bestätigt fand, konnten die Überlebenden deutscher Konzentrationslager, die vor dem 1. Oktober 1953 nach Spanien zurückgekehrt waren, nach wie vor nur auf ein großzügiges Entgegenkommen der westdeutschen Entschädigungsbehörden hoffen. Für diese kleine Gruppe von bis zu 1000

201 Botschaft Madrid an Auswärtiges Amt, 21. 1. 1959, PA/AA, Ref. 501, Bd. 929.

202 Auswärtiges Amt an Botschaft Madrid, 6. 3. 1959, PA/AA, Ref. 501, Bd. 929.

203 Botschaft Madrid an Auswärtiges Amt, 7. 4. 1959, PA/AA, Ref. 501, B. 929. Hier auch das Folgende.

204 Ebenda. In dem Schreiben hatte die Botschaft mitgeteilt, daß sie noch mit der Prüfung beschäftigt sei und sich „vorbehalte, ihm zu gegebener Zeit eine Antwort zukommen zu lassen“. Ob die erbetenen Bescheinigungen zu einem späteren Zeitpunkt ausgestellt wurden, erscheint fraglich. Zumindest findet sich in den einschlägigen Akten der Rechtsabteilung kein Hinweis.

205 Innenministerium des Landes Nordrhein-Westfalen an Auswärtiges Amt, 15. 6. 1959, PA/AA, Ref. 501, Bd.929. Hier auch das Folgende. Das Urteil des Bundesgerichtshofs - Az.: IV ZR 85/58 - war am 11. 7. 1958 ergangen. Das Auswärtige Amt hatte im Januar und im April 1959 in Düsseldorf nachgefragt. Auswärtiges Amt an Innenministerium, 30.4. 1959, PA/AA, Ref. 501, Bd. 929. 
Personen ${ }^{206}$ engagierte sich Richard Haendel, der Vertrauensanwalt des deutschen Generalkonsulats in Barcelona, in besonderer Weise. Haendel trat gegenüber dem Regierungspräsidenten in Köln im Oktober 1959 für eine wohlwollende Gesetzesauslegung ein, die nicht nur den Gleichheitsgrundsatz, sondern auch die besonderen Verhältnisse im Spanien Francos berücksichtige. Er verwies darauf, daß die einstigen NS-Verfolgten ganz und gar auf sich allein gestellt seien. Das Regime habe die Rückkehrer „wie Staatenlose behandelt“ und entschädige sie auch „nicht für die im deutschen Konzentrationslager erlittenen Schäden“. Unter diesen Umständen könne niemand der Betroffenen verstehen, warum ein Flüchtling, der „trotz der furchtbaren Folterungen, die er im deutschen Konzentrationslager erlitten" habe, im Gegensatz zu den Hinterbliebenen nicht entschädigt werden solle.

Eindringlich schilderte Haendel auch dem Generalkonsulat die materiellen und psychischen Nöte der Heimkehrer207, die zu Recht anführten: „Wir haben mit unserer Arbeit Deutschland in Kriegszeiten Nutzen gebracht, keinen Lohn dafür bekommen, nur unzureichende Ernährung und schwere Mißhandlungen, die es als Wunder erscheinen lassen, daß wir überhaupt noch leben, die uns aber für unser ganzes Leben krank und arbeitsunfähig gemacht haben. Es wäre für uns und unsere Familien besser gewesen, wenn auch wir wie die Mehrzahl unserer Kameraden im Konzentrationslager gestorben wären. Wir hätten weniger zu leiden brauchen“, so die bittere Klage, „und unsere Familien hätten wenigstens jetzt keine Not, und wir fielen der Familie nicht durch Gebrechlichkeit oder Arbeitsunfähigkeit zur Last“. Haendel erinnerte daran, daß das Bundesentschädigungsgesetz trotz all seiner „Härten“208 und „Lücken“ einen Härteausgleich oder einen Vergleich zu Gunsten der Opfer ausdrücklich vorsehe. Die Entschädigung der „unschuldigen Opfer des Nationalsozialismus“ sei eine „nationale moralische Verpflichtung“. Käme man dieser nicht nach, wäre das auch in Spanien nach seiner Überzeugung dem „deutschen Ansehen" nicht förderlich. Ohnehin stellten die Ansprüche der wenigen Überlebenden auch keine finanzielle Belastung für die Bundesrepublik dar. Vermutlich blieb Haendels Appell aber vergeblich ${ }^{209}$.

Ähnlich schwierig gestaltete sich die materielle Wiedergutmachung für Tausende früherer spanischer Zwangsarbeiter. Exemplarisch dafür war der Fall von Luis Posse Rales, der zehn Jahre um eine Entschädigung gekämpft hatte ${ }^{210}$. Seine Klage vor dem Oberlan-

206 Diese Zahl nannte jedenfalls Rechtsanwalt Haendel im Oktober 1959 gegenüber dem Regierungspräsidenten in KöIn. Zwar stehe ihm keine Statistik zur Verfügung, aber nach glaubhaften Angaben der aus den Konzentrationslagern Zurückgekehrten seien es „allerhöchstens 1000 Lebende“, die noch Ansprüche stellen könnten, „wahrscheinlich aber weniger als 1000“. Haendel an Regierungspräsident Köln (Entschädigungsbehörde) 8. 10. 1959, PA/AA, Ref. 501, Bd.929. Hier auch das Folgende.

${ }^{207}$ Haendel an Generalkonsulat Barcelona, 18. 11. 1959, PA/AA, Ref. 501, Bd.929. Hier auch das Folgende.

${ }_{208}$ Haendel an Regierungspräsident Köln, 8. 10. 1959, PA/AA, Ref. 501, Bd. 929.

209 Zumindest ließ sich in den Akten der Rechtsabteilung im Auswärtigen Amt kein Hinweis auf eine veränderte Haltung der Entschädigungsbehörden finden. Die deutsche Botschaft hatte die beiden Schreiben von Haendel im Januar 1960 kommentarlos an das Auswärtige Amt weitergeleitet. Botschaft Madrid an Auswärtiges Amt, 13.1.1960, PA/AA, Ref.501, Bd.929. Die von Haendel erhoffte Unterstützung durch das Generalkonsulat war ausgeblieben. Haendel an Generalkonsulat, 18. 11. 1959, PA/AA, Ref. 501, Bd. 929.

210 Viele spanische NS-Opfer waren finanziell gar nicht in der Lage, vor bundesdeutschen Gerichten eine Klage einzureichen. Im Fall von Luis Posse Rales halfen Kölner Anwälte aus dem sozialdemokratischen Umfeld. Gespräch Prof. Wilhelm Alff (Bremen) mit dem Verfasser, 4. 10. 1990. 
desgericht Köln ${ }^{211}$ leitete 1968 eine Wende in der Rechtsprechung ein. Posse gehörte zu jenen fast 27000 republikanischen spanischen Flüchtlingen, die seit 1940 in Frankreich von der deutschen Besatzungsmacht für militärische Bauvorhaben der „Organisation Todt“ (OT) ${ }^{212}$ zwangsrekrutiert worden waren ${ }^{213}$. Zwar hatte der 11. Zivilsenat des Oberlandesgerichts (OLG) in Köln in einem vergleichbaren Verfahren 1962 bereits bestätigt, daß das NS-Regime die sogenannten Rotspanier „durchweg als potentielle politische Gegner"214 ansah; entschädigungsrechtliche Konsequenzen hatte dies für das Gericht aber nicht. Mit einer aus heutiger Sicht haarsträubenden Rabulistik befand der Zivilsenat, es handele sich hierbei jedoch nicht um die in § 1 BEG gemeinte Gegnerschaft: Diese setze nämlich voraus, daß „sich jemand eine Vorstellung von der Innenpolitik der Nationalsozialisten gemacht und sie abgelehnt hat“. Mindestens müsse die „verfolgende Stelle geglaubt haben, gegen einen innenpolitischen Gegner des Nationalsozialismus vorgehen zu müssen“. Ausländern fehle, so argumentierten die Richter, - von seltenen Ausnahmen einmal abgesehen - eine „innere Einstellung zur deutschen Innenpolitik, selbst wenn sie jeder Form des ,Faschismus“ feindlich gegenüberstanden“. Damit wurde den NS-Machthabern noch im nachhinein eine Definitionsmacht zugestanden: Denn hätten die deutschen Behörden, hieß es in dem Urteil, in dem Kläger einen „ernst zu nehmenden politischen Gegner gesehen, so hätten sie ihn - wie so manchen anderen ,Rotspanier“ in ein Konzentrationslager gebracht" und nicht auf eine Baustelle am sogenannten Atlantikwall. Daher spreche nichts dafür, daß man den Kläger als ,innenpolitischen Gegner" habe treffen wollen, wie dies $§ 1$ BEG voraussetze. Den Betroffenen wurde somit von der bundesdeutschen Justiz ihr Schicksal als Verfolgte rundweg abgesprochen. Für sie wird es hingegen keinerlei Bedeutung gehabt haben, aus welchem Grund sie verfolgt worden waren.

Sechs Jahre später - in einem anderen politischen Klima - revidierte der gleiche Zivilsenat, gestützt auf neue Ermittlungen und erweiterte historische Kenntnisse, seinen Standpunkt. Der Präsident des Senats, Franz-Josef Wilhelmy, hatte nach eigener Aussage

211 Oberlandesgericht Köln, Zivilsenat 11a (Entsch.) 58/67, Teilurteil, 10.5. 1968, Entschädigungsrechtsstreit Luis Posse Rales gegen das Land Nordrhein-Westfalen, vertreten durch den Regierungspräsidenten in Köln (künftig: OLG Köln, Zivilsenat 11a (Entsch.) 10.5. 1968). Der Kläger war im Juni 1941 in Frankreich von deutschen Behörden verhaftet und in ein Zwangsarbeitslager bei Bordeaux gebracht worden. Von dort habe er im U-Boot-Stützpunkt Bordeaux bis zu seiner Befreiung im August 1944 Zwangsarbeit unter haftähnlichen Bedingungen leisten müssen. Vgl. ebenda, S. 3. Posse hatte bereits 1958 einen Antrag auf Wiedergutmachung gestellt, den der Regierungspräsident in Köln erst nach über vier Jahren ablehnte, weil die Behauptung von Posse, er sei aus Gründen politischer Gegnerschaft gegen den Nationalsozialismus verfolgt worden, nicht näher dargelegt und begründet worden sei. Die daraufhin im November 1962 eingereichte Klage wurde 1967 vom Landgericht Köln verworfen, ehe das Oberlandesgericht schließlich die Berufung zuließ. Den Hinweis auf diesen Musterprozeß verdankt der Verfasser Prof. Wilhelm Alff (Bremen), der an diesem Verfahren als Gutachter des Instituts für Zeitgeschichte beteiligt war.

212 Die nach dem Generalinspekteur für das deutsche Straßenwesen und Generalbevollmächtigten für die Regelung der Bauwirtschaft, Fritz Todt, benannte Organisation, war seit 1938 für den Bau militärischer Anlagen - wie den sogenannten Atlantikwall in Frankreich - eingerichtet worden. Auf den Baustellen wurden Hunderttausende von Kriegsgefangenen, KZ-Häftlingen, ausländischen Zivilarbeitern und Zwangsarbeitern eingesetzt. Vgl. Benz (Hrsg.), Enzyklopädie des Nationalsozialismus, S. 629.

213 Vgl. Alff, Die republikanischen spanischen Flüchtlinge „Rotspanier“, Stuttgart 1966, S. 285.

214 OLG Köln 11 U (Entsch) 41/62, 23. 11. 1962; Abschrift des Urteils in: PA/AA, Ref. 501, Bd. 929. Hier auch das Folgende. 
„regelrecht Geschichtsforschung"'215 betreiben müssen, um die Verhältnisse in den südfranzösischen OT-Lagern rekonstruieren zu können. Die 108 Seiten lange Urteilsbegründung ${ }^{216}$ vermittelt eine neue Sicht der Zwangsarbeit, die von der westdeutschen Justiz - zumindest im Fall der sogenannten Rotspanier - bisher allein als Folge des kriegsbedingten Mangels von Arbeitskräften gesehen wurde. Ausgangspunkt einer zutreffenden Würdigung könne, so die Kölner Richter, nur die Einschätzung sein, welche die spanischen Flüchtlinge „unter der nationalsozialistischen Gewaltherrschaft erfahren haben“.

Dabei stellte das Oberlandesgericht im Gegensatz zur Vorinstanz zunächst fest, daß die Verfolgung der „Rotspanier“ in Frankreich nicht allein auf die Einweisung von Tausenden in Konzentrationslager ${ }^{217}$ beschränkt blieb. Während das Landgericht in dem zwangsweisen Arbeitseinsatz keine Verfolgung gesehen hatte, wurde dieses Vorurteil nun massiv kritisiert: „Verfehlt und ohne Erkenntniswert“, erscheine es, den „Willen zur Arbeitskraftausbeutung in einen Gegensatz zum Verfolgungswillen zu bringen“. Vielfach sei übersehen worden, daß die nationalsozialistischen Dienststellen bei der „Frage der Verfolgung und der Ausbeutung der Arbeitskraft nicht vor einem Entweder-Oder standen, sondern beides in sehr unterschiedlichen Schattierungen zu verbinden wußten“. Zu einer entschädigungsrechtlichen Bewertung gehörten daher auch die jeweiligen Umstände des Arbeitseinsatzes und die Lebensbedingungen in den Zwangsarbeitslagern. Angesichts des vitalen Interesses der Nationalsozialisten, den Arbeitskräftemangel durch billige bewachte Arbeitskräfte zu verringern, ergebe sich der Schluß, daß die sogenannten Rotspanier „nicht wegen ihrer politischen Unzuverlässigkeit“, sondern trotz dieser Einschätzung am Atlantikwall eingesetzt wurden.

Die Haltung der OT zeige, wie zuverlässig die „Sicherungsvorkehrungen“ eingeschätzt worden seien, die es sogar erlaubt hätten, „selbst als gefährliche politische Gegner betrachtete Opfer bis zur physischen und psychischen Erschöpfung auszubeuten, ohne nennenswerte Reaktionen befürchten zu müssen“. Denn Schikanen und Mißhandlungen waren in den OT-Lagern an der Tagesordnung. Dem verharmlosenden Tenor der bisherigen Urteile mochte sich das OLG nicht anschließen: Der Zivilsenat bemängelte, daß die Vorinstanzen Übergriffe mitunter nur „dürftig“ als „Willkür“ einzelner Personen oder gelegentliche persönliche „Schindereien abgetan“ hatten. So sei bislang auch nicht versucht worden, „solche Mißhandlungen als geschehen zu unterstellen“. Bei nachgewiesenen Tätlichkeiten habe das Landgericht angenommen, diese seien auf den „allgemein rauhen Ton auf Baustellen“, sprachliche Mißverständnisse oder „echte Disziplinverstöße“ zurückzuführen gewesen: „Das überzeugt keineswegs“, rügte das OLG. Derartige Grausamkeiten gegenüber „Rotspaniern“, die neben „Juden, Russen und Konzentrationslager- und Straf-

\footnotetext{
215 „Ein Anwalt im Wettlauf mit dem Tod“, in: Kölnische Rundschau, 19. 10. 1969. Die Geschichte von Luis Posse Rales wurde hier, ein Jahr, nachdem das OLG das Teilurteil wegen seiner grundsätzlichen Bedeutung zur Revision zugelassen hatte, noch einmal erzählt. Zu diesem Zeitpunkt erschien es nämlich überaus fraglich, ob Posse angesichts seines Gesundheitszustandes das Ende des langwierigen Rechtsstreits überhaupt noch erleben würde.

216 OLG Köln, Zivilsenat 11a (Entsch.) 58/67, 10.5.1968. Das Gericht hatte zu seiner Urteilsfindung „sämtliche Rotspanier-Sachen“" herangezogen und verwertet. Vgl. ebenda, S. 11.

217 Das Gericht hielt fest, daß die „,nationalsozialistische Gewaltherrschaft die ersten republikanisch-spanischen Flüchtlinge, die ihr in die Hände fielen, in einer Weise verfolgt hat, die alle Zeichen einer Gruppenverfolgung an sich trug und zu den schlimmsten Verfolgungsmaßnahmen gehört". Ausschlaggebend hierfür waren „Gründe der Rache und damit Gründe politischer Gegnerschaft". Ebenda, S. 14.
} 
häftlingen“ die „einzigen streng bewachten Arbeitskräfte“ in Frankreich waren, erklärten sich für das Gericht „überzeugend“ allein aus der politischen Gegnerschaft der Nationalsozialisten.

Insgesamt liest sich das Urteil über weite Strecken wie eine Generalkritik an den vorangegangenen Entscheidungen. Zeugenaussagen seien einseitig bewertet worden: Es gebe "gewichtige Bedenken“ gegen die „festgestellte grundsätzliche Verläßlichkeit deutscher Zeugen und die ebenso prinzipiell angezweifelte Glaubwürdigkeit der spanischen Betroffenen“. Zumal auch die Vorstellung, daß die OT eine „völlig unpolitische Bauorganisation" gewesen sei, der Wirklichkeit nicht gerecht werde. Ihre Führung, insbesondere die sogenannte Frontführung, habe nämlich meist aus bewährten Parteigenossen oder SSMitgliedern bestanden, die neben ihrer eigentlichen Aufgabe zugleich „Verfolgungsabsichten" realisiert hätten. Am Ende sprach das Oberlandesgericht Luis Posse Rales eine Entschädigung von 4200 DM zu. Einer Revision wurde zugestimmt, weil mit dem „Arbeitseinsatz als Verfolgungsmaßnahme“ eine Rechtsfrage von grundsätzlicher Bedeutung entschieden werden müsse. Die Entscheidung hatte aber Bestand. In den siebziger Jahren kamen die hier getroffenen Bewertungen mehr und mehr zum Tragen ${ }^{218}$ und führten zu entschädigungsfreundlicheren Urteilen.

Dennoch gingen viele Spanier lange Zeit leer aus. Viele hatten Antragsfristen versäumt oder sich außerstande gesehen, Stichtags- und Wohnsitzvoraussetzungen zu erfüllen. Andere wußten nichts von ihren Wiedergutmachungsansprüchen und nur wenige hatten sich zu einer Klage vor deutschen Gerichten durchringen können. Nachdem das BEG bereits 1969 ausgelaufen war, richteten sich die Hoffnungen zuletzt auf einen neuen, 1981 gegründeten Sonderfonds der Bundesregierung für nichtjüdische Verfolgte. Dieser „zur Abgeltung von Härten in Einzelfällen "219 vorgesehene Fonds über maximal 100 Millionen DM kam vor allem notleidenden republikanischen Spaniern zugute, die glaubhaft angeben konnten, „über die Möglichkeiten der Wiedergutmachung nicht oder nur unzureichend informiert gewesen zu sein“. Bis zum 31. August 1986 waren von den spanischen NS-Opfern 13080 Anträge ${ }^{220}$ eingegangen; damit bildeten die Spanier sogar noch vor den

218 Kennzeichnend hierfür war ein Artikel in der Zeitschrift „Rechtsprechung zum Wiedergutmachungsrecht“ (RzW), die von 1949 bis 1981 als Beilage zur „Neuen Juristischen Wochenschrift" erschien. Dort hieß es 1973 im Hinblick auf die bei der „Organisation Todt“ eingesetzten spanischen Flüchtlinge: Es lasse sich - von Ausnahmen abgesehen - „nicht rechtfertigen, es als Willkür einzelner Lagerkommandanten oder von der Führung nicht gebilligte Ausschreitung von Unterführern zu werten und abzutun, wenn ,Rotspanier' ebenso unmenschlich wie Konzentrationslagerhäftlinge behandelt wurden. Diese Art des Vorgehens [...] entsprach vielmehr mindestens dem Willen Himmlers, soweit nicht überhaupt ausdrückliche Anweisungen des SD vorlagen, und ist daher als nat.-soz. Gewaltmaßnahme i. S. des $§ 2$ BEG zu betrachten."Vgl. RzW 24. Jg. (1973), H. 2, S. 53 f., hier S. 53.

${ }^{219}$ Bericht der Bundesregierung über Wiedergutmachung und Entschädigung für nationalsozialistisches Unrecht sowie über die Lage der Sinti, Roma und verwandter Gruppen, Deutscher Bundestag, Drucksache 10/6287, 31.10. 1986. Hier auch das Folgende. Zur rechtlichen Genese dieses Härtefonds vgl. Brodesser, Wiedergutmachung und Kriegsfolgenliquidation, S. 120-123.

${ }_{220}$ Im Februar 2001 hatte sich nach Angaben des zuständigen Regierungspräsidenten in Köln die Zahl der Anträge auf 15366 erhöht. 9679 Betroffene bekamen eine einmalige Beihilfe von 5000 DM; 5687 Anträge wurden wegen unvollständiger Unterlagen oder fehlender Bedürftigkeit abgelehnt. Die Antragsteller wurden bis 1985 nicht nach ihrer Nationalität erfaßt. Mitteilung Regierungspräsident Köln an den Verfasser, 9. 3. 2001. Die von Aschmann genannte Zahl von etwa 2000 Entschädigungsberechtigten, bei der sie sich allein auf Angaben der spanischen Botschaft in Paris stützt, ist insofern viel zu niedrig angesetzt; vgl. Aschmann, „Treue Freunde..."?, S. 388. 
Sinti und Roma die größte Gruppe. Diese hohe Zahl belegt einmal mehr die jahrzehntelang ausgebliebene Unterstützung der Regierung in Madrid. So verzichtete Franco-Spanien im Gegensatz zu anderen europäischen Staaten auf ein Entschädigungsabkommen mit der Bundesrepublik. Überdies ließ das Regime der vollmundigen Ankündigung, es werde ,jede mögliche Unterstützung “221 bei Entschädigungsanträgen leisten, da nicht der Anschein erweckt werden sollte, ,als ob die Gewährung derartiger Entschädigungen den Bemühungen rotspanischer Elemente zu danken sei“, keine Taten folgen. Die spanischen NS-Verfolgten, die immer auch Franco-Gegner waren, blieben auf sich gestellt.

221 Memorandum betr. schwebender Fragen, an deren Lösung die spanische Regierung interessiert ist, 17. 10. 1960, PA/AA, Ref. 501, Bd. 929. 